\title{
Shape of plutons in crustal shear zones: A tectono-magmatic guide based on analogue models
}

\author{
Maria Michail ${ }^{a}$, Michael Rudolf ${ }^{b}$, Matthias Rosenau ${ }^{b}$, Alberto Riva ${ }^{a}$, Piero Gianolla ${ }^{a}$, \\ Massimo Coltorti ${ }^{a, c}$ \\ a University of Ferrara, Department of Physics and Earth Sciences, Via Saragat 1, 44122 Ferrara, Italy \\ b Helmholtz Centre Potsdam, GFZ German Research Centre for Geosciences, Telegrafenberg, 14473 Potsdam, \\ Germany \\ c National Institute of Geophysics and Volcanology, Palermo branch, Via Ugo la Malfa 153, 90125 Palermo, Italy
}

Correspondence: Matthias Rosenau (rosen@gfz-potsdam.de)

This version of the manuscript has been submitted to Journal of Structural Geology and has not undergone peer review (pre-print). A revised version has been accepted and published as:

Maria Michail, Michael Rudolf, Matthias Rosenau, Alberto Riva, Piero Gianolla, Massimo Coltorti (2021): Shape of plutons in crustal shear zones: A tectono-magmatic guide based on analogue models, Journal of Structural Geology, https://doi.org/10.1016/j.jsg.2021.104417.

\section{(c) 2021.}

This manuscript version is made available under the CC-BY-NC-ND 4.0 license http://creativecommons.org/licenses/by-nc-nd/4.0/ 
1 Shape of plutons in crustal shear zones: A tectono-magmatic guide based on analogue

2 models

4 Maria Michail a, Michael Rudolf ${ }^{b}$, Matthias Rosenau ${ }^{b}$, Alberto Riva a , Piero Gianolla ${ }^{a}$, Massimo 5 Coltorti a,c

6 a University of Ferrara, Department of Physics and Earth Sciences, Via Saragat 1, 44122 Ferrara, 7 Italy

8 b Helmholtz Centre Potsdam, GFZ German Research Centre for Geosciences, Telegrafenberg, 914473 Potsdam, Germany

10 c National Institute of Geophysics and Volcanology, Palermo branch, Via Ugo la Malfa 153, 90125 11 Palermo, Italy

13 Corresponding author: Maria Michail, email address: mchmra@unife.it, tel. 00393200486527

15 Keywords:

16 1. Analogue modelling;

17 2. Magma emplacement;

18 3. Strike-slip tectonics;

19 4. Transtension;

20 5. Pluton shape 
22 Plutons in crustal shear zones may exploit inherited structures, interfere with strain localizing or be 23 deformed passively. To constrain the relative timing of such tectono-magmatic constellations in 24 natural settings is not always straight-forward. We here present sandbox-type analogue model experiments simulating magma emplacement into simple and transtensional crustal shear zones to test the diagnostic potential of pluton shape with respect to timing and setting. Observations based on surface deformation and intrusion shape exemplify the interplay between evolving and inherited tectonic structures and magma uprising. We observe markedly asymmetric intrusions in association with dikes reflecting the regional stresses, fault pattern and finite strain field. At the same time, the presence of an intrusion modifies the tectonic evolution, but only transiently, resulting in short-lived faults, reactivation and inversion. Diagnostic attributes include the pluton's aspect ratio, its orientation and amplitu de as well as dike association. Accordingly, syn-tectonic intrusions show the highest pluton amplitudes and intermediate elongation oriented parallel to between Riedel shears in

\section{Introduction}

41 The spatial association of plutons and shear zones has long been recognized. Revealing their 42 temporal and spatial relation as a key to understand the mechanisms of tectono-magmatic 43 interaction, is a matter of research since. The interactions of tectonic and magmatic processes are 44 often ambiguous and hard to interpret (Paterson and Schmidt, 1999; Paterson and Tobisch, 1992). 45 It is generally recognised that both inherited structures and active faults represent key features in 
46 crustal-scale magma transport and emplacement (Hutton, 1988; Hutton and Reavy 1992;

47 Vigneresse 1995; Román-Berdiel et al., 1997; Petford et al., 2000; Handy et al., 2001; Rosenberg, 48 2004; Corti et al., 2005; Galland et al., 2006; Galland et al., 2007b). Likewise, the presence of 49 magma in actively deforming crust may control fault localization and structural evolution (e.g. 50 Holohan et al., 2008; Dooley and Schreurs, 2012; Gomes et al., 2019). The delineated scenarios of 51 pre-, syn- and post-tectonic magmatism and the mechanisms involved remain poorly understood 52 taking also into account that gathering information from the field could be rather challenging. Beside 53 the limited outcrops in some areas, observations are, in most cases, restricted to the final stage of 54 magma emplacement which is often overprinted. In addition, the deformed upper crustal layers that 55 once hosted the magmatic chamber are in most cases subject to erosion and therefore missing from 56 the field. Consequently, the information on the incremental and finite deformation has to be inferred 57 with much effort from structural indicators and the processes taking place at depth must be 58 extrapolated (Vigneresse, 1995).

59 Modelling can help in overcoming some of the restrictions of field analysis and guide researchers 60 by identifying key observables and testing hypothesis. While all kinds of modelling have tackled 61 tectono-magmatic interaction, including analytical (e.g. Mandal and Chakraborty, 1990) and 62 numerical modelling (e.g. Burov et al., 2003), analogue models where used in particular for the 63 typically cross-scale and four-dimensional problems posed by tectono-magmatic processes (see 64 e.g. review by Galland et al., 2015). Amongst them, studies on syn-tectonic magma emplacement 65 prevail: a) in compressional settings (Galland et al., 2003, 2006, 2007; Mazzarini et al., 2010; 66 Montanari et al., 2010); b) in strike-slip settings (Román-Berdiel et al., 1997; Corti et al., 2005; 67 Mazzarini et al., 2010; Gomes et al., 2019); c) in transpressional settings (Benn et al., 1998); d) in 68 transtensional settings (Román-Berdiel et al., 2000; Corti et al., 2003) and finally e) in extensional 69 settings (Román-Berdiel et al., 1999; Mazzarini et al., 2010; Corti et al., 2003).

70 With a few exceptions (Holohan et al., 2008; Dooley and Schreurs, 2012; Gomes et al., 2019), 71 previous works were focused on syn-tectonic intrusion scenarios. However, little evidence exists 
72 from analogue modelling regarding crustal shearing of pre- tectonic intrusion scenarios. Similarly,

73 the post-tectonic intrusion system is very poorly studied, where exploitation of inherited structures

74 from the uprising intrusion is still under debate. In this paper, we aim at closing th is knowledge gap 75 and test the diagnostic potential of pluton shape for relative timing with a new set of analogue model 76 experiments simulating magma emplacement with in the upper brittle crust rising from a basal ductile 77 shear zone. We conducta systematic series of magma emplacement scenarios in simple shear and 78 transtensional regime (Fig. 1). To cover the full range of relative timing, we realize pre-tectonic, syn79 tectonic and post-tectonic intrusion scenarios (Table 1).

80 In contrast to earlier analogue modelling studies with a similar goal (e.g. Román -Berdiel et al., 1997;

81 Corti et al., 2005; Holohan et al., 2008; Mazzarini et al., 2010 ), we do not use a Riedel-type 82 experiment with a linear velocity discon tinuity at the base but a more realistic distributed basal shear 83 zone (e.g. Dooley and Schreurs, 2012, and references therein). The viscous-weak body, in contrast 84 to previous work (Holohan et al., 2008; Dooley and Schreurs, 2012; Gomes et al., 2019) is not lying 85 parallel to the shear zone, but it is introduced vertically and in direct contact to the shear zone. In 86 addition, in previous work the tectonic deformation of the magmatic chamber and the brittle crust, 87 induced by the vertical upraising of the viscous - body, prior to and following the tectonic 88 deformation, is not recorded. In the present study the magmatic chamber is not represented as an 89 igneous pocket, but it is injected vertically, deforming this way the sand layers (no topography has 90 been added in this study) before, during and after the tectonic deformation. In addition, the weak 91 body appears with a fixed radius $=2 \mathrm{~cm}$, since the focus of the study is on the progressive 92 interference with the brittle crust, for all emplacement scenarios. For this reason and in contrast to 93 previous studies (Dooley and Schreurs, 2012; Zwaan and Schreurs, 2017) the intrusion geometry 94 and its initial orientation (angular position) relative to the shear zone are not evaluated.

95 Using state of the art kinematic monitoring techniques (Digital Image correlation - DIC; Structure96 from-Motion - SfM), the full 3D surface deformation over time (i.e. 4D deformation) and the final 97 intrusion three-dimensional shapes are captured digitally at high resolution and accuracy. Based on 
98 this experimental data set, which is openly available (Michail et al., 2020), we verify existing 99 diagnostic features (e.g. pluton aspect ratio, orientation) and new attributes (pluton amplitude, dike association) of pluton shape and validate them against selected field examples. The presented models appear as a guide to the interpretation of necessarily incomplete and limited field observations. (Figure 1 here)

\section{Methods and materials}

\subsection{Experimental setup}

105 The experimental setup consists of two mobile plastic plates on a 1 by $1 \mathrm{~m}$ wide solid steel support 106 platform. The mobile plates are moved by linearactuators, controlled by stepper motors, in opposite 1d,f) are presented (Table 1).

113 For the simple shear regime, the gap between the mobile plates is oriented parallel to the plates' motion (Fig. 1c,e), while in the transtensional configuration, they are oriented with an angle, $\alpha$, of $15^{\circ}$ (Fig. 1d). Relative plate velocity is fixed to $1 \mathrm{~mm} / \mathrm{min}$, for all experiments, which corresponds to a simple shear rate of $4.2^{*} 10^{-4} \mathrm{~s}^{-1}$ across the width of gap resulting in a final relative displacement of the two sides of the shear zone of $60 \mathrm{~mm}$ for all experiments. A low shear rate, together with a viscous fluid, rough inner edges of the mobile plates and polished and lubricated surface of the metal base, result in a well distributed deformation within the gap although minor localization of shear and extension at the shear zone boundaries is unavoidable. Simple shear and transtensional models are run under dextral and sinistral senses of shear, respectively, in order to ease their distinctness. (Table 1 here) 
123 A 40-mm thick, sieved quartz sand layer representing the brittle upper crust (Fig. 1a-b) covers the

mobile plates and the basal shear zone. On top of each mobile plate, fixed, motion-parallel sidebars confine the sand layer laterally and helps in model preparation (Fig. 1a,e). In the centre of the basal shear zone, a motor-controlled piston pushes silicone oil up through a pipe (with $40 \mathrm{~mm}$ diameter)

placed beneath the experiment's foundation, to simulate the magma ascen ding from the lower crust into the upper-crustal shear zone (Fig. 1e-f). The piston moves at a velocity of $1 \mathrm{~mm} / \mathrm{min}$, which translates into an injection rate of $21 \mathrm{~mm}^{3} / \mathrm{s}$ for all experiments (Table 1). All the experiments are performed under air-controlled ambient conditions $\left(23^{\circ}-25^{\circ} \mathrm{C}, 50 \%\right.$ humidity $)$.

\subsection{Analogue materials}

The viscous analogue material used for both the intrusion and the basal ductile layer is a silicone oil (Polydimethylsiloxane PDMS, G30M by K. Obermeier GmbH). It has a density of $965 \mathrm{~kg} \mathrm{~m}^{-3}$ and a Newtonian viscosity of $22.4 \mathrm{kPa}$ s at laboratory strain rates below $10^{-2} \mathrm{~s}^{-1}$ (Rudolf et al., 2016; see Table 2). Earlier studies showed that similar material is a suitable analogue for ductile lower crust and, at reduced viscosity, for low density-high viscosity (i.e. granitic) magmas simulation (e.g. Román-Berdiel et al., 1997; Benn et al., 1998, 2000; Galland et al., 2015). We here use one material for simulating both the ductile lower crust and the magma in order to reduce rheological complexity but also due to practical reasons, i.e. to avoid gravitational flow of the material at the end of the experiment and to allow manual excavation of the ductile shear zone and the intrusion.

Sieved dry quartz-sand (G12) functions as brittle analogue of the upper crust. The sand is a wellsorted, well-rounded and fine-grained $(<400 \mu \mathrm{m})$ sand of fluvial origin (Klinkmüller et al., 2016; Rosenau et al., 2018). When sieved, a bulk density $\rho \sim 1600 \mathrm{kgm}^{-3}$ is reached and the sand layer is characterized by internal friction coefficients $\mu$ of $0.69,0.62,0.55$ (static, reactivated, sliding) and a cohesion $C$ in the order of $50-110 \mathrm{~Pa}$ (Table 1). The localization behaviour of sand produces shear zones several grain diameters wide rather than idealized infinitely narrow faults. However, we here use the term "faults", to describe the small-scale shear zones, evolving in the analogue model because of the generally close dynamic similarity (Ritter et al., 2016). With the term "shear zone" in 
contrast we refer to the regional deformation zone composed of several faults evolving on top of the basal ductile shear zone.

\section{1}

\subsection{Scaling and Similarity}

152 The experiments are scaled following the principles of geometric, kinematic and dynamic similarities 153 to the natural prototype (Hubbert, 1937; Ramberg, 1981; Weijermars and Schmeling, 1986). 154 Accordingly, for a brittle-viscous sandbox model under normal gravity, the stress scaling dictates 155 the length and time scaling. In the pressure-dependent brittle regime and under normal gravity, the 156 length scale $L^{*}$ can be delineated from densities and cohesion in the model and prototype following 157 the scaling law:

$158 L^{*}=C^{*} / \rho^{*}$

where the asterisks denote the model/prototype ratios known as the scaling factors (i.e. $C^{*}=$ $C_{\text {model }} / C_{\text {prototype). }}$. Inserting numbers for the scaling factors for density and cohesion of our brittle analogue rock material $\left(C_{\text {model }} \sim 10-100 \mathrm{~Pa}, \rho_{\text {model }}=1600 \mathrm{~kg} / \mathrm{m}^{3}\right)$ and typical upper crustal rocks $\left(C_{\text {prototype }}=10 \mathrm{MPa}\right.$, prototype $\left.=2600 \mathrm{~kg} / \mathrm{m}^{3}\right)$ yields a length scaling factor of $L^{*}$ in the order of $0.6-$ $6 \times 10^{-6}$, i.e. $1 \mathrm{~cm}$ in the model equals $0.6-6 \mathrm{~km}$ in nature (Table 2). Consequently, our model represents an intrusion into the upper 2-20 km thick crust. For our models, due to dimensional identity, the stress scale is also fixed by the choice of cohesion to $\sigma^{*}=1-10 \times 10^{-6}$.

In the strain-rate dependent viscous regime the time-scale $T^{*}$ can be delineated, based on dimensional arguments, from the viscosities $\eta$ in the model and in nature using the formerly set stress scale and following the scaling law

$T^{*}=\eta^{*} / \sigma^{*}$

170 With the viscosity of the silicone oil ( $\left.\eta_{\text {model }} \sim 10^{4} \mathrm{Pas}\right)$ and considering a typical viscosity range for 171 magma ( $\eta$ prototype $=10^{4}-10^{10}$ Pas), this scaling yields highly unsuitable laboratory time scales, that 172 require running the experiments at even lower rates than in nature. This dilemma has already been 173 noticed by Ramberg (1981) who stated that magma cannot be properly scaled because even the 
most viscous (low water content, high silica) magma would require an analogue fluid, which is even 175 less viscous than water and which does not exist. (Table 2 here)

176 To solve this dilemma, we here consider the rising magmatic body not as a homogenous melt with 177 low viscosity but as a succession of rapid melt injections into the crust over millions of years. This 178 is in accordance to the general view that plutons grow transiently over the Ma timescale fed by 179 magma that transits through lower crustal shear zones episodically on the hundreds to thousands 180 of years timescale (e.g. Handy et al., 2001, Patterson et al., 2011, Brown, 2013). The resulting 181 magmatic system has therefore an effective bulk viscosity much higher than that of the individual 182 melt components and which is more similar to ductile lower (quartz-feldspatic/andesitic) crust at typical regional tectonic strain rates ( $\eta$ prototype $>10^{20}$ Pas at $<10^{-14} \mathrm{~s}^{-1}$, e.g. Shinevar et al., 2015). Such an alternative interpretation of the analogue model is not only consistent with modern views of episodic pluton growth but considers at the same time, though highly simplified, thermal aspects of the emplacement process (i.e. cooling and crystallization between injection episodes; Gomes et al., 2019). Following this reasoning and considering a Million-yeartime scale of pluton growth, we derive the time scale by relating the filling times of our model pluton (ca. $10^{-8} \mathrm{~m}^{3} / \mathrm{s}$ ) to mean natural rates of $10^{2} \mathrm{~km}^{3} / \mathrm{Ma}$ (e.g. Patterson et al., 2011). Accordingly, we arrive at $T^{\star}=10^{-13}(1$ second in the lab corresponds to ca. 30.000 years, Table 2). According to this timescale the applied velocity of 1 $\mathrm{mm} / \mathrm{min}$ scales to ca. $0.5 \mathrm{~mm} / \mathrm{a}$ in nature and a corresponding shear rate of ca. $10^{-17} \mathrm{~s}^{-1}$.

\subsection{Monitoring and Analysis}

We use state-of-the-art digital image correlation techniques for kinematic monitoring of the model surface deformation (Particle Image Velocimetry, PIV) and for deriving the surface topography and intrusion shape (Structure-from-Motion, SfM). All digital data generated in this study are published open access in Michail et al. (2020). 
198 A stereoscopic pair of charge-coupled device (CCD) cameras (11 MPx, 14bit, LaVision Imager 199 ProX) monitor the model surface during the experimental run at a frequency of $0.3 \mathrm{~Hz}$ (Fig. 2a). 200 Digital image correlation, using a least square minimization technique (as implemented in La Vision 201 Davis 8), allows a quasi-continuous quantitative monitoring of the topographic evolution and surface 202 deformation at high spatio-temporal resolution according to the principles of PIV (Adam et al., 2005).

203 We derive 3D incremental and cumulative surface deformation pattern (i.e. velocity fields, strain 204 fields and topography) at the sub-millimetre resolution.

205 From the surface velocity field, we produce surface strain maps which show the incremental shear 206 strain $E_{x y}$ (the unitof which is millistrain, $m S$ ), highlighting active faults and their kinematics. Positive values (red colors in all Figures) indicate a clockwise rotation or dextral shear sense and negative values (blue colors in all Figures) indicate anti-clockwise rotation or sinistral shear. The final shear strain is computed as the cumulative (or finite) displacement field indicating the relative importance of individual faults in accommodating deformation over the full experimental range.

\subsubsection{Structure-from-Motion (SfM)}

212 To obtain the 3D model reconstruction of the final topography (digital elevation model, DEM) and 213 the final intrusion shape (digital intrusion model, DIM) at high resolution we rely on the Structure214 from-motion (SfM) technique (Westoby et al., 2012) using digital images taken at the end of every 215 experiment with a customer grade DSLR camera (NIKON D80, $10 \mathrm{MPx}$ ). Images including 216 perspective views of both the final model surface and the model intrusion after excavation taken 217 from various angles are used for the 3D model reconstruction achieved by using Agisoft PhotoScan 218 (Professional Edition). For visualization coloured DIM-contours have been extracted from the 219 models.

220 The intrusion's geometry (pluton shape) is quantified using various dimensionless parameters 221 derived from the DIM: 


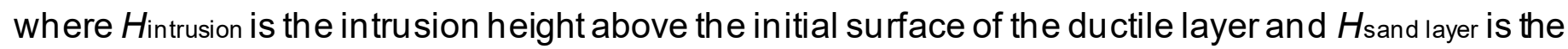
225 thickness of the sand layer (i.e. $40 \mathrm{~mm}$ ). Second, the aspect ratio

227 calculated based on the length $L$ and width $W$ of the ellipse that fits to the DIM perimeter at a given contour level.

229 Third, the orientation of the intrusion, that is described by $\Theta$, defined as the angle between the long 230 axis $L$ of the fitted ellipse and the strike of the basal shear zone. $\Theta$ is counted counter clockwise. 231 Aspect ratio and angle of intrusion are derived for each contour level allowing the analysis of the 232 shape as a function of height.

\section{$233 \quad 3$ Experimental results}

234 Nine experiments in total are presented and discussed in the following sections (Table 1): i) three 235 reference experiments (Group R); ii) three models of intrusion under (dextral) simple shear (Group 236 A) and iii) three models of intrusion under (sinistral) transtension (Group B). Pre-, syn and post237 tectonic intrusion scenarios are presented for the Groups A and B. Group R consists of a static 238 intrusion without applied shear (R0), a simple shear (RS) and a transtensional experiment (RT), 239 both without intrusion. Rates of intrusion and deformation are kept constant in all experiments as 240 well as the thickness of the brittle layer.

\section{3.1 Reference models (Group R)}

242 The surface evolution of the reference experiments, namely the static intrusion model (R0, Fig. 2a$243 \mathrm{c}$ ), the simple shear model (RS, Fig. 2d-f) and the transtension model (RT, Fig. 2g-i) is summarised

244 in Fig. 2. In the R0 model, a circular sand dome starts to form above the intrusion as soon as the 
injection has started ( $V_{\text {inj }}=3.2 \mathrm{ml}$; Fig. 2a). Gradually, the sand layer forms an elongated rectangular

246

247 domal uplift preserved until the latest intrusion stage, bound by lateral reverse faults, parallel to the basal ductile layer (Fig. 2b-c). The uplift rate decreases with time. (Figure 2 here)

For the reference experiments under simple shear (RS) and transtensional (RT) deformation the surface evolution shows a typical sequence of structures consistent with previous studies using a distributed basal shear zone and dry sand layers (Román-Berdiel et al., 1997; Corti et al., 2005; Dooley and Schreurs, 2012). In the very early evolution stage of the RS model ( $\left.d_{r e l}=5.0 \mathrm{~mm}\right)$ a diffuse beltstarts to form above the basal ductile shear zone (Fig. 2d). With increasing displacement, early en-échelon synthetic Riedel shears $(R)$ develop with a trend of $\sim 20^{\circ}$ to the trace of the basal shear zone (drel = $16.1 \mathrm{~mm}$; Fig. 2e). Lower-angle synthetic shears develop between the overlapping $R$ shears, having a strike of $\sim 15^{\circ}$ (Fig. $2 \mathrm{e}$ ). The final deformation surface pattern ( $\mathrm{drel}=38.3 \mathrm{~mm}$ ) is characterised by the formation of an active and continuous master fault (MF), as a result of the linkage of the individual early shear structures, parallel to the basal shear zone, along which less active anastomosing minor faults which define shear lenses and pop-up structures (drel $=38.3 \mathrm{~mm}$; Fig. 2f). The final surface width of the shear zone (ca. $50 \mathrm{~mm}$ ) is larger than the basal shear zone (40 mm; Fig. 2f).

The transtensional reference experiment (RT) shows an early evolutionary history similar to the simple shear experiment with the formation of a diffuse shear zone above the basal ductile shear zone (Fig. 2g-i). Linkage of early right-stepping and overlapping $R$ shears occur along lower angle structures ( $Y, P$ shears) causing a deformation localization in the central part and forming a throughgoing master fault from early on $(\mathrm{d}=11.1 \mathrm{~mm}$; Fig. $2 \mathrm{~g}-\mathrm{h})$. During the final stage, the deformation partitions between lateral faults and fault-bounded rhomboidal basin structures (Fig. 2i). In this stage, the pull-apart basin structure is cut short by strike-slip faults that continue to propagate towards the dominating parallel boundary faults. This results in lengthening and narrowing of the pull-apartbasin in a direction parallel to the displacementvector. The final surface width of the shear zone is larger (ca. $60 \mathrm{~mm}$ ) than the basal shear zone (44.4 mm; Fig. 2i). 


\subsubsection{Effect of intrusion on fault pattern}

273 The three models presented in this group show the evolution of deformation with the presence of analogue magma injection that predates (A1, pre-tectonic model), coincides (A2, syn-tectonic model) and post-dates (A3 post-tectonic model) the applied simple shear deformation. Our observations focus on the interactions taking place between faulting and intrusion and how they affect the fault pattern evolution and the final intrusion geometry.

The pre-tectonic intrusion experiment, model A1 (Fig. 3), consists of two parts: during the first half of the experiment, static intrusion takes place $\left(V_{i n j}=37.3 \mathrm{ml}\right)$ causing a domal uplift $\left(\Delta \mathrm{h}_{\text {init }}=7 \mathrm{~mm}\right.$, Fig. 3a) as described for the R0 model (Fig. 2a-C). In the second half of the experiment, following the static intrusion, dextral shearing is applied. Accordingly, in the early intrusion stage there is no obvious fault formation (Fig. 3a). Once shearing started diffuse deformation occur in a spindle-like surface area (drel=11.4; Fig. 3b) forming a wider shear domain bound by transpressional faults. At a later stage of shearing (drel $=22.2 \mathrm{~mm}$; Fig. 3c) a system of strike-slip faults consisting of two lateral and one central fault is cutting through the uplifted domain. The finite fault pattern (Fig. $3 d-f$ ) is, in contrast to the model RS, characterized by a wider strike-slip system encompassing the

intrusion area and external transpressional faults which have been active mainly du ring early stages of deformation. (Figure 3 here)

The fault pattern in the syn-tectonic intrusion experiment, model A2 (Fig. 4), initially evolves in a 290 similar fashion as in model A1. In the early deformational stage $(\mathrm{drel}=3.9 \mathrm{~mm} ; \mathrm{Vinj}=4.9 \mathrm{ml}$; Fig. $4 \mathrm{a})$ a diffuse spindle-like shear zone occurs encompassing the uplifting centre. With ongoing shearing and intrusion (drel $=6.7 \mathrm{~mm} ; V_{\text {inj }}=4.9 \mathrm{ml}$; Fig. $4 \mathrm{~b}$ ) transpressional faults localize at the periphery of the spindle-like area embracing the intrusion domain as well as Riedel shear in the centre. In the late stage $\left(\right.$ drel $=27.8 \mathrm{~mm} ; V_{\mathrm{inj}}=35.0 \mathrm{ml} ;$ Fig. $4 \mathrm{c}$ ) deformation localizes into a narrow strike-slip fault system cutting the intrusion area. This set of parallel, locally transtensional faults cause the depressing of the uplifted central domain (Fig. 4e). The finite fault pattern (Fig. 4d-f) shares 
characters of the reference model RS (a central strike-slip fault system; Fig. $2 d-f$ ) and the pretectonic model A1 (early stage transpressional faults swinging around the intrusion area; Fig. 3b).

(Figure 4 here)

The post-tectonic experiment, model A3 (Fig. 5) consists again of two parts: In the first half, the experiment follows according to the observations documented for the RS model (drel $=30 \mathrm{~mm}$; Fig. $2 d-f$ ) resulting in a system of strike-slip faults (Fig. 5a) at the start of intrusion. In the second half of the experiment, static intrusion causes formation of new lateral faults (in the "south" of the intrusion) but also the reactivation of inherited, lateral faults (in the "north" of the intrusion; $V_{\text {inj }}=12.6-32.2 \mathrm{ml}$; Fig. 5b-c). Importantly, active faults in opposite corners of the intrusion show a synthetic sense including dextral and sinistral shear(Fig. 5b-c). Consequently, dextral displacementacross inherited faults acquired in the first half of the experiment is now partly inverted. The finite fault pattern (Fig. $5 d-f$ ) is a composite of partly re-activated strike-slip faults similar to the reference model R0 (Fig. $2 \mathrm{~h}-\mathrm{i})$ and new reverse faults embracing a central domal uplift. (Figure 5 here)

\subsubsection{Effect of deformation on intrusion shape}

Among the three emplacement scenarios there is a significant variation regarding the final geometrical features of the intrusion described by the intrusion's absolute height $(\mathrm{H})$ and normalized amplitude (A), its aspect ratio ( $r=$ length/width) and the orientation of its long axis (angle $\theta)$. The intrusion models appear strongly deformed and asymmetric, revealing the tectonic impact during their emplacement, and have a systematic generic relation to the regional stress and finite strain fields (Fig. 6).

The intrusion of Model A1 (pre-tectonic, Fig. 6a-d), which has been passively deformed is characterized by low height and amplitude $\left(\mathrm{H}_{\mathrm{A} 1}=15 \mathrm{~mm}, \mathrm{~A}_{\mathrm{A} 1}=0.38\right)$, compared to intrusions from other scenarios. Its asymmetry is related to displacement along the crosscutting faults developing late in the experiment. The lower part of the intrusion represented e.g. by the contourlevel $\mathrm{c}_{1}=3 \mathrm{~mm}$ shows a relatively high aspect ratio $\left(r_{1}=2.7\right)$ with the long axis of the intrusion forming a low angle of $\theta_{1}=12^{\circ}$ to the shear zone. At higher contour levels the intrusion progressively elongates $(r>3)$ 
323

324

and rotates antithetic (i.e. anticlockwise) with respect to the dextral simple shear (e.g. $\theta_{2}=34^{\circ}$ at $\mathrm{c}_{2}$ $=12 \mathrm{~mm}$ ) becoming subparallel to the elongation direction of the finite strain tensor (Fig. $7 ;$ A.2). The intrusion roof is sculpted by one central and two lateral dikes that represent silicone oil intruding upwards along the master fault (MF) and the lateral faults, obviously during the post-intrusion stage of the experiment. (Figure 6 here)

The intrusion Model A2 (syn-tectonic, Fig. 6e-h) is characterized by an acute roof resulting in a significant height and amplitude $\left(\mathrm{H}_{\mathrm{A} 2}=24 \mathrm{~mm} ; A_{\mathrm{A} 2}=0.6\right.$; Fig. $\left.6 \mathrm{e}-\mathrm{f}\right)$ compared to intrusions from other scenarios. It shows a strong asymmetric wing shape with opposing orientation to the intrusion model A1. At lower levels, the intrusion has a high aspect ratio (e.g. $\left.r_{1}=2.5\right)$ with the long axis almost parallel to the shear zone $\left(\theta_{1}=1^{\circ}\right)$. Upwards, the intrusion progressively rotates synthetically into the orientation of Riedel shears (e.g. $\theta_{2}=-10^{\circ}$ at $\mathrm{c}_{2}=20 \mathrm{~mm}$ ) while keeping its aspect ratio rather constant(Fig. 7 ; A.3). Lateral dikes flank the central upheaval with all of them exploiting faults formed during intrusion. The wing shape of the intrusion in association with scissor tailed and offset apophyses appears unique to this scenario. (Figure 7 here)

The intrusion Model A3 (post-tectonic, Fig. $6 \mathrm{i}-\mathrm{I}$ ) is characterized by a more domal shape with intermediate height and amplitude $\left(\mathrm{H}_{\mathrm{A} 3}=22 \mathrm{~mm} ; \mathrm{A}_{\mathrm{A} 3}=0.55\right)$. It appears sub-circular to gently elongated $(r<2)$ and largely subparallel to the shear zone with no systematic change of aspect ratio and orientation with height (Fig. 7 ; A.4). The roof is rounded and sculpted by a central dike $\left(\mathrm{r}_{2}=1.9\right.$ at $\mathrm{c} 2=$ $19 \mathrm{~mm}$ ) and two lateral dikes exploiting inherited structures (Fig. 6i-j).

\subsection{Transtensional intrusion models (Group B)}

\subsubsection{Effect of intrusion on fault evolution}

Transtensional intrusion experiments demonstrate, similarly to Group A, ongoing interactions developing between the intrusion and the fault pattern evolution for all three scenarios. 
347 In the first half of the pre-tectonic intrusion experiment, model $\mathrm{B} 1$, static intrusion takes place $\left(\mathrm{V}_{\mathrm{inj}}=\right.$ $34837.7 \mathrm{ml}$ ), deforming the initially flat topography and causing a domal surface uplift ( $\Delta \mathrm{h}$ init $=7 \mathrm{~mm}$; 349 Fig. 8a) above the centre. In the second half of the experiment, transtension is applied and a diffuse spindle-like shear zone occurs ( $d r e l=5.6 \mathrm{~mm}$; Fig. $8 \mathrm{~b}$ ) similar as in the pre-tectonic simple shear model A1. With ongoing transtension, lateral oblique normal faults and oblique Riedel shears localize deformation (drel= $16.7 \mathrm{~mm}$; Fig. 8c) causing subsidence along the shear zone. The initial central dome is crosscut by a fault system ( $P$ and $Y$-shears) that links the "northern" and "southem" boundary faults, which remain active until the end of the experiment (Fig. 8c-f). Similar to the reference model (RT, Fig. 2g-i), Riedels form an en-enchelon array of oblique normal faults within the basin (Fig. 8d). The finite deformation pattern of the surface is characterised by a well-defined elongated pull-apart basin (Fig. 8d-f). The domal uplift, caused by the initial intrusion, is overprinted and appears as a remaining gentle upliftin the centre (Fig. 8e). Notably, the topographic expression of the pre-tectonic intrusion is much less than in the corresponding simple shear model A1 (Fig. 3e). (Figure 8 here)

The early stage of the syn-tectonic intrusion experiment, model B2, is characterized by diffuse shear and Riedel shear formation ( $d_{\text {rel }}=1.2 \mathrm{~mm} ; V_{\text {inj }}=1.5 \mathrm{ml}$; Fig. 9a). At an intermediate stage $\left(d_{\text {rel }}=8.3\right.$ $\left.\mathrm{mm} ; V_{\mathrm{inj}}=10.5 \mathrm{ml}\right)$ and along with subsidence, the linkage of these Riedel shears form a dominant fault zone that diverges from the strike of the basal shear zone to form a releasing stepover centred on the intrusion domain (Fig. 9b). At a late stage $\left(d_{r e l}=16.7 ; V_{i n j}=21 ;\right.$ Fig. 9c) oblique normal faults bound the outer basin margins and curve towards the centre (Fig. 9c). As the master fault continues to propagate, it crosscuts and deforms the evolving basin. The finite fault pattern (Fig. $9 d-e$ ) is, in contrast to the reference model (RT, Fig. $2 \mathrm{~g}-\mathrm{i}$ ), characterised by a more segmented and curved faults bounding the elongate basin with the deep central graben flanked by horst blocks. (Figure 9 here)

The post-tectonic intrusion experiment, model B3 (Fig. 10), is divided again into two parts: the first transtension as described for model RT model (Fig. $2 \mathrm{~g}-\mathrm{i}$ ), resulting in a fault-controlled, spindle- 
373 shaped pull-apart basin $\left(d_{r e l}=30 \mathrm{~mm}\right.$; Fig. $\left.10 \mathrm{a}, \mathrm{d}\right)$. Then static intrusion $\left(V_{\mathrm{inj}}=13 \mathrm{ml}\right)$ starts to form

374 a domal uplift, triggering the re-activation of the pre-existing faults (Fig. 10b). Similarly as observed 375 in model A3, inherited faults are reactivated and partly inverted (Fig. 10b-c). The master fault is re376 activated in sinistral sense while dextral displacement occurs along inverted boundary faults $\left(V_{i n j}=\right.$ 377 18.6; Fig. 10c). The finite topography (Fig. 10d-e) directly reflects the intrusion at depth with in the 378 basin system (Fig. 10d-e). (Figure 10 here)

\subsubsection{Effect of deformation on intrusion geometry}

380 The intrusion Model B1 (pre-tectonic, Fig. 11a-d) is like the corresponding Model A1 characterized 381 by low height and amplitude and enhanced by post-emplacement flattening in the transtensional regime $\left(H_{B 1}=5 \mathrm{~mm} ; A_{B 1}=0.13\right)$. The intrusion's aspect ratio shows characteristic high values but with no systematic change with height (Fig. 12; A.5), varying from 1.8 at $\mathrm{C}_{1}=1 \mathrm{~mm}$ (Fig. 11c) to 1.9 at $\mathrm{C}_{2}=3 \mathrm{~mm}$ (Fig. 11d). The orientation of the intrusion, similar to $\mathrm{A} 1$, rotates from the base to the top antithetic (i.e. clockwise) with respect to the sinistral sense of transtensional shear to become subparallel to the finite strain tensor (e.g. $\theta_{2}=42^{\circ}$; Fig. 12). The intrusion's flat roof is sculpted by lateral dikes exploiting faults developing during the post-emplacement deformation. (Figure 11 here)

The intrusion Model B2 (syn-tectonic; Fig. 11e-h) similarly to model A2 is characterised by an acute shape $\left(\mathrm{H}_{\mathrm{B} 2}=22 \mathrm{~mm} ; \mathrm{A}_{\mathrm{B} 2}=0.6\right)$. The intrusion's base shows an intermediate aspect ratio of $\mathrm{r}_{1}=1.7$ with the long axis subparallel to the shear zone boundary (e.g. $\theta_{1}=-10^{\circ}$; Fig. $11 \mathrm{~g}$ ). Upwards, the intrusion rotates synthetically towards the maximum horizontal stress orientation, $\sigma$ Hmax (Fig.11h; Fig. 12; A.6). This model bears a smooth roof top and lateral dikes flanking the central upheaval. The asymmetric wing shape marked by a scissor tail apophyses that trails behind the intrusion are similarly observed for model A2 (Fig. 6e-h). (Figure 12 here)

Finally, the intrusion Model B3 (post-tectonic, 11j-I) is a sub-circular to slightly elongated intrusion of domal shape $\left(\mathrm{H}_{\mathrm{B} 3}=20 \mathrm{~mm} ; \mathrm{A}_{\mathrm{B} 3}=0.5\right)$. At lower contour levels, the intrusion shows an aspect 
ratio of $r 1=1.4$ with the long axis parallel to the shear zone like model A3 (Fig. 11k; Fig. 12; A.7).

400 The intrusion has an asymmetric roof of carrying a central dike $\left(\mathrm{r}_{2}=1.7\right.$ at $\left.\mathrm{c}_{2}=18 \mathrm{~mm}\right)$ and two 401 lateral dikes (Fig.11l). The latter exploits inherited faults $\left(\theta_{2}=-11^{\circ}\right.$; Fig. 7).

\section{Discussion of experimental results}

403 We here present sandbox-type analogue model experiments simulating magma emplacement into 404 simple and transtensional crustal shear zones to test the diagnostic potential of the finite pluton 405 shape with respect to timing and setting of its emplacement. Observations based on surface 406 deformation and intrusion shape illustrate strong interactions between evolving and inherited 407 tectonic structures and magma uprising, plus constitute an important contribution in defining the 408 diagnostic potential of pluton shape for the timing and the tectonic setting of the emplacement.

\subsection{Synthesis and comparison of experimental results}

\subsubsection{Controlling parameters on pluton emplacement}

411 In this study the timing of the magmatic emplacement with respect to the regional tectonic 412 deformation is inferred as a controlling parameter on the finite pluton geometry and emplacement 413 mode. Parallelly, the shape of the produced intrusions, based on the timing of their emplacement, 414 is suggested as an effective diagnostic feature. Notably, the findings of this work extend the results of previous stu dies which observed and described experiments restricted under reference conditions 416 (static, shear deformation) and processes of syn-tectonic magmatic emplacement.

Based on our observations, the pluton emplacement is directly controlled by the syn-active evolving faults, for both groups in pre- and syn-tectonic scenarios. At the same time, strain localization on the weak body influences the upward fault propagation. Post-tectonic models are influenced and overprinted by the boundary conditions and indirectly by the inherited fault structures during their emplacement. According to our observations and in agreement with previous related studies 422 (Román-Berdiel et al., 1997; 2000; Corti et al., 2005) local interactions between on-going fault propagation and magma uprising induce asymmetric intrusion shapes. In addition, the thickness 
ratio between the brittle and ductile band, influence the interactions between the intrusive analogue magma and the developing model surface fault pattern. In our case, the ratio between the ductile band $(7 \mathrm{~mm})$ and the brittle layer thickness $(40 \mathrm{~mm})$ is fixed at 0.175 . This ratio allows us to observe the overburden deformation without the fault pattern being completely overprinted by deformations induced by piercement of the surface.

Román-Berdiel et al. (2000) pointed out the importance of the divergence angle, $\alpha$, in deformation

transtension the fault pattern is similar to pure simple shear kinematics, therefore resulting in similar geometries for the syn-tectonic intrusions. The fault structures observed in the reference

experiments (RS and RT), during which no intrusion takes place, are very similar to those described

in previous experiments (e.g. Tchalenko, 1970; Wilcox et al., 1973; Naylor et al., 1986). Moreover,

for $\alpha<30^{\circ}$, the deformation is mainly located in the central part of the model and the localization of brittle deformation is very high (Román-Berdiel et al., 1999; 2000).

Previous studies have shown that variations in the displacement velocity and the intrusion rate control the final geometry and orientation of the syn-tectonic magmatic body emplaced in the upper crustal layer (Román-Berdiel et al., 1997; Corti et al., 2005). According to these studies, high horizontal-displacement or low intrusion rates resulted in normal pluton asymmetry with the pluton's long axis parallelising the velocity discontinuity (VD) zone, whereas low horizontal-displacement or high intrusion rates, generated plutons with reverse asymmetry (magmatic emplacement controlled by tensional faults). In this study the variation of the ratio between tectonic displacement rate and intrusion rate is constant. However, by varying the time of emplacement we also captured observations on the pluton's asymmetry. Both pre-tectonic models show normal pluton asymmetry, with the long pluton axis forming with the shear zone angles of $\theta=28^{\circ}$ (Model A1, Fig. 6c-d) and $\theta$ $=42^{\circ}$ (Model B1, Fig. 11c-d) and stretched to the extension direction. In the contrary, syn - and posttectonic models, from both experimental groups, show reverse asymmetry with their long axis stretched to the compression direction, forming low angles with the shear zone (Fig. 6, Fig. 11f,i). 
451 The significant geometrical differences of the finite intrusions' shape observed among the 452 emplacement scenarios (Fig. 6, Fig. 11) reveal strong interactions between deformation and 453 intrusion emplacement (Román-Berdiel et al., 1997; Corti et al., 2005; Galland et al., 2007a; 454 Montanari et al., 2010; Gomes et al., 2019). Our experimental results, in both simple and 455 transtensional shear settings, show that pre- and syn-tectonic scenarios produce more elongated 456 and fault-controlled intrusions in comparison to the less deformed post-tectonic intrusions 457 characterised by low aspect ratios. The presence of intrusion causes regional surface uplift above 458 the injection point and interferes with the fault structure evolution during their propagation. 459 Regarding the reference models, with no intrusion presence, fault-controlled pull-apartbasin system and of high subsidence rate occur for the transtensional group. The simple shear deformation results in a low angle main deformed linear zone formed by low angle shears and anastomosing shear lenses. Exception to this topography is Model A2 that resulted in narrow pull-apart system divided 463 and displaced by the MF (Fig. 4e).

In accordance to the study of Gomes et al. (2019), this study illustrates that the shear zone deformation can be significantly modified by rheological heterogeneities by looking at the shearzone 466 perturbation effect arising from passive (pre-tectonic) viscous-weak bodies. The pre-tectonic plutons, $\mathrm{A} 1$ and $\mathrm{B} 1$, with the gradual evolution of the post-emplacement shearing start to accumulate strain deformation in a ductile manner acquiring a sigmoidal (initially circular) shape of high aspect ratio and the lowest amplitude among all models (Fig. 6a-d, Fig. 11 a-d). This is very well shown from the shapeanalysis, where the lower levels of these intrusions are subparallel to the shearzone while the highest levels follow the finite stretching direction (Fig. 6c-d, Fig. 11c-d). The surface 472 structures observed only for this model are acting separately over the domal uplift and not as one 473 master fault(Fig. 3f). These above results seem compatible with the inferred observation on caldera 474 collapse modelling and the case of strike-slip deformation of brittle layer containing a passive 475 magmatic chamber (Holohan et al., 2008), where the magmatic chamber showed a NE-SW pluton 
axis orientation, stretched approximately parallel to the extensional direction (in accordance to

current study Models A1 and B1). The limitation of pre-tectonic models, by the fault structures

developing subparallel to the boundary of the shear zone is an observation that is only attributed to

the variations on the overburden thickness (Román-Berdiel et al.,1997). The presence of the weak

body delays the upward propagation of the synthetic Riedel shears and results in a wider shear

zone, in respect to its reference model (Fig. 2f, Fig. 3f). Fact that is inferred from the deformational

response and the delay of the shear zone formation on the brittle surface, in comparison to the reference models (Fig. 2, Fig. 3, Fig.8).

In the case of the syn-tectonic intrusions, direct and strong interactions are developing among fault

propagation and magma ascent. Faults control and confine the emplacement of the intrusions,

resulting in narrow and acute pluton shape that follows the highly active master fault (e.g. Román-

Berdiel et al., 1997; Corti et al., 2005; Mazzarini et al., 2010). Syn-tectonic models in simple shear deformation show the highest pluton amplitude among all models ( $\mathrm{A}_{\mathrm{A} 2}=0.6$; Table 3 ). From the shape analysis of the excavated intrusion s is inferred local faultcontrol on the intrusions' bound aries and orientation. Models A2 and B2, are initially orientated subparallel to the shear zone (intrusions' lower level), with very low long axis angles. The deviation of their deformational is registered at their highest levels when Model A2 seems to follow the Riedel orientation (Fig. 6h) while Model B2 is oriented subparallel to SHmax.

The post-tectonic intrusions, Models A3 and B3, ascend without being exposed to the stress field, besides the push from below during their ascent. The shape analysis reveals a characteristic subcircular intrusion of an intermediate amplitude $\left(\mathrm{A}_{A 3}=0.55 ; \mathrm{A}_{B 1}=0.5 ;\right.$ Table 3$)$ and with an analogous axis orientation to the syn-tectonic models (Fig. 6k-I, Fig. 11k-I). Only from the strain analyses it is inferred that in both settings, the uprising intrusions interferes and reactivates the preexisting brittle structures (Fig. 5c, Fig. 10c).

As a second order feature, the dike system overprinting the intrusions, is observed and analysed upon excavation. Diking occurs locally and along fault structures and for all models, is developing 
502 either on the intrusion's flat roof top, as in the cases of pre- and post-tectonic emplacement models 503 (Fig. 6a-b; i-j, Fig. 11a-b; i-j) or as a form of a sheared tail intrusion's extension, as in the case of 504 the syn-tectonic A2 and B2 Models (Fig. 6e-f, Fig 11e-f).

505 Our models have shown that the pluton's geometry functions as an excellentfirst order discriminator for the timing of the intrusion with respect to tectonic activity. In addition, this study offers information on the surface deformation, often limited during field work due to the occurrence of natural (e.g. erosion) and tectono-magmatic processes. The diagnostic attributions are summarized in Table 3.

\section{9 (Table 3 here)}

\subsection{Model boundary conditions, simplifications and limitations}

511 Effect of the basal ductile shear zone on the emplacementprocess

512 We use a ductile homogenous shear zone as a basal kinematic boundary condition, which mimics 513 a natural mid-crustal shear zone. Apart from distributing deformation, the ductile material also 514 influences the emplacement mechanisms as reported in previous studies (Román-Berdiel et al., 515 1997, 2000; Corti et al., 2005; Montanari et al., 2010; Mazzarini et al., 2010). In those models, the 516 presence of a widespread ductile layer is a pre-requisite to allow lateral flow and emplacement in 517 laccolith style. It is suggested that for the syn-intrusive deformation the rheological stratification 518 caused a deeper level of emplacement with respect to purely brittle models and thus controls the timing of magma emplacement. For our experiments, instead of a widespread ductile layer, we introduced a basal ductile band. Intrusions are allowed within the ductile band and above the fixed injection tube. The effects described previously is similarly active in our setup with lateral intrusion 522 aided by the ductile material.

Ignoring thermal and strain-rate dependent effects on rheology.

524 The deformation in our experiments was accomplished by a quasi-stationary rheology including temperature- and strain rate-insensitive brittle and Newtonian viscous materials. Our modelling 526 faces therefore some limitations regarding rheological principals (Corti et al., 2003). Magma cooling 
is considered in simplified way by choosing a relatively high viscosity of the model magma (see

chapter on scaling and similarity 2.3). Thermal effects caused by the intrusion-related heating on

the rheology of the crustal rocks were not taken into consideration for our modelling as for all other

models of this type (Román-Berdiel et al., 1997; Corti et al., 2003; Galland et al., 2003, 2006, 2007;

Montanari et al., 2010; Mazzarini et al., 2010). At shallow crustal levels as those targeted here,

intrusion of rather small amounts of hot material into cold crust has likely a minor effect on the 541 regional scale. geotherm and thereby on the rheology in general. However, the brittle-ductile transition might be more sensitive to even small fluctuations in the geotherm caused by episodic heat advection by veining and long-termemplacement of the intrusion (e.g. Handy and Streit, 1999; Brown, 2013). Any modification of the rheology around the base of our models including temperature and strain -rate dependent viscosity changes or even switches in the dominant deformation mechanisms (and thereby the geometry of the brittle-viscous transition) is however beyond the scope of this modelling approach. While we consider this drawback of the method more significant at a small scale, numerical modelling might help in verifying the validity of our more stationary approach on a more

What drives deformation in the model versus nature?

543 In our experiments model magma is rising due to two different forces: pressure applied externally and internal buoyancy forces (e.g. Ribe and Davaille, 2013; Wouter et al., 2016). Though qualitative similar mechanisms act in nature the dynamic similarity is hard to verify. Pressure in the model is controlled by the applied intrusion rate and decreases over an experimental run as the intrusion rate is kept constant while the volumetric fraction added to the growing intrusion decreases with $1 / \mathrm{t}$ systematically. Given the geometric and kinematic similarities described above we suspect a realistic de-pressurization scenario in the model. However, given the lack of quantitative observations in nature a conclusion remains elusive. Buoyancy in the model is likely more important than in nature because the density ratio between PDMS and sand is low $(1: 1.7)$ while it may be closer to equality (1:1) or even $>1$ (negatively buoyant) in nature, depending on magma composition. 
553 As we observe silicone dikes intruding the overburden in a similar fashion as in nature (e.g. roof 554 dikes, see below), we suspect however, that buoyancy driven intrusion (i.e. diapirism) mimics residual melt injection driven by local pressure anomalies in the prototype.

\subsection{Comparison with nature}

Analogue modelling may be characterised by strong limitations and simplifications, mainly related to the inability to reproducing natural thermal and rheological conditions. In addition, limitations on direct comparison among natural and analogue models may be due to restricted exposure of plutons. From our observations, the spatial and temporal relationships between emplacementrelated structures and intrusion vary with the level of the exposure. Analogue modelling studies have managed to reproduce models with similar geometrical features of the plutons in the upper crustal levels, for different tectonic settings, supporting the field evidences on tectonic control during pluton emplacement (Castro, 1987; Hutton, 1988) and testifying the reliability of this modelling approach (Román-Berdiel et al., 1997, 2000; Galland et al., 2003; Corti et al., 2005; Gomes et al., 2019).

The current analogue modelling approach provides new insights on the reliability of the finite pluton shape as a diagnostic key-feature for constraining the temporal timing (pre-, syn-and post-tectonic) and spatial conditions (tectonic setting) of the shallow crustal level emplacement. To validate our experimental observables, we test them along with some secon d-order attributes against six cases of well-defined natural examples, emplaced in simple shear and transtensional zones (Fig.13).

\subsubsection{Natural examples of intrusions along simple shear zones}

The pre-tectonic Teixeira Pluton (Fig. 13a,d) - This elongated ENE-trending batholith $(80 \mathrm{~km} \times 25$ $\mathrm{km}$ ) is situated in NE Brazil and within azone that is defined by the E-trending Patos, the So Josèdos Cordeiros and the Juru shear zones (Fig.13a). The pre-tectonic Teixeira batholith is a leucocratic granite to quartz-syenite in composition that shows a crystallization age of $591 \pm 5 \mathrm{Ma}$ (Zircon U/Pb). The batholith fabrics, determined by anisotropy of magnetic susceptibility (AMS) and mineral shape preferred orientation, support a pre-transcurrent batholith emplacement scenario (Archanjo et al., 
2008). This natural example carries similar features to the pre-tectonic Model A1 of this study (Fig.

6a-d). The pluton is characterised by high aspect ratio $(L / W>5)$, with the long axis orientated subparallel to the extensional direction, forming an angle of $\alpha=15^{\circ}$. The Teixeira pluton, on map view, is elongated in a northeast-southwest direction, consistent with the dextral pure strike-slip motion (Fig.13a).

Another natural example with similar characteristics to the pre-tectonic model A1 is the granitic Tazenakht Pluton in Morocco. The pluton's deformation follows its emplacement with in a left lateral strike slip fault, running along its northern side (Ennih and Liegeois, 2001; Gasquet et al., 2008). The boundaries developing between the fault structure and the intrusion boundaries are sharp. The pluton was probably subject to a minor rotation during the deformational post-intrusion event. This natural example is characterised by high axis ratio ratio $(L / W=1.6)$ and the pluton's long axis forms an angle of $\alpha=29^{\circ}$ with the shear zone. The local presence of dykes and the geometrical features of the pluton are similar to those observed for the Model A1.

The syn-tectonic Cabeza de Araya Pluton (Fig. 13b,e) - The plutons of the Central Extremadura batholith in the Iberian Massif (Fernández and Castro, 1999) is a natural example of syn-tectonic plutonism. This natural example was imposed to tectonic deformation during its emplacement, triggered by a right-lateral shear zone (Vigneresse and Bouchez, 1997; Fernández and Castro, 1999; Corti et al., 2005). The emplacement mode of the pluton is coeval with the dextral regional shear zone (Castro, 1985). The pluton shows an aspect ratio of $L / W=2.7$, with the long axis forming an angle of $\alpha=-45^{\circ}$ parallel to the compression direction (NW-SE direction, Fig. 13b). Similarly, an intermediate axis ratio is observed for the syn-tectonic Model A2 ( $r=2.5$; Fig. $6 \mathrm{~g}, \mathrm{~h})$. The model's long axis that corresponds to the higher contour levels is orientated with the angle of $\left(\theta=-10^{\circ}\right)$, making this natural model a prototype for this emplacement scenario. In addition to this, there are also other important natural examples of syn-tectonic intrusion emplacement scenarios that shows similarities to our observations: 1) Karawanken pluton (Visonà and Zanferrari, 2000; Rosenberg, 
2004); 2) The Lizio pluton (Román-Berdiel et al., 1997; Fernandez and Castro, 1999; Corti et al., 604 2005); 3) Cases of Syn-tectonic magmatism along the Periadriatic Fault System (Rosenberg, 2004).

The post-tectonic Vila Pouca de Aguiar pluton (Fig. 13c,f) - This is a natural example of a posttectonic granitic intrusion that is emplaced after the main left-lateral shear phase event (Sant'Ovaia et al., 2000). It is suggested that the first to be emplaced and the least evolved granite type (Vila Pouca de Aguiar Granite) upwelled from the local, NE-trending fault-zone, acting as a dike, and formed a thin sill where NE-directed magma flow was dominant. In this case, the pre-existing features exert a major role during emplacement leading to the roughly alignment of the intrusion with the shear zone $\left(\alpha=-4^{\circ} ;\right.$ Fig.13f), with the pluton axis parallel to the compression direction. Even if the pre-tectonic group generated intrusions with the lowest aspect ratios $(r<1.5$; Fig. 7), the intrusion ellipses corresponding to higher contour levels resulted in a similar aspect ratio $(r=1.9)$ and elongated shape to the Vila Pouca de Aguiarpluton (Fig. 6l).

Another characteristic natural example of post-tectonic emplacement is the Águas Frias (AF) pluton (Martins et al., 2009; Fig. 13c). This post-tectonic granitic pluton is situated NE from the Vila Pouca de Aguiar pluton, occupying an area of $30 \mathrm{~km}^{2}$ and is associated with Penacova-Régua-Verin fault (PRVF) that belongs to the NNE-trending brittle fault system. Its emplacement is fed through a deep conduit located at the centre of the pluton. VPA and AF plutons show similar in mineralogical, chronological and magnetic features. Their feeding zones are located within the NNE-SSW Penacova-Régua -Verin Fault. (Figure 13 here)

\subsubsection{Natural examples for intrusion into transtensional shear zones}

The pre-tectonic Eğrigöz pluton (Fig. 13g,j) - This natural example regards a N-S elongated (40x15 km) granite body (20.5 $\pm 1.1-18.9 \pm 1.2 \mathrm{Ma}$.; Catlos et al., 2012), situated in the northern Menderes metamorphic core complex and covering an area of $330 \mathrm{Km}^{2}$. Its geometrical features show a high aspect ratio of $L / W=2.6$ and an axis trend of $\alpha=46^{\circ}$ (parallel to the extension direction), analogous to the observations made for the higher contour levels of the strongly deformed pre-tectonic Model B1 $\left(r=1.9 ; \theta=42^{\circ} ;\right.$ Fig.11d; Table 3). The 20km-long, NE-striking Gerni shear zone is closely linked 
to the pulses of magmatic activity and assumed to have propagated immediately following the emplacement of the Eğrigöz pluton. Stress tensor results of the Eğrigöz pluton indicate that the shear zone has been predominant under NE-SW-trending extension. The presence of the aplitic and pegmatitic dikes along the periphery and stru ctu rally upper parts of the pluton (Erkül et al., 2017) are rather common and similarly reproduced during the analogue Model B1 experiment (Fig. 11ab). In addition to this example, more plutons are registered carrying similar diagnostic features of pre-tectonic emplacement mode : 1) The Totoltepec Pluton (Kirsch et al., 2013); 2) The Devonian granitoid of Pampa de Achala, in Central Argentina (Simpson et al., 2001); 3) The Koyunoba pluton (Erkül et al., 2017).

The syn-tectonic Monzoni Intrusive Complex (Fig. 11) - This 4 km-long intrusion situated in the central Dolomites in Italy offers a great occasion for comparison due to its excellent threedimensional exposure. However and mainly due to contact metamorphism around the pluton and

the syn-metamorphic thermally driven fluid circulation, field observations are very limited, an d still

642 there is very poor knowledge of kinematic indications. Based on analogue modelling observations,

new insights on the shear zone and fault structures, of the missing upper crustal layer that once

hosted the emplaced magmatic chamber, is achieved. It is assumed that the pluton's emplacement

mode is controlled by the Middle Triassic tectonics, however the time of emplacement (syn-tectonic or indirect post-tectonic emplacement) along the left-lateral shear zone is still under discussion. According to our model observations, this pluton exhibits diagnostic characteristics similar to a synto late tectonic intrusion. The pluton's long axis trends with an angle of $\alpha=-14^{\circ}$, parallel to the compressional field, and shows an aspect ratio of $L M=2$ (Fig. 13k). The shape analysis of this pluton shows similarity to the Model B2 $\left(-10<\theta<-19^{\circ} ; r=1.7 ;\right.$ Fig. 11g-h $)$. The syn-magmatic dike swarms, cropping out at the intrusion area, appear to cut the deformed sedimentary country rocks and intrude the magmatic edifice (Sloman 1989; Bonadiman etal., 1994; Gianolla et al., 2010; Abbas et al., 2018) while the pluton carries a NE-SW striking apophysis that trails the intrusion at its SW boundary. Similar natural examples of syn-tectonic emplacement mode are: 1) The Mortagne pluton (Román-Berdiel et al., 1997); 2) The Los Pedroches pluton (Aranguren et al., 1997; Román-Berdiel 
et al., 2000); 3) The Jihlava Intrusion (Verner et al., 2006); 4) The Hombreiro pluton (Román-Berdiel

657 et al., 2000); 5) The Gulf of Aden Ridge (Corti et al., 2003).

658 The post-tectonic La Tojiza Pluton (Fig. 13i,I) - The La Tojiza granite is cropping out in the 659 Mondon edo Nappe Domain (Fig. 13c) and according to geochronological data it consists with a U$660 \mathrm{~Pb}$ age of $295 \pm 2 \mathrm{Ma}$ (Fernàndez-Suàrez et al., 2000). This post-tectonic association is composed 661 of granite-granodiorite-tonalite-monzogranite intrusions. The intrusion reactivated the inherited 662 transtensional tectonic structures, leading to the emplacement and formation of a sub-circularpluton 663 of $16 \mathrm{~km}$-diameter (Aranguren et al., 2003). Its thickness is estimated of $1 \mathrm{~km}$ and the root zone is 664 located at its eastern border. The pluton shows an axis trend of $a=-6^{\circ}$ and parallel to the

compressional field, with the pluton's aspect ratio L/W $=1.2$ (Fig. 13I). Most of the observed aplitic dikes are present on the roof of the pluton and oblique to the magnetic lineation. These features are in great accordance to the lower contour levels of the post-tectonic Model B3 $\left(\theta=0^{\circ} ; r=1.4\right.$; Fig. 11k-I). The Plasenzuela Intrusion (Central Extremadura, Spain; Fernandez and Castro, 1999) represents another natural example for this emplacement scenario, characterised by a well-defined rounded pluton shape of low aspect ratio $(L / \mathrm{W} \sim 1)$.

672 This study provides new insights on the application of the finite pluton shape as a diagnostic in dicator for constraining the tectonic setting and the relative timing of magma emplacement versus tectonics. 674 Three scenarios on pluton emplacement (pre-, syn- and post-tectonic) in two different tectonic settings (simple shear, transtension) are tested and analysed. The intrusion shapes (aspect ratio, principal axis trend, amplitude) and the model surface deformation are measured and described, 677 providing useful insights for the understanding of the interactions occurring between tectonics and magmatism. The main insights and conclusions supported by this study are the following:

1. Incremental strain analysis and final surface deformation reveal a different deformational pattern among the scenarios and strong interactions between tectonics and magma 
emplacement. Pre-tectonic models accumulate regional strain during shearing, resulting in the delay and diffusion of the brittle structures during their up-ward propagation. Here, the final shear zone appears wider than the respective reference model and crosscut but more than one well-defined fault. Syn-tectonic emplacement causes the major boundary faults to extend and curve towards the centre and the formation of a narrow fault-controlled pull-apart basin overprinted by the master fault. The inverse shear sense, captured in strain maps, caused during intrusion is observed exclusively in the post-tectonic scenario.

2. The final shape of the intrusions emplaced along the shear zones with a different timing respect to the tectonic activity show significant deformational variations, delineating its reliability as a diagnostic feature. Observations coming from both tectonic groups (simple shear and transtension) infer parallel deformational pattern and geometrical characteristics for the intrusions of similar timing of emplacement (pre-, syn- or post-tectonic). Based on the analytical shape analysis, the asymmetric and deformed final intrusions reflect the regional stresses and finite strain field. The axis aspect ratio and trend are evolving against the contour level for each model, remaining consistent among those emplaced coevally.

3. Among the emplacement scenarios, the pre-tectonic intrusions appear strongly elongated parallel to the extension field with the lowest amplitude and the highest aspect ratios. The intrusion's flat top is cross cut by more post-emplacement shears. Syn-tectonic models are characterised by high amplitude and moderate aspect ratios. They bear acute roofs, oriented parallel to the compression direction, and scissor-tail apophysis that trails the intrusion. The sub-circular post-tectonic models show the lowest aspect ratios and a similar orientation to syn-tectonic models.

4. Faults that crosscut the central zone overprint the emplaced or up-lifting intrusion, navigating the intrusions' margins and serving as pathway for diking. The higher levels of the syn- and post-tectonic intrusion boundaries appear parallel to and constrained by the synthetic faults developing on the surface. The lateral expansion of pre-tectonic models is 
bounded by the major fault structures developing subparallel to the boundary of the shear zone, while their top is overprinted by roof-diking guided by crosscutting shears.

5. The obtained diagnostic attributes are tested successfully against natural prototypes, confirming the diagnostic potential and reliability of the intrusion's shape for constraining the time and the tectonic setting of the magmatic emplacement.

\section{Data Availability}

713 Supplementary data to this article can be found online at: https://dataservices.gfz714 potsdam.de/xxx

\section{Acknowledgments}

717 The experiments were performed at the HelTec - Helmholtz Laboratory for Tectonic Modelling of the 718 Helmholtz Centre Potsdam - German Research Centre for Geosciences (GFZ), in Potsdam 719 (Germany). The authors wish to thank F. Neumann and T. Ziegenhagen (GFZ German Research 720 Centre for Geosciences) for their technical support and engineering. T. Román-Berdiel for her 721 valuable reviews on a previous version of the manuscript, as well as E. Carminati (Sapienza 722 University), M. Mattei (Roma Tre University) and C. Bonadiman (University of Ferrara) for their 723 constructive discussions and contributions. Part of this research was funded by the IUSS-PhD 724 mobility grant (University of Ferrara). The research has been supported by the Deutsche 725 Forschungsgemeinschaft (DFG) through CRC1114 "Scaling Cascades in Complex Systems", 726 Project B01 and EPOS - the European Plate Observing System. 
Abbas, H., Michail, M., Cifelli, F., Mattei, M., Gianolla, P., Lustrino, M., Carminati, E., 2018. Emplacement modes of the Ladinian plutonic rocks of the Dolomites: Insights from anisotropy of magnetic susceptibility. J. Struct. Geol. 113, 42-61. https://doi:10.1016/j.jsg.2018.05.012.

Adam, J., Urai, J.L., Wieneke, B., Oncken, O., Pfeiffer, K., Kukowski, N., Lohrmann, J., Hoth, S., Van der Zee, W., Schmatz, J., 2005. Shear localisation and strain distribution during tectonic faulting - new insights from granular-flow experiments and high-resolution optical image correlation techniques. J. Struct. Geol. 27, 283-301. https://doi:10.1016/j.jsg.2004.08.008.

Aranguren, A., Cuevas, J., Tubia, J.M., Román-Berdiel, T., Casas-Sainz, A., Casas-Ponsati, A., 2003. Granite laccolith emplacement in the Iberian arc: AMS and gravity study of the La Tojiza pluton (NW Spain). J. Geol. Soc. London. 160, 435-445. https://doi:10.1144/0016-764902-079

Bartlett, W.L., Friedman, M., Logan, J.M., 1981. Experimental folding and faulting of rocks under confining pressure Part IX. Wrench faults in limestone layers. Tectonophysics 79, 255-277. https://doi:10.1016/0040-1951(81)90116-5.

Benn, K., Odonne, F., De Saint Blanquat, M., 1998. Pluton emplacement during transpression in brittle crust: New views from analogue experiments. Geology 26, 1079-1082. https://doi:10.1130/0091-7613(1998)026<1079: PEDTIB>2.3.CO.

744 Benn, K., Odonne, F., Lee, S.K.Y., Darcovich, K., 2000. Analogue scale models of plu ton emplacement during transpression in brittle and ductile crust. Trans. R. Soc. Edinb. Earth Sci. 91, 111121. https://doi:10.1130/0-8137-2350-7.111.

Bonadiman, C., Coltorti, M., Siena, F., 1994. Petrogenesis and T-fO 2 estimates of Mt. Monzoni Complex (central Dolomites, Southern Alps); a Triassic shoshonitic intrusion in a transcurrent geodynamic setting. Eur. J. Mineral. 6, 943-966. 
750 Brown, M., 2013. Granite: From genesis to emplacement. Geol. Soc. Am. Bull. 125, 1079-1113. https://doi:10.1130/B30877.1.

Burov, E., Jaupart, C., and Guillou-Frottier, L., 2003. Ascent and emplacement of buoyant magma bodies in brittle-ductile upper crust. J. Geophys. Res. 108. https://doi: 10.1029/2002JB001904

Catlos, E. J., Jacob, L., Oyman, T., \& Sorensen, S., 2012. Long-term exhumation of an Aegean metamorphic core complex granitoids in the Northern Menderes Massif, western Turkey. American Journal of Science, 312(5), 534-571.

Castro, A., Fernández, C., 1998. Granite intrusion by externally induced growth and deformation of the magma reservoir, the example of the Plasenzuela pluton, Spain. J. Struct. Geol. 20, 12191228. https://doi:10.1016/S0191-8141(98)00056-X.

Corti, G., Bonini, M., Conticelli, S., Innocenti, F., Manetti, P., Sokoutis, D., 2003. Analogue modelling of continental extension: A review focused on the relations between the patterns of deformation and the presence of magma. Earth-Science Rev. 63, 169-247. https://doi:10.1016/S00128252(03)00035-7.

Corti, G., Moratti, G., Sani, F., 2005. Relations between surface faulting and granite intrusions in analogue models of strike-slip deformation. J. Struct. Geol. 27, 1547-1562. https://doi:10.1016/j.jsg.2005.05.011.

De Saint Blanquat, M., Horsman, E., Habert, G., Morgan, S., Vanderhaeghe, O., Law, R., Tikoff, B., 2011. Multiscale magmatic cyclicity, duration of pluton construction, and the paradoxical relationship between tectonism and plutonism in continental arcs. Tectonophysics 500, 20-33. https://doi:10.1016/j.tecto.2009.12.009. 
771 Dooley, T.P., Schreurs, G., 2012. Analogue modelling of intraplate strike-slip tectonics: A review and new experimental results. Tectonophysics 790, 574-575, 1-71. https://doi.org/10.1016/j.tecto.2012.05.030.

ErkülF., Erkül, S.T., Manap, H.S., Çolak, C., 2017. An extensional and transtensional origin of elongated magmatic domes and localised transfer faults in the northern Menderes metamorphic core complex, western Turkey. Geodinamica Acta 29, 139-159. https://doi:10.1080/09853111.2017.1343523.

Ennih, N., Liégeois, J.P., 2001. The Moroccan Anti-Atlas: The West African craton passive margin with limited Pan-African activity. Implications for the northern limit of the craton. Precambrian Res. 112, 289-302. https://doi:10.1016/S0301-9268(01)00195-4.

Fernández, C., Castro, A., 1999. Pluton accommodation at high strain rates in the upper continental crust. The example of the Central Extremadura batholith, Spain. J. Struct. Geol. 21, 1143-1149. https://doi:10.1016/S0191-8141(99)00086-3.

Fernández, C., Castro, A., 1999. Pluton accommodation at high strain rates in the upper continental crust. The example of the Central Extremadura batholith, Spain. J. Struct. Geol. 21, 1143-1149. https://doi:10.1016/S0191-8141(99)00086-3.

Fernández-Suárez, J., Dunning, G.R., Jenner, G.A., and Gutiérrez-Alonso, G., (2000). Variscan collisional magmatism and deformation in NW Iberia: constraints from U-Pb geochronology of granitoids. J. Geol. Soc. 157, 565-576.

Ferré, E.C., Galland, O., Montanari, D., Kalakay, T.J., 2012. Granite magma migration and emplacement along thrusts. Int. J. Earth Sci. 101, 1673-1688. https://doi:10.1007/s00531-012-0747-6.

792 Fossen, H., Teyssier, C., Whitney, D.L., 2013. Transtensional folding. J. Struct. Geol. 56, 89-102. https://doi:10.1016/j.jsg.2013.09.004. 
794 Galland, O., Holohan, E., van Wyk de Vries, B., Burchardt, S., 2015. Laboratory Modelling of Volcano Plumbing Systems: A Review. In: Breitkreuz C., Rocchi S. (eds) Physical Geology of Shallow Magmatic Systems. Adv. Volcanol.Springer, 1-68. https://doi:10.1007/11157_2015_9.

Galland, O., Cobbold, P.R., de Bremond d'Ars, J., Hallot, E., 2007b. Rise and emplacement of magma during horizontal shortening of the brittle crust: Insights from experimental modeling. J. Geophys. Res. Solid Earth 112, 1-21. https://doi:10.1029/2006JB004604.

Galland, O., Cobbold, P.R., Hallot, E., de Bremond d'Ars, J., Delavaud, G., 2006. Use of vegetable oil and silica powder for scale modelling of magmatic intrusion in a deforming brittle cru st. Earth Planet. Sci. Lett. 243, 786-804. https://doi:10.1016/j.epsl.2006.01.014.

Galland, O., de Bremond d'Ars, J., Cobbold, P.R., Hallot, E., 2003. Physical models of magmatic intrusion during thrusting. Terra Nova 15, 405-409. https://doi:10.1046/j.13653121.2003.00512.x.

Galland, O., Hallot, E., Cobbold, P.R., Ruffet, G., de Bremond d'Ars, J., 2007a. Volcanism in a compressional Andean setting: A structural and geochronological study of Tromen volcano (Neuquén province, Argentina). Tectonics 26. https://doi:10.1029/2006TC002011.

Gasquet, D., Ennih, N., Liegeois, J.P., Soulaimani, A., Michard, A., 2008. The Pan-African Belt, in: Continental Evolution: The Geology of Morocco. Lecture Notes in Earth Sciences. 33-64.

Gomes, A.S., Rosas F.M., Duarte J.C., Schellart W.P., Almeida J., Tomás, R., Strak, V., 2019. Analogue modelling of the brittle shear zone propagation across upper crustal morpho-rheological heterogeneities. J. Struct. Geol. 126, 175-197. https://doi: 10.1016/j.jsg.2019.06.004.

Handy, M.R., Mulch, A., Rosenau, M. and Rosenberg, C. L., 2001. The role of faultzones and melts as agents of weakening, hardening and differentiation of the continental crust: a synthesis. Geol. Soc. Spec. Publ., 186, 305-332. https://doi:10.1144/GSL.SP.2001.186.01.18. 
817 Handy, M.R., Streit, J.E., 1999. Mechanics and mechanisms of magmatic underplating: Inferences 818 from mafic veins in deep crustal mylonite. Earth Planet. Sci. Lett. 165, 271-286. https://doi:10.1016/S0012-821X(98)00272-6.

Holohan, E.P., Van Wyk de Vries, B., Troll, V.R., 2008. Analogue models of caldera collapse in strike-slip tectonic regimes. Bull. Volcanol.70,773-796. https://doi .org /10 .1007/s00445 -007 -0166 -x. Hubbert, M.K., 1937. Theory of scalable models as applied to the study of geologic structures. Geol. Soc. Am. Bull. 48, 1459-1520. doi:10.1130/GSAB-48-1459.

Hutton, D.H.W., Reavy, R.J., 1992. Strike-slip tectonics and granite petrogenesis. Tectonics 11, 960-967. https://doi:10.1029/92TC00336.

Hutton, D.H.W., 1988. Granite emplacement mechanisms and tectonic controls: inferences from deformation studies. Trans. R. Soc. Edinb. Earth Sci. 79, 245-255. https://doi:10.1017/S0263593300014255.

Kirsch, M., Keppie, J.D., Murphy, J.B., Lee, J.K.W., 2013. Arc plutonism in a transtensional regime: The late Palaeozoic Totoltepec pluton, Acatlán Complex, southern Mexico. Int. Geol. Rev. 55, 263-286. https://doi:10.1080/00206814.2012.693247.

Klinkmüller, M., Schreurs, G., Rosenau, M., Kemnitz, H., 2016. Properties of granular analogue model materials: A community wide survey. Tectonophysics 684, 23-38. https://doi:10.1016/j.tecto.2016.01.017.

Koptev, A., Burov, E., Gerya, T., Le Pourhiet, L., Leroy, S., Calais, E., Jolivet, L., 2017. Plumeinduced continental rifting and break-up in ultra-slow extension context: Insights from 3D numerical modeling. Tectonophysics. Article in press. https://doi:10.1016/j.tecto.2017.03.025. 
838 Verner, K., Žák J., Hrouda, F., Holub, F., 2006. Magma emplacement during exhumation of the lower- to mid-crustal orogenic root: the Jihlava syenitoid pluton, Moldanubian Unit, Bohemian Massif. J Struct Geol. 28,1553-1567.

Mandal, N., Chakraborty, C., 1990. Strain fields and foliation trajectories around pre-, syn-, and posttectonic plutons in coaxially deformed terranes. Geol. J. 25, 19-33. https://doi:10.1002/gj.3350250103.

Mazzarini, F., Musumeci, G., Montanari, D., Corti, G., 2010. Relations between deformation and upper crustal magma emplacement in laboratory physical models. Tectonophysics 484, 139_ 146. https://doi:10.1016/j.tecto.2009.09.013.

847 Michail, M., Rudolf, M., Rosenau, M., Riva A., Gianolla, P., Coltorti, M., 2020. Digital image correlation data from analogue modelling experiments addressing magma emplacement along simple shear and transtensional fault zones. GFZ Data Services. http://doi.org/10.5880/fidgeo2020.033.

Montanari, D., Corti, G., Sani, F., Del Ventisette, C., Bonini, M., Moratti, G., 2010. Experimental investigation on granite emplacement during shortening. Tectonophysics 484, 147-155. https://doi:10.1016/j.tecto.2009.09.010.

Paterson, S.R., Okaya, D., Memeti, V., Economos, R., Miller, R.B., 2011. Magma addition and flux 855 calculations of incrementally constructed magma chambers in continental margin arcs: Combined field, geochronologic, and thermal modeling studies. Geosphere 7, 1439-1468. https://doi:10.1130/GES00696.1. 
860 Paterson, S.R., Tobisch, O.T., 1988. Using pluton ages to date regional deformations: problems with commonly used criteria. Geology 16, 1108-1111.

Petford, N., Cruden, A.R., McCaffrey, K.J., Vigneresse, J.-L., 2000. Granite magma formation, transport and emplacement in the Earth's crust. Nature 408, 669-673. https://doi:10.1038/35047000.

865 Ramberg, H., 1981. Gravity, deformation and the Earth's crust: In Theory, Experiments, and Geological Application. London, Academic Press, 452.

Riedel, W., 1929. Zur Mechanik geologischer Brucherscheinungen. Zentralblatt Mineral., Geol. u. Paläont. B, 354-368.

Ritter, M.C., Leever, K., Rosenau, M., Oncken, O., 2016. Scaling the sandbox-Mechanical (dis) similarities of granular materials and brittle rock. Journal of Geophysical Research: Solid Earth, 121(9), 6863-6879. https://doi:10.1002/2016jb012915.

Román-Berdiel, T., 1999. Geometry of granite emplacement in the upper crust: contributions of

Román-Berdiel, T., Aranguren, A., Cuevas, J.L., Tubia, J.M., Gapais, D., Brun, J.-P., 2000. Experianalogue modelling, in: Castro, A., Fernandez, C., Vigneresse, J.L. (Eds.), Understanding granites: Integrating new and classical techniques. Geological Society, London, Special Publications. 168. 77-94. https://doi:10.1144/GSL.SP.1999.168.01.06. ments on granite intrusion in transtension, in: Ven deville, B., Mart, Y., Vigneresse, J.L. (Eds.), Salt, Shale and Igneous Diapirs in and around Europe. Geological Society, London, Special Publications. 174. 21-42. https://doi:10.1144/GSL.SP.1999.174.01.02. 

ment and nature. Am. J. Sci. 297, 651-678. https://doi:10.2475/ajs.297.6.651.

Rosen berg, C.L., 2004. Shear zones and magma ascent: A model based on a review of the Tertiary magmatism in the Alps. Tectonics 23, 21. https://doi:10.1029/2003TC001526.

Rosenau et al. (2018): Ring-shear test data of quartz sand G12 used for analogue experiments in the Helmholtz Laboratory for Tectonic Modelling (HelTec) at the GFZ German Research Centre for Geosciences in Potsdam. GFZ Data Services. https://doi:10.5880/GFZ.4.1.2019.003.

Rudolf, M., Boutelier, D., Rosenau, M., Schreurs, G., Oncken, O., 2016. Rheological benchmark of silicone oils used for analog modeling of short- and long-term lithospheric deformation. Tectonophysics 684, 12-22. https://doi:10.1016/j.tecto.2015.11.028.

Sant'Ovaia, H., Bouchez, J.L., Noronha, F., Leblanc, D., Vigneresse, J.L., 2000. Composite-laccolith emplacement of the post-tectonic Vila Pouca de Aguiar granite pluton (northern Portugal): A combined AMS and gravity study. Trans. R. Soc. Edinb. Earth Sci. 91, 123-137. https://doi:10.1017/S026359330000732X.

Schellart, W.P., Strak, V., 2016. A review of analogue modelling of geodynamic processes: Approaches, scaling, materials and quantification, with an application to subduction experiments. J. Geodyn. 100, 7-32. https://doi:10.1016/j.jog.2016.03.009.

Schöpfer, M.P.J., Steyrer, H.P., 2001. Experimental modeling of strike-slip faults and the self-similar behavior. Geol. Soc. Am. Mem. 193, 21-27. https://doi:10.1130/0-8137-1193-2.21.

Schreurs, G., 2003. Fault development and interaction in distributed strike-slip shear zones: an experimental approach, in: Storti, F., Holdsworth, R.E., Salvini, F. (Eds.), Intraplate Strike-Slip deformation belts. Geological Society, London, Special Publications. 35-52. https://doi:10.1144/GSL.SP.2003.210.01.03. 
Shinevar, W.J., Behn, M.D., Hirth, G., 2015. Compositional dependence lower crustal viscosity, Geophys. Res. Lett. 42, 8333-8340. https://doi:10.1002/2015GL065459.

Simpson, C., Whitmeyer, S.J., De Paor, D., Gromet, L.P., Miro, R., Krol, M., and Short, H., 2001. Sequential ductile to brittle reactivation of major fault zones along the accretionary margin of Gondwana in Central Argentina. In: Holdsworth, R.E. et al. (eds.) The Nature and Tectonic Significance of Fault Zone Weakening. Geol. Soc. London, Special Publications, 186, 233-255.

Sloman, L., 1989. Triassic shoshonites from the Dolomites, northern Italy: alkaline arc rocks in a strike-slip setting. J. Geophys. Res. 94, 4655-4666.

Vigneresse, J.L., 1995. Control of granite emplacement by regional deformation. Tectonophysics 249, 173-186. https://doi:10.1016/0040-1951(95)00004-7.

Vigneresse, J.L., Bouchez, J.L., 1997. Successive Granitic Magma Batches During Pluton Emplacement: the Case of Cabeza de Araya (Spain). J. Petrol. 38, 1767-1776. https://doi.org/10.1093/petroj/38.12.1767.

Visonà, D., Zanferrari, A., 2002. Some constraints on geochemical features in the Triassic mantle of the easternmost Austroalpine-Southalpine domain: evidence from the Karawanken pluton (Carinthia, Austria). International Journal of Earth Sciences, 89 (2000), 40-51.

Weijermars, R., Schmeling, H., 1986. Scaling of Newtonian and non -Newtonian fluid dynamics without inertia for quantitative modelling of rock flow due to gravity (including the concept of rheological similarity). Phys. Earth Planet. Inter. 43, 316-330. https://doi:10.1016/00319201(86)90021-X.

Westoby, M.J., Brasington, J., Glasser, N.F., Hambrey, M.J. \& Reynolds, J.M., 2012. Structurefrom-Motion photogrammetry: A low-cost, effective tool for geoscience applications. Geomorphology, 179, 300-314. doi:10.1016/j.geomorph.2012.08.021. 
929 Wilcox, R.E., Harding, T.P., Seely, D.R., 1973. Basic wrench tectonics. Am. Assoc. Pet. Geol. Bull. $930 \quad 57,74-96$. https://doi:10.1306/819A424A-16C5-11D7-8645000102C1865D.

931 Xiao, Y., Wu, G., Lei, Y., Chen, T., 2017. Analogue modeling of through-going process and devel932 opment pattern of strike-slip fault zone. Pet. Explor. Dev. 44, 368-376. 933 https://doi:10.1016/S1876-3804(17)30043-5. 


\section{Table 1 Model characteristics and experimental conditions}

\begin{tabular}{|c|c|c|c|c|c|c|c|}
\hline Models & \begin{tabular}{|} 
Thickness of \\
brittle layer
\end{tabular} & $\left|\begin{array}{l}\text { Thickness of } \\
\text { ductile layer }\end{array}\right|$ & $\begin{array}{l}\text { Intrusion } \\
\text { rate, Ir }\end{array}$ & $\begin{array}{l}\text { Injected } \\
\text { Volume, Iv }\end{array}$ & $\begin{array}{c}\text { Relative dis- } \\
\text { placement } \\
\text { rate, Dv }\end{array}$ & $\begin{array}{l}\text { Total horizontal } \\
\text { displacement, Dt }\end{array}$ & $\begin{array}{c}\text { Experiment } \\
\text { Duration }\end{array}$ \\
\hline \multicolumn{8}{|c|}{ Reference models (Group R) } \\
\hline Simple shearRS & $40 \mathrm{~mm}$ & $7 \mathrm{~mm}$ & - & - & $1.0 \mathrm{~mm} / \mathrm{min}$ & $30 \mathrm{~mm}$ & $30 \mathrm{~min}$ \\
\hline Transtension RT & $40 \mathrm{~mm}$ & $7 \mathrm{~mm}$ & - & - & $1.0 \mathrm{~mm} / \mathrm{min}$ & $30 \mathrm{~mm}$ & $30 \mathrm{~min}$ \\
\hline Static In trusion R0 & $40 \mathrm{~mm}$ & $7 \mathrm{~mm}$ & $21.0 \mathrm{~mm}^{3} / \mathrm{s}$ & $37.7 \times 10^{3} \mathrm{~mm}^{3}$ & - & - & $30 \mathrm{~min}$ \\
\hline \multicolumn{8}{|c|}{ Simple shear models (Group A) } \\
\hline Pre-tectonic intrusion A1 & $40 \mathrm{~mm}$ & $7 \mathrm{~mm}$ & $21.0 \mathrm{~mm}^{3} / \mathrm{s}$ & $37.7 \times 10^{3} \mathrm{~mm}^{3}$ & $1.0 \mathrm{~mm} / \mathrm{min}$ & $30 \mathrm{~mm}$ & $60 \mathrm{~min}$ \\
\hline Syn-Tectonic Intrusion A2 & $40 \mathrm{~mm}$ & $7 \mathrm{~mm}$ & $21.0 \mathrm{~mm}^{3} / \mathrm{s}$ & $37.7 \times 10^{3} \mathrm{~mm}^{3}$ & $1.0 \mathrm{~mm} / \mathrm{min}$ & $30 \mathrm{~mm}$ & $30 \mathrm{~min}$ \\
\hline Post-tectonic intrusion A3 & $40 \mathrm{~mm}$ & $7 \mathrm{~mm}$ & $21.0 \mathrm{~mm}^{3} / \mathrm{s}$ & $37.7 \times 10^{3} \mathrm{~mm}^{3}$ & $1.0 \mathrm{~mm} / \mathrm{min}$ & $30 \mathrm{~mm}$ & $60 \mathrm{~min}$ \\
\hline \multicolumn{8}{|c|}{ Transtension models (Group B) } \\
\hline Pre-tectonic intrusion B1 & $40 \mathrm{~mm}$ & $7 \mathrm{~mm}$ & $21.0 \mathrm{~mm}^{3} / \mathrm{s}$ & $37.7 \times 10^{3} \mathrm{~mm}^{3}$ & $1.0 \mathrm{~mm} / \mathrm{min}$ & $30 \mathrm{~mm}$ & $60 \mathrm{~min}$ \\
\hline Syn-Tectonic Intrusion B2 & $40 \mathrm{~mm}$ & $7 \mathrm{~mm}$ & $21.0 \mathrm{~mm}^{3} / \mathrm{s}$ & $37.7 \times 10^{3} \mathrm{~mm}^{3}$ & $1.0 \mathrm{~mm} / \mathrm{min}$ & $30 \mathrm{~mm}$ & $30 \mathrm{~min}$ \\
\hline Post-tectonic intrusion B3 & $40 \mathrm{~mm}$ & $7 \mathrm{~mm}$ & $21.0 \mathrm{~mm}^{3} / \mathrm{s}$ & $37.7 \times 10^{3} \mathrm{~mm}^{3}$ & $1.0 \mathrm{~mm} / \mathrm{min}$ & $30 \mathrm{~mm}$ & $60 \mathrm{~min}$ \\
\hline
\end{tabular}


938 Table 2 Material properties and scaling factors

\begin{tabular}{llll}
\hline Parameters & Models & Nature & $\begin{array}{l}\text { Model/ Nature } \\
\text { (Scaling factor) }\end{array}$ \\
\hline Brittle material & Quartz Sand & Upper Crust & \\
Length, $\mathrm{L}$ & $0.01 \mathrm{~m}$ & $0.6-6 \mathrm{~km}$ & $0.6-6 \times 10^{-6}$ \\
Cohesion, $\mathrm{C}$ & $10-100 \mathrm{~Pa}$ & $10 \mathrm{MPa}$ & $1-10 \times 10^{-6}$ \\
Density, $\rho$ & $1600 \mathrm{Kg} / \mathrm{m}$ & $2600 \mathrm{~kg} / \mathrm{m}$ & 0.615 \\
Gravity, g & $9.81 \mathrm{~m} / \mathrm{s}$ & $9.81 \mathrm{~m} / \mathrm{s}$ & 1 \\
\hline Viscous material & Silicone oil & Intrusion/ shear zone & \\
Viscosity, $\eta$ & $3 \times 10^{4} \mathrm{~Pa} \mathrm{~s}$ & $>10^{18} \mathrm{~Pa} \mathrm{~s}$ & $3.0 \times 10^{-14}$ \\
Density, $\rho$ & $965 \mathrm{~kg} / \mathrm{m}$ & $1600 \mathrm{~kg} / \mathrm{m}$ & 0.603 \\
Time, $\mathrm{t}$ & $1 \mathrm{sec}$ & $30000 \mathrm{yrs}$ & $10^{-13}$ \\
\hline
\end{tabular}


940 Table 3 Summarizing table of diagnostic attributes as suggested by the analogue models for the different em941 placement scenarios.

\begin{tabular}{|c|c|c|c|c|c|}
\hline \multirow[t]{2}{*}{ Model } & \multicolumn{2}{|c|}{ Pluton Elongation ${ }^{a}$} & \multirow[t]{2}{*}{ Orientation $^{a}$} & \multirow[t]{2}{*}{ Dike system } & \multirow{2}{*}{$\begin{array}{c}\text { Pluton Am- } \\
\text { plitude, A }\end{array}$} \\
\hline & Group A & Group B & & & \\
\hline Pre-tectonic & $\operatorname{High}\left(r_{\mathrm{A} 1}>1.5\right)$ & High $\left(r_{B 1}>1.5\right)$ & Long axis // extension & Roof & Low \\
\hline Syn-Tectonic & $\operatorname{High}\left(r_{\mathrm{A} 2}>1.5\right)$ & Medium/High ${ }^{\mathrm{b}}\left(\mathrm{r}_{\mathrm{B} 2}>1.5\right)$ & Long axis // compression & $\begin{array}{c}\text { Lateral } \\
\text { (apophysis) }\end{array}$ & High \\
\hline Post-tectonic & $\operatorname{Low}\left(r_{\mathrm{A} 3}<1.5\right)$ & Low $\left(r_{B 3}<1.5\right)$ & Long axis // compression & Roof & Medium \\
\hline
\end{tabular}

942 a Based on an ellipse fitted to thelower $\left(C_{1}\right)$ and higher $\left(C_{2}\right)$ contour level of the intrusion.

943 b Based on repetition models (100, 59, 95; see Appendix A.1) 
(a)

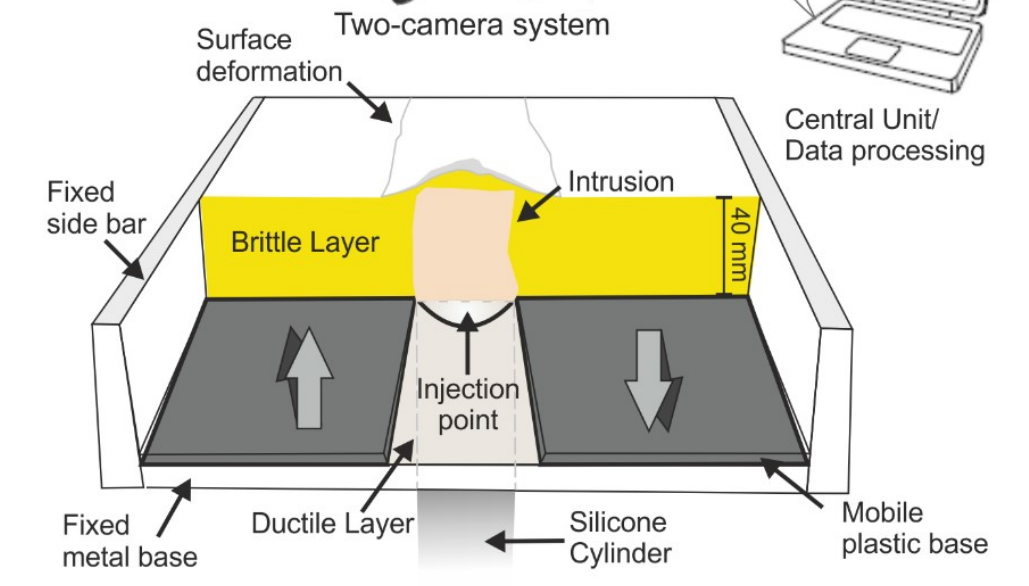

(b)

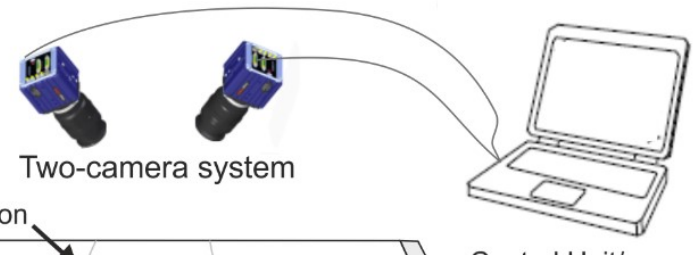

Central Unit/ Data processing plastic base
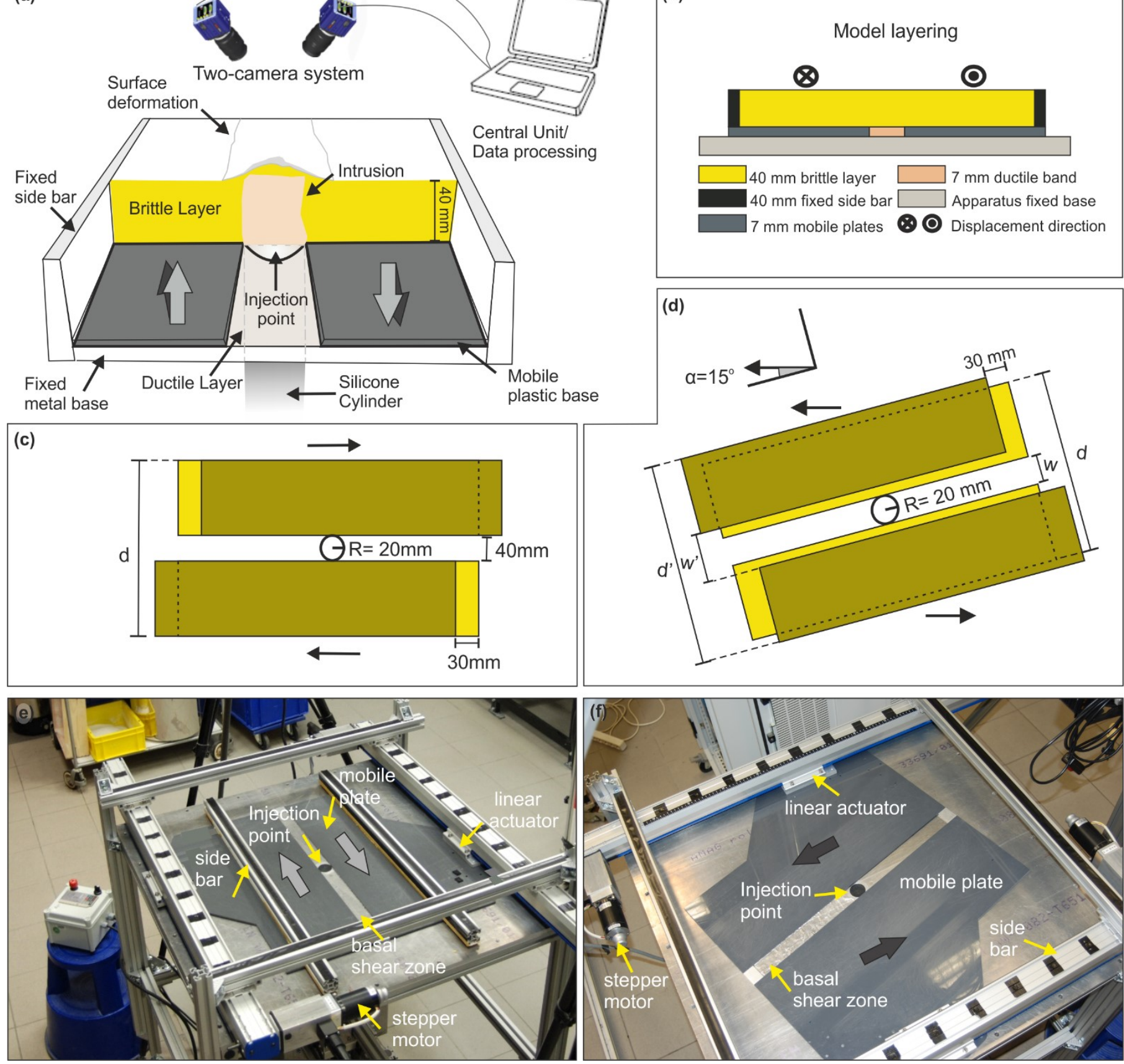

Fig. 1 Details of the experimental apparatus. Details of the experimental set-up. (a) Schematic cut-out 3D view depicting its various components; (b) Model layering; kinematic basal boundary conditions for (c) Sketch of the experimental setting of the simple shear deformation $(d=310 \mathrm{~mm})$ and $(d)$ the transtensional deformation (obliquity $\alpha=15^{\circ}$ ) with the initial (yellow) and final (green) positions of the mobile plates $\left(w=40 \mathrm{~mm}\right.$, $w^{\prime}=55.5$

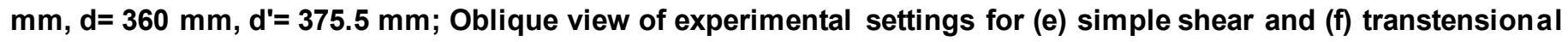
deformation. Arrows indicate the direction of plate movement. 

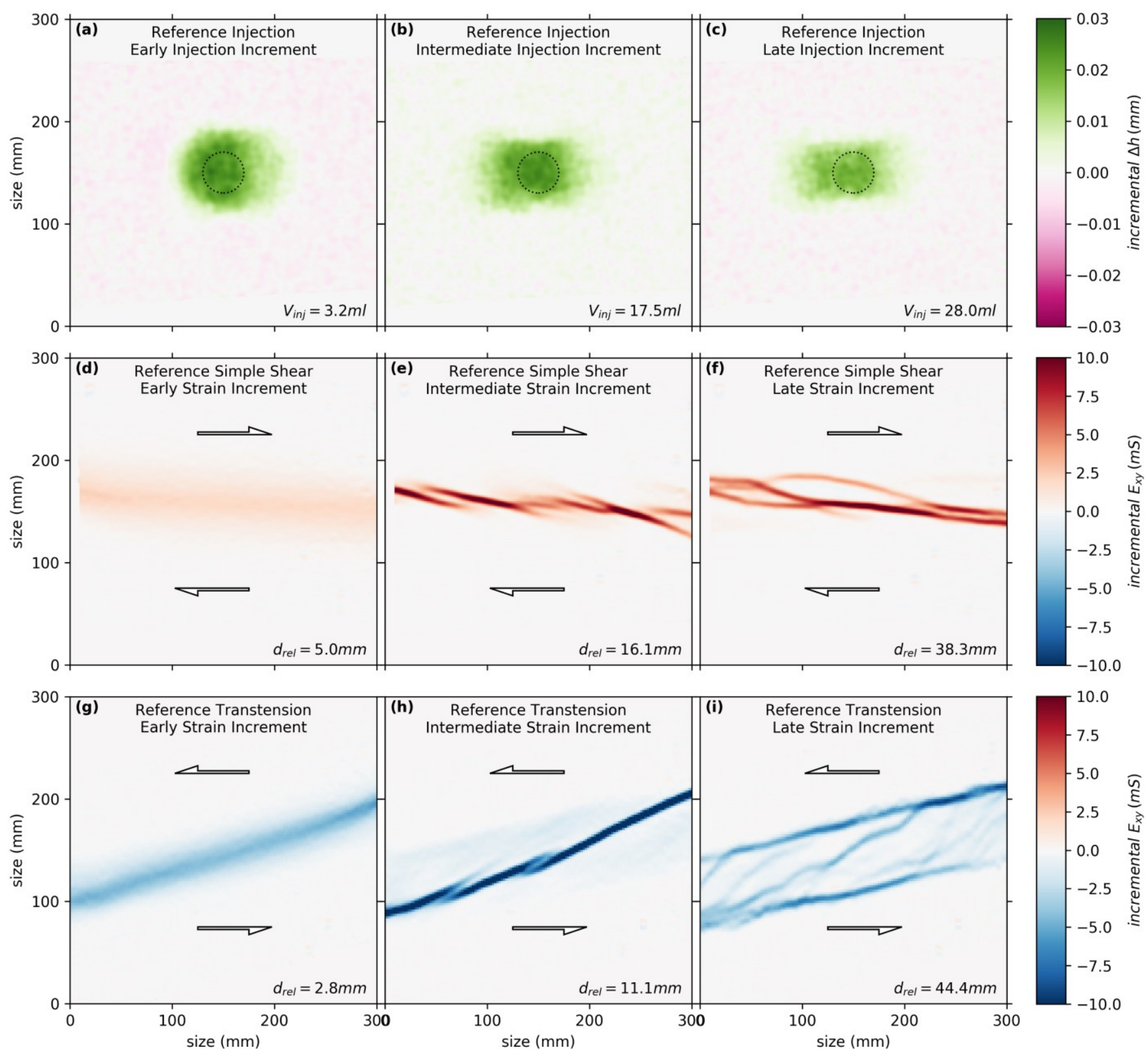

Fig. 2 Surface evolution and deformational pattern of the reference experiments( Group R): (a-c) representative stages (with $V_{i n j}=3.2,17.5,28.0 \mathrm{ml}$ ) of the topographic evolution (vertical displacement $\Delta \mathrm{h}$ ) of the static intrusion model R0; $(d-f)$ representative stages $\left(a t d_{r e l}=5.0,16.1,38.3 \mathrm{~mm}\right.$ ) of the strain field (shear stain Exy) of the simple shear model RS and $(g-i)$ representative stages (at $d_{r e l}=5.0,16.1,38.3 \mathrm{~mm}$ ) of the strain field (shear stain Exy) of the transtension model RT. Positive values of Exy (in red) indicate a dextral shear sense and negative values (in blue) indicate sinistral shear. Dotted circles indicate the position of the basal injection. 


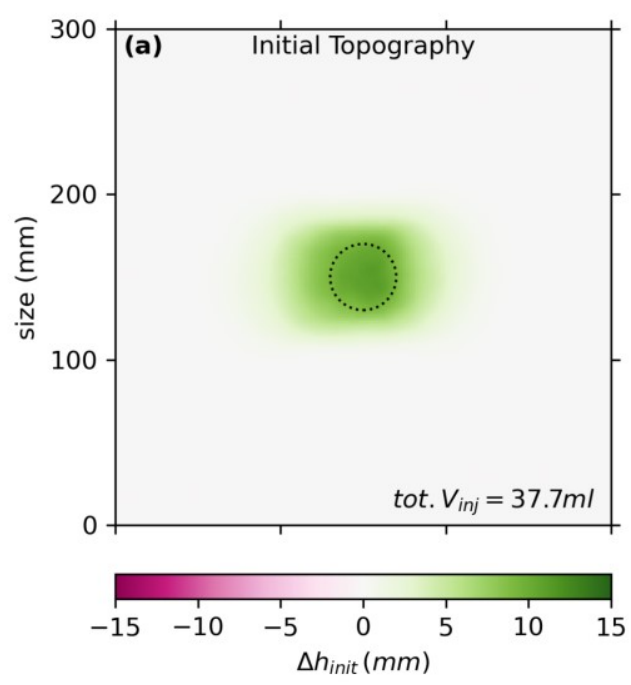

A1 - Pre-tectonic Simple Shear
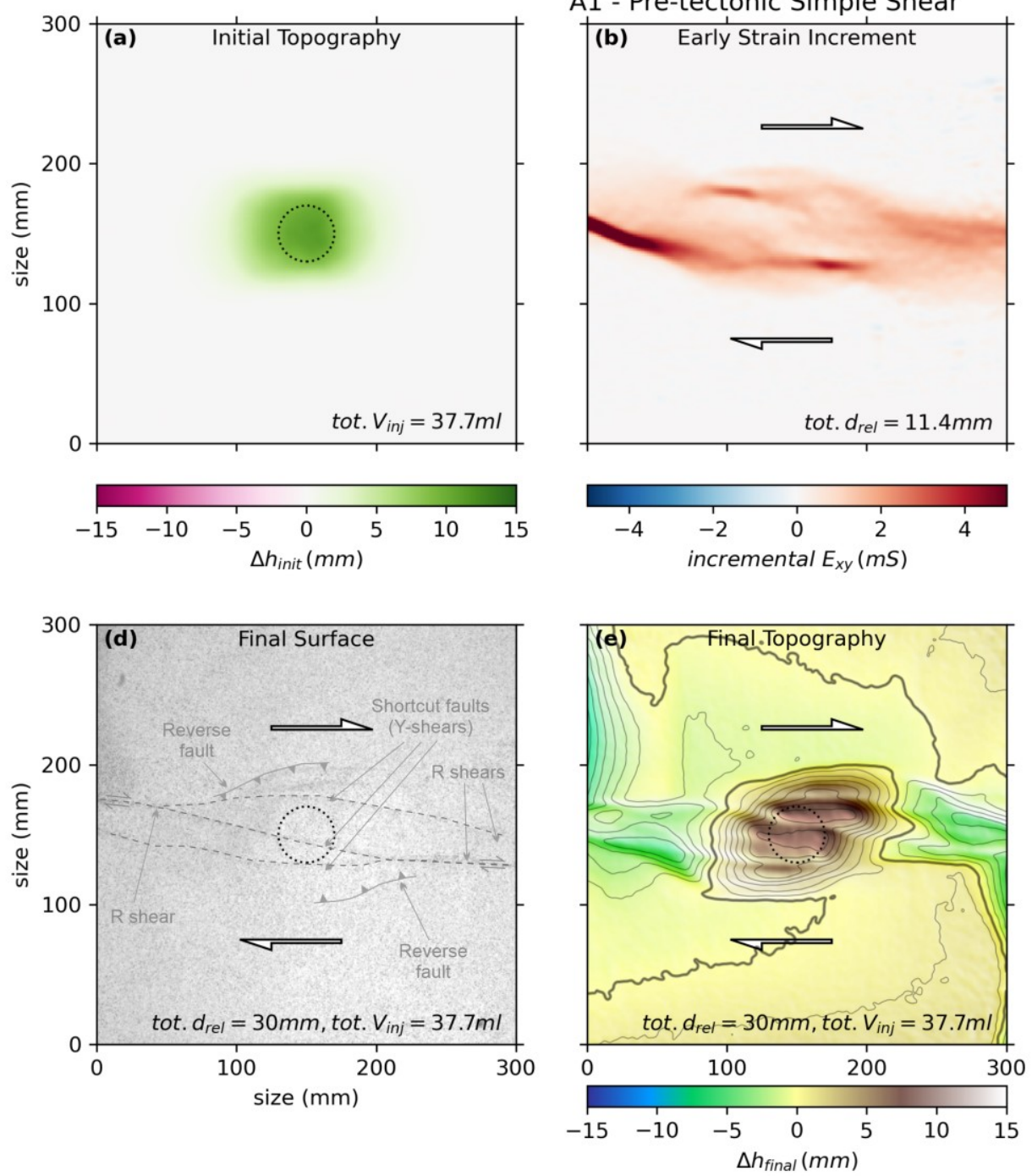
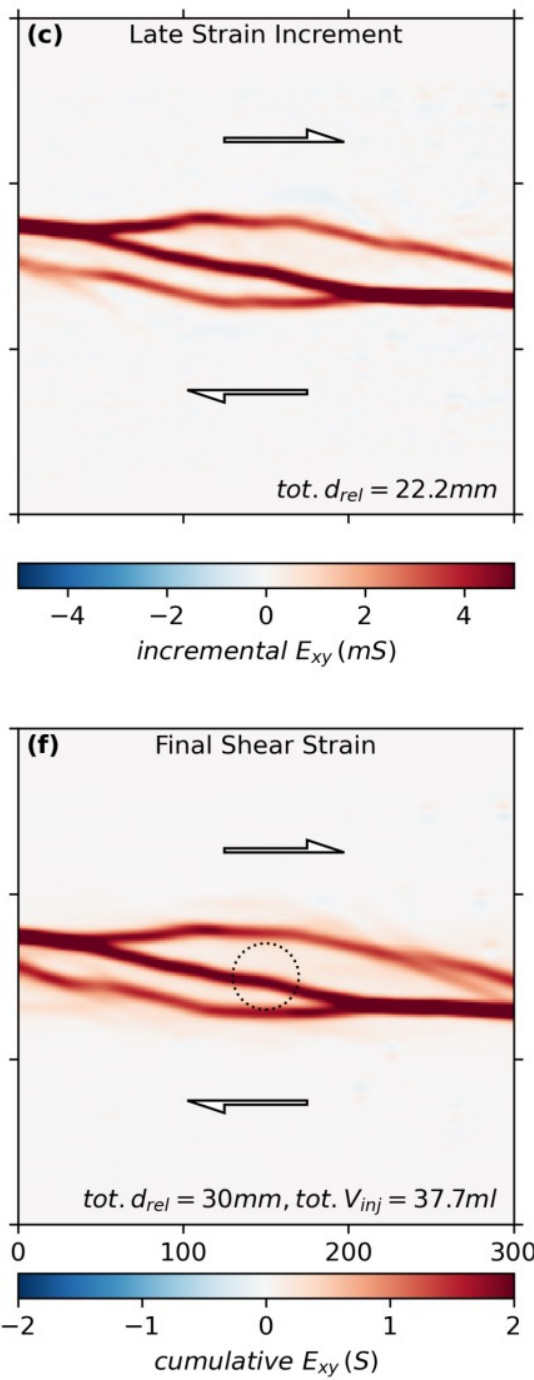

Fig. 3 Surface deformation of the pre-tectonic intrusion model in simple shear (Model A1). Shown are snapshots of the evolution: (a) Topography the end of static intrusion $\left(\mathrm{V}_{\mathrm{inj}}=37.7 \mathrm{ml}\right)$, (b) incremental strain during an early stage of displacement $\left(d_{r e l}=11.4 \mathrm{~mm}\right)$, and $(c)$ during a late stage $\left(d_{r e l}=22.2 \mathrm{~mm}\right)$. Panels in the second row show the final (cumulative deformation) stage of the model $\left(d_{r e l}=30 \mathrm{~mm}, V_{i n j}=37.7 \mathrm{ml}\right)$ : (d) surface image; $(e)$ cumulative vertical displacement (tot. $d_{r e l}=30 \mathrm{~mm}$ ) and (f) cumulative shear strain $\left(E_{x y}\right)$. Dotted circles indicate the position of the basal injection. 


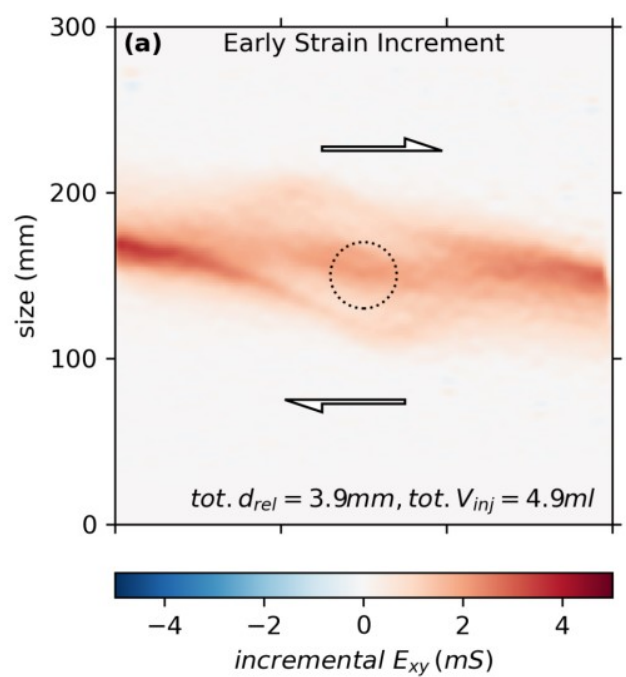

A2 - Syn-tectonic Simple Shear
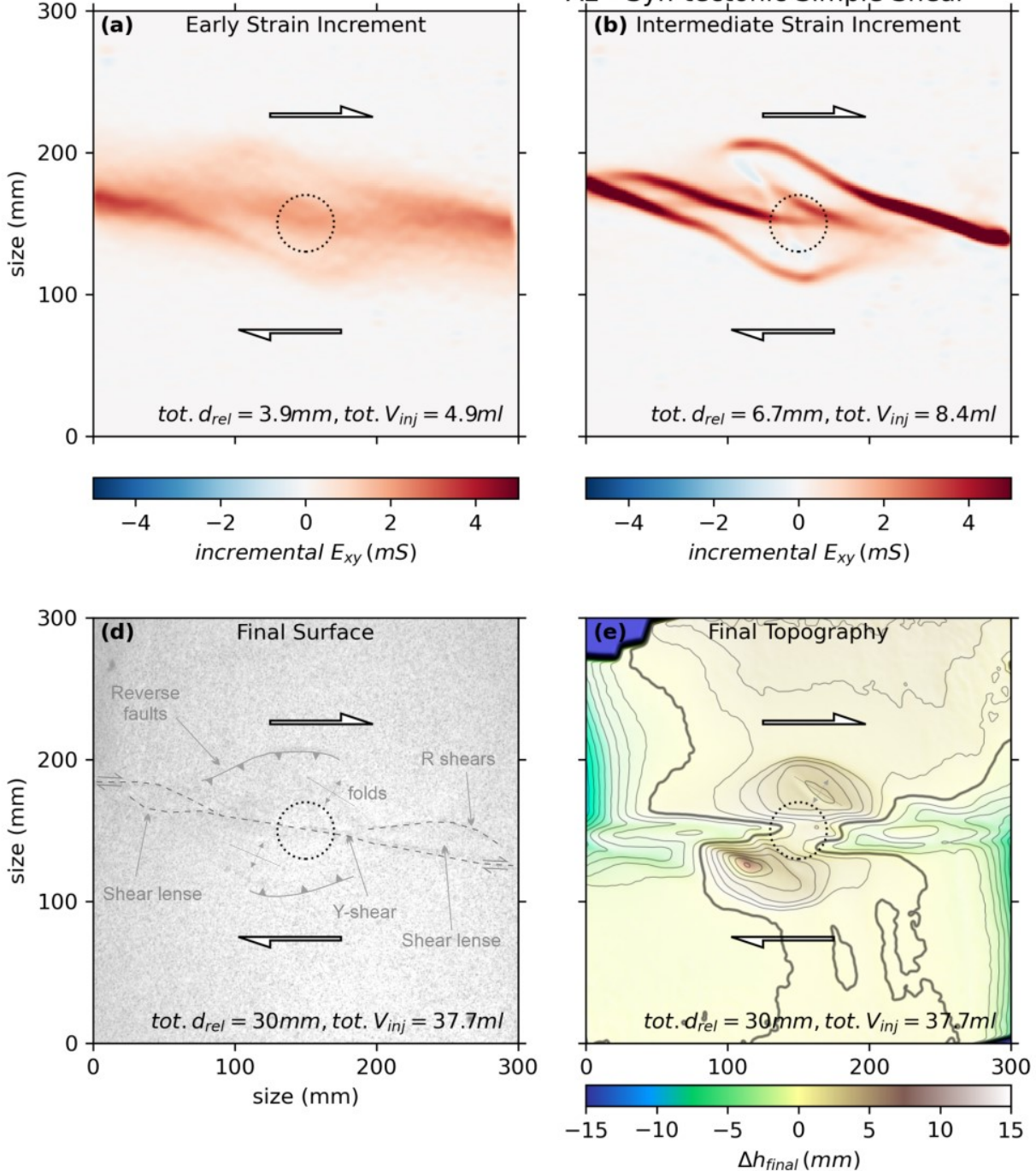
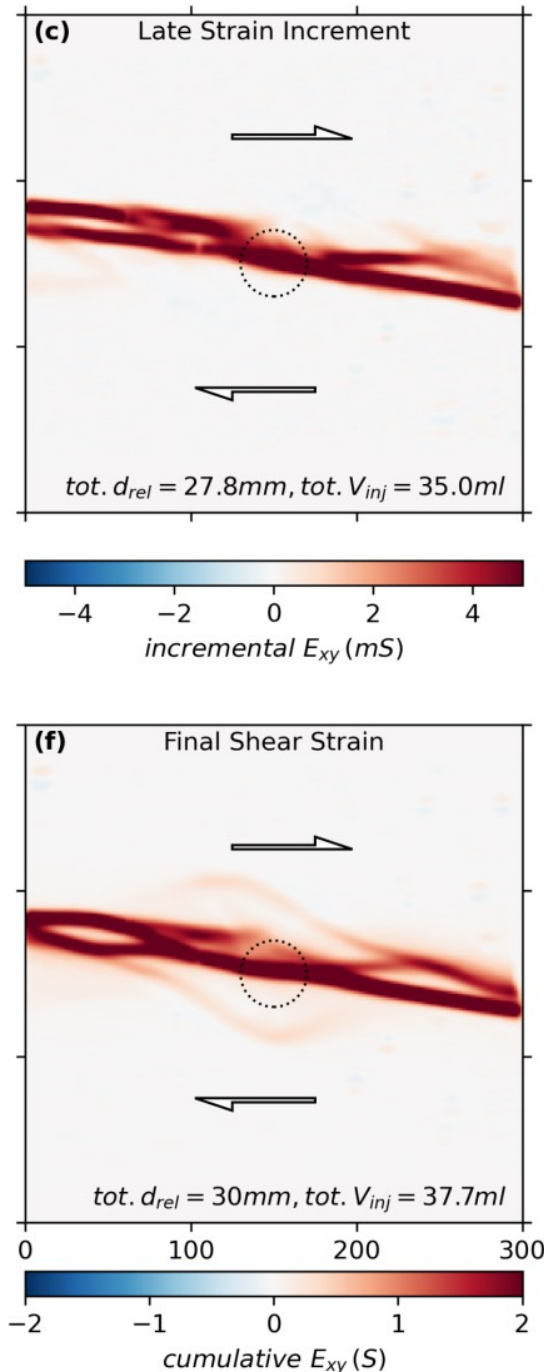

Fig. 4 Surface deformation of the syn-tectonic intrusion model in simple shear (Model A2). Shown are snapshots of the evolution: Incremental strain during an (a) early $\left(V_{i n j}=4.9 \mathrm{ml}\right.$ and $\left.d_{r e l}=6.7 \mathrm{~mm}\right)$, (b) intermediate $\left(V_{\mathrm{inj}}=8.4\right.$ $\mathrm{ml}$ and $\left.d_{r e l}=6.7 \mathrm{~mm}\right)$ and $(c)$ late stage $\left(V_{\mathrm{inj}}=35.0 \mathrm{ml}\right.$ and $\left.d_{r e l}=27.8 \mathrm{~mm}\right)$. Panels in the second row show the final (cumulative deformation) stage $\left(d_{\mathrm{rel}}=30 \mathrm{~mm}, V_{\mathrm{inj}}=37.7 \mathrm{ml}\right.$ ): (d) surface image; (e) cumulative vertical displacement (tot. $d_{\text {rel }}=30 \mathrm{~mm}$ ) and (f) cumulative shear strain $\left(E_{x y}\right)$. Dotted circles indicate the position of the basal injection. 


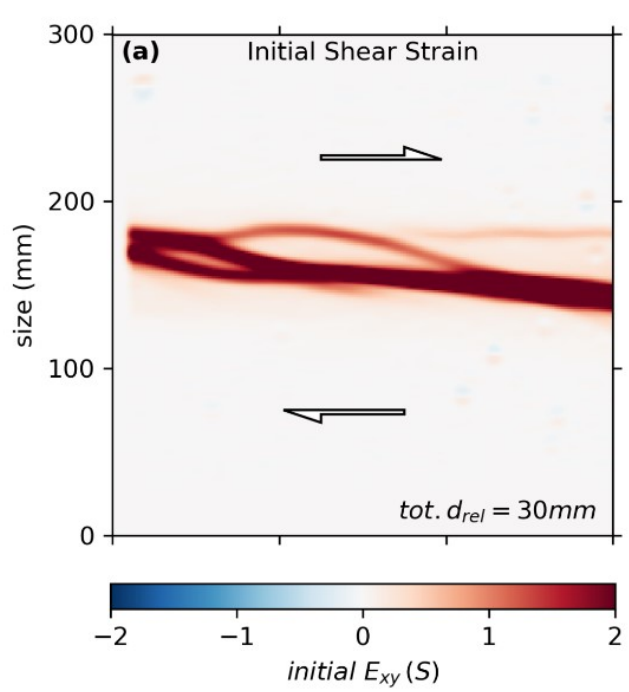

A3 - Post-tectonic Simple Shear
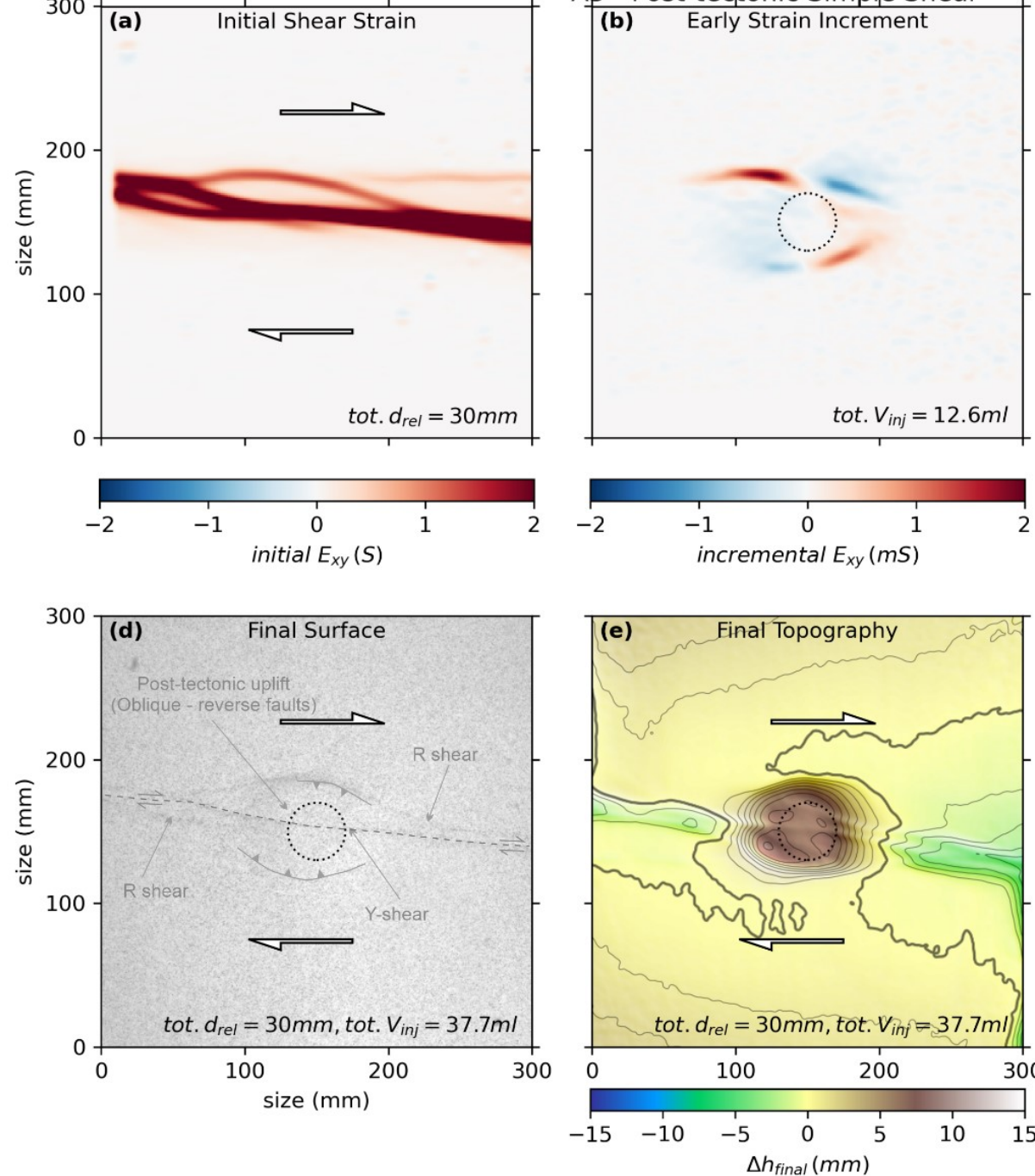
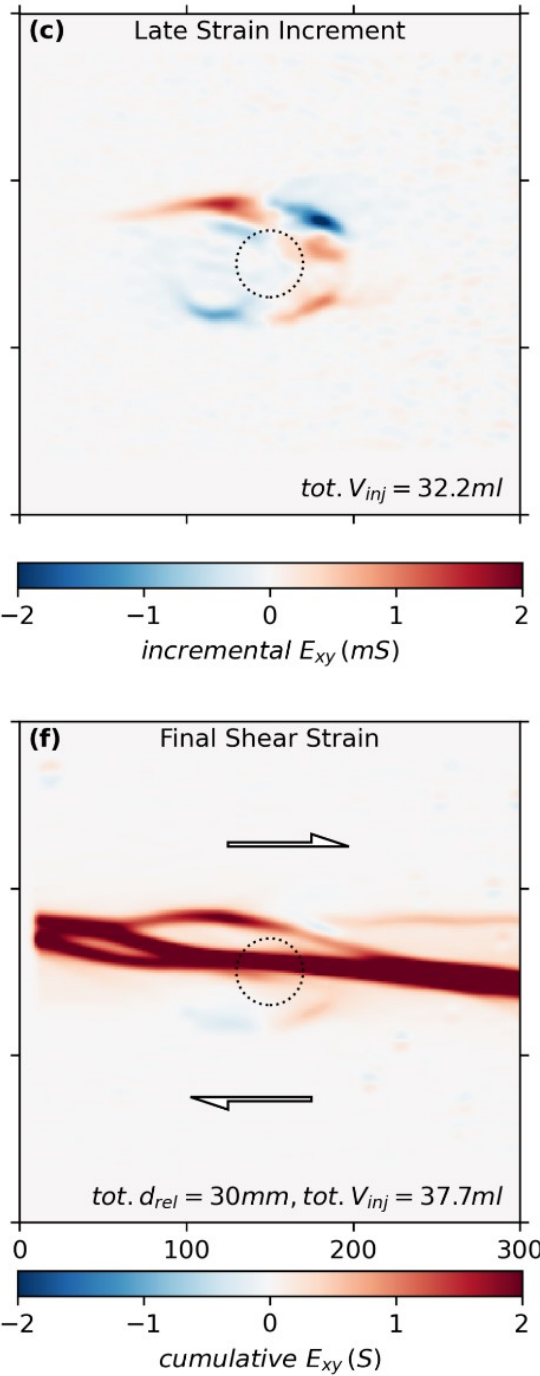

Fig. 5 Surface deformation of the post-tectonic intrusion model in simple shear (Model A3). Shown are snapshots of the evolution: (a) Accumulated strain at the beginning of intrusion $\left(d_{\text {rel }}=30 \mathrm{~mm}\right.$ ), (b) incremental strain

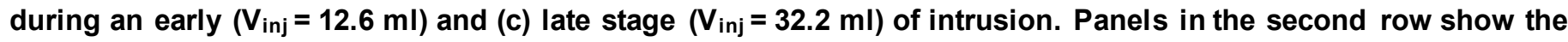
final (cumulative deformation) stage $\left(d_{r e l}=30 \mathrm{~mm}, V_{i n j}=37.7 \mathrm{ml}\right.$ ): (d) surface image; (e) cumulative vertical displacement (tot. $d_{r e l}=30 \mathrm{~mm}$ ) and (f) cumulative shear strain $\left(E_{x y}\right)$. Dotted circles indicate the position of the basal injection. 

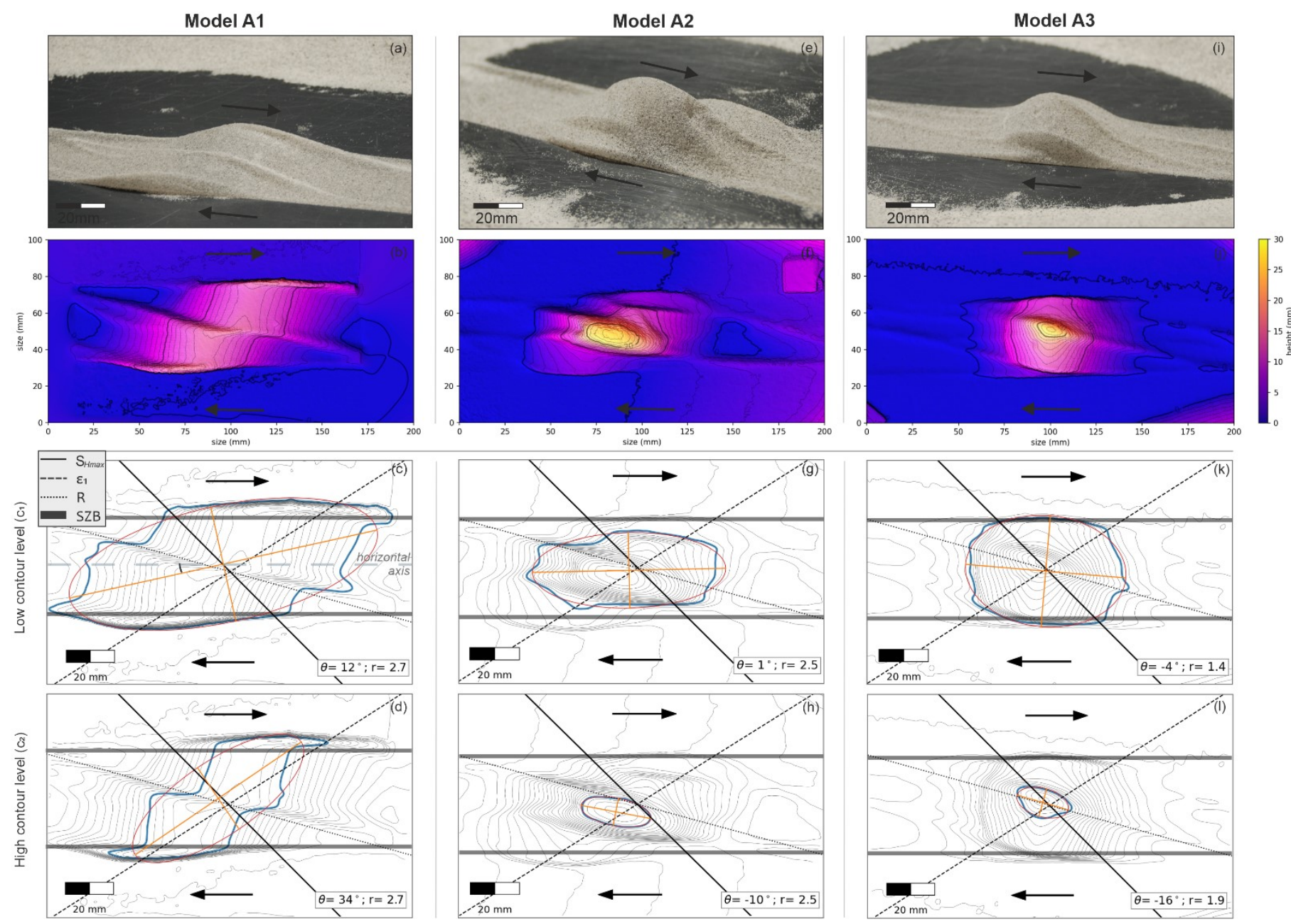

Fig. 6 Models of the intrusions in the simple shear regime (Group A): Model A1 (a-c); Model A2 (d-f) and Model

A3 (g-i). (a, d, g) Oblique views of the excavated intrusions; (b, e, h) Digital Intrusion Models (DIM) coloured and

with contour lines; (c, $f, i)$ Orientation and geometry of the intrusion (in map view), where $\theta=$ the angle between

the long axis (orange) of the fitted ellipse (red) and the strike of the basal shear zone. $r$ is the intrusion's aspect

ratio (length-to-width ratio, L/W). Light and dark grey quadrants indicate contraction and extensional quadrants,

respectively. 

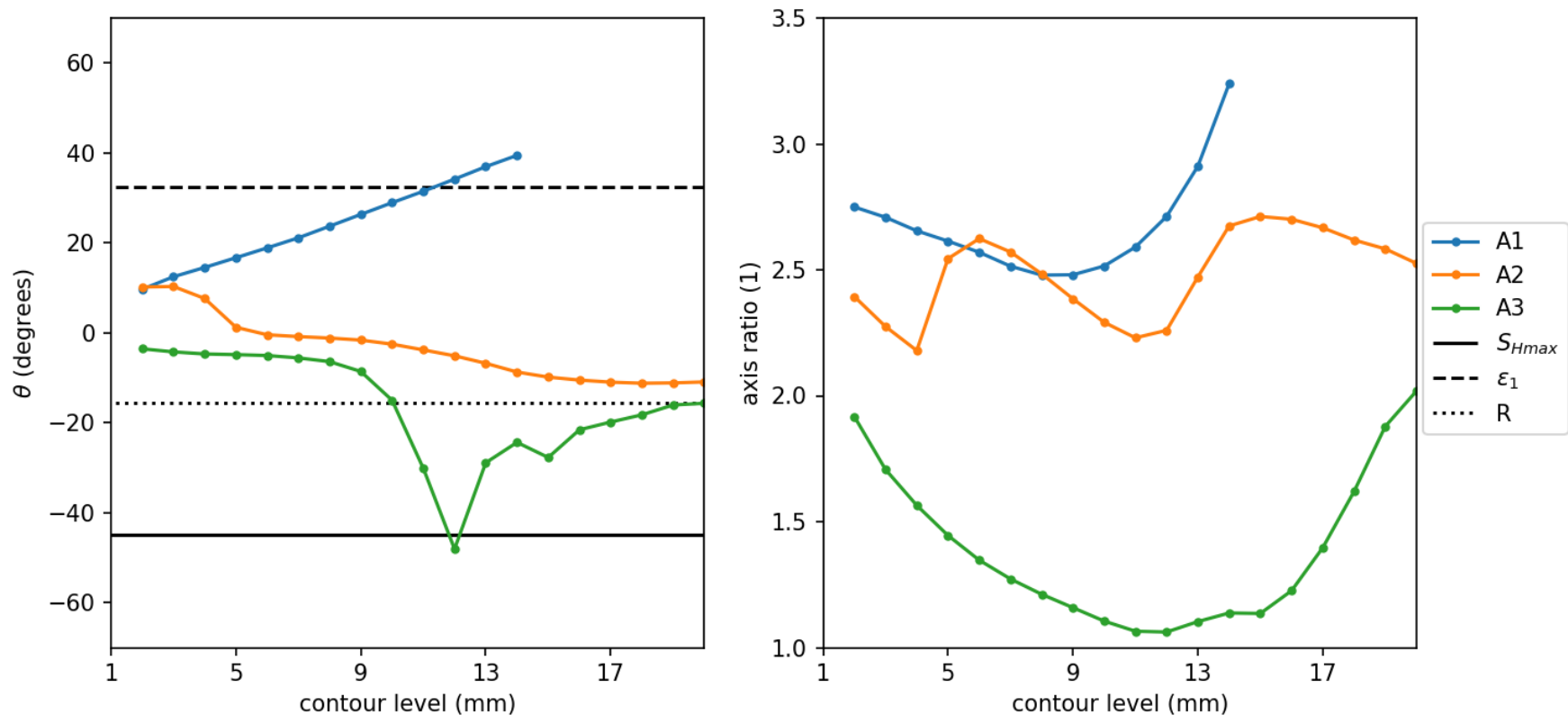

Fig. 7 Series A experimental results expressed in graph of angles and ratios ellipses vs. intrusion contour level. 


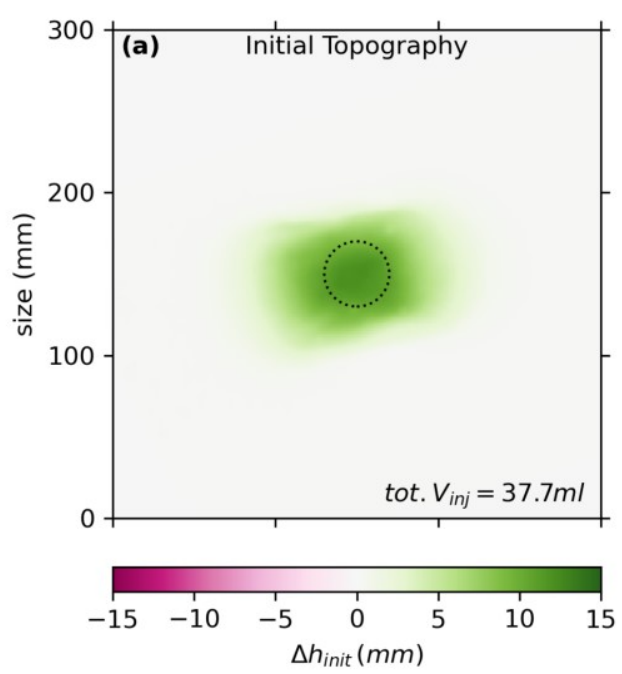

B1 - Pre-tectonic Transtension

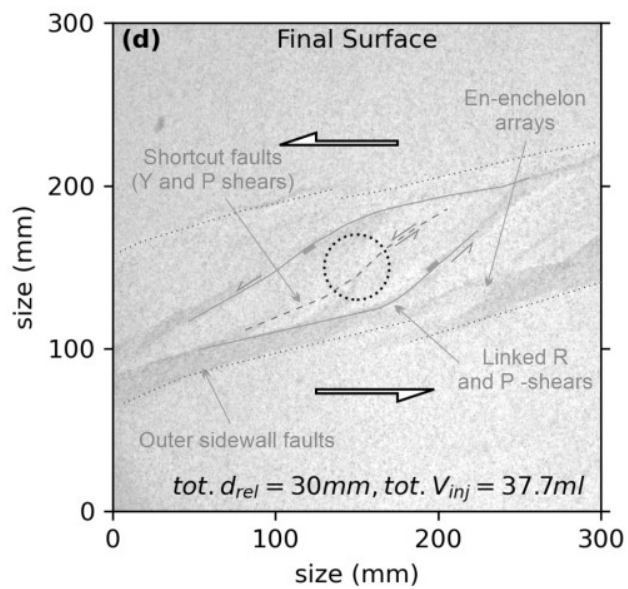

989

Fig. 8 Surface deformation of the pre-tectonic intrusion model in transtension (Model B1). Shown are snapshots representative of the evolution: (a) Topography the end of static intrusion $\left(V_{\mathrm{inj}}=37.7 \mathrm{ml}\right)$, (b) incremental strain during an early stage of displacement $\left(d_{\text {rel }}=5.6 \mathrm{~mm}\right)$, and $(c)$ during a late stage $\left(d_{\text {rel }}=16.7 \mathrm{~mm}\right)$. Panels in the second row show the final (cumulative deformation) stage of the model $\left(d_{\text {rel }}=30 \mathrm{~mm}, V_{i n j}=37.7 \mathrm{ml}\right.$ ): $(d)$ surface image; (e) cumulative vertical displacement (tot. $d_{r e l}=30 \mathrm{~mm}$ ) and (f) cumulative shear strain $\left(E_{x y}\right)$. Dotted circles
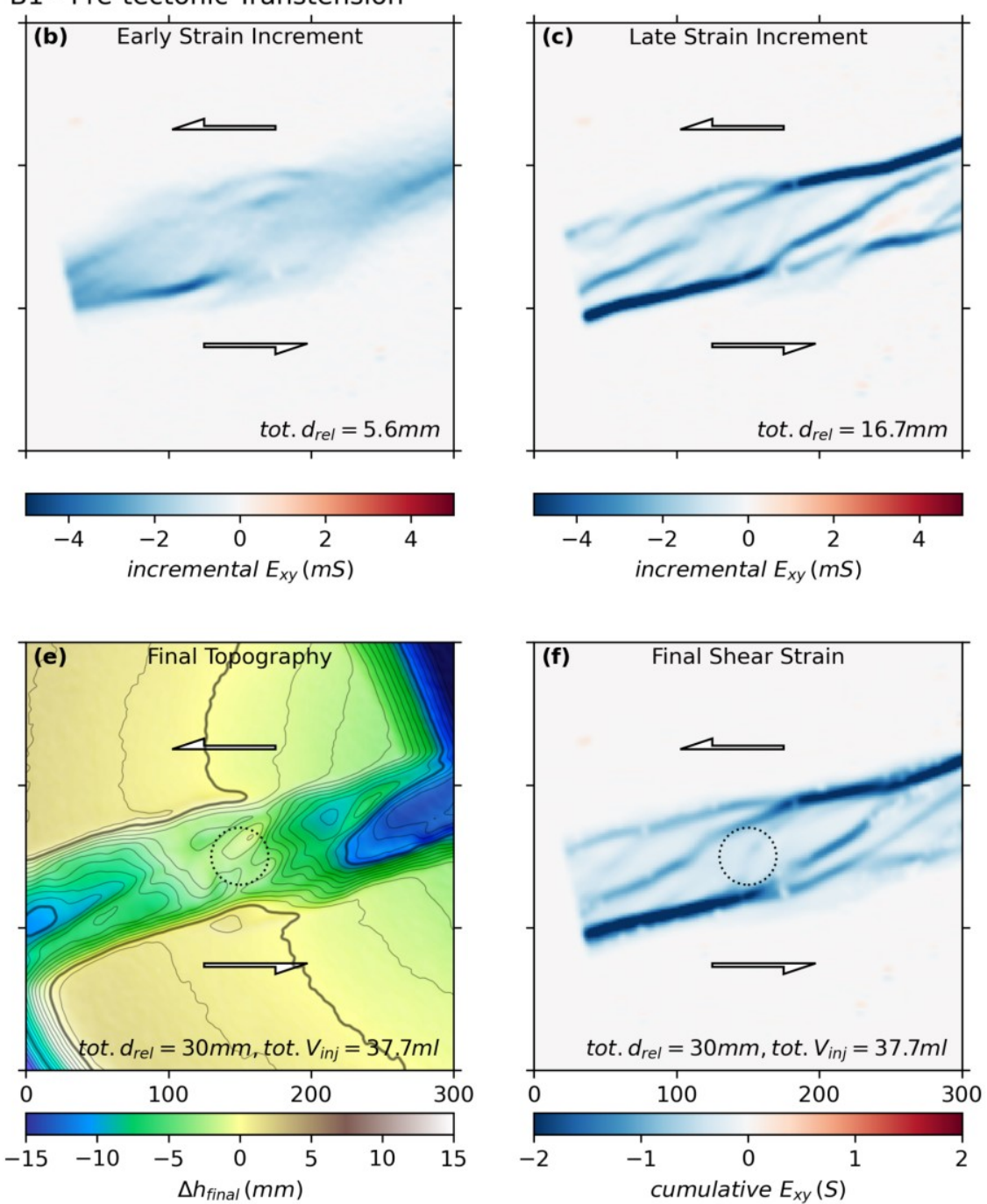
indicate the position of the basal injection. 


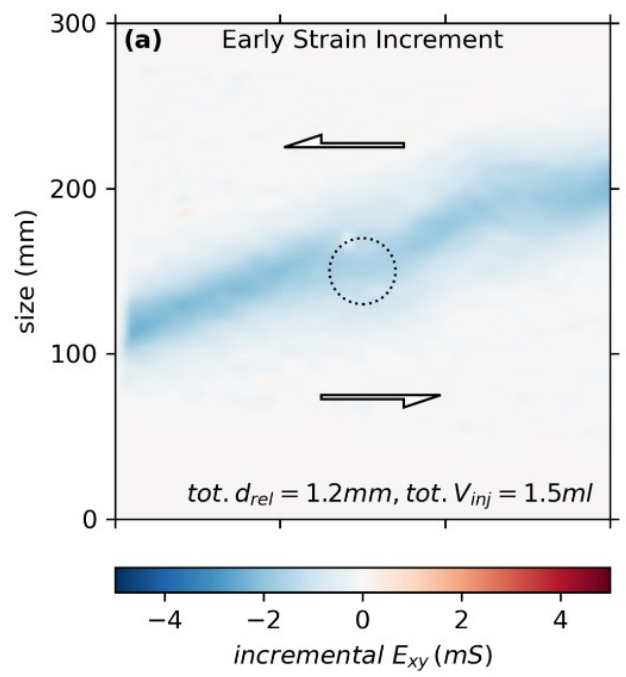

B2 - Syn-tectonic Transtension
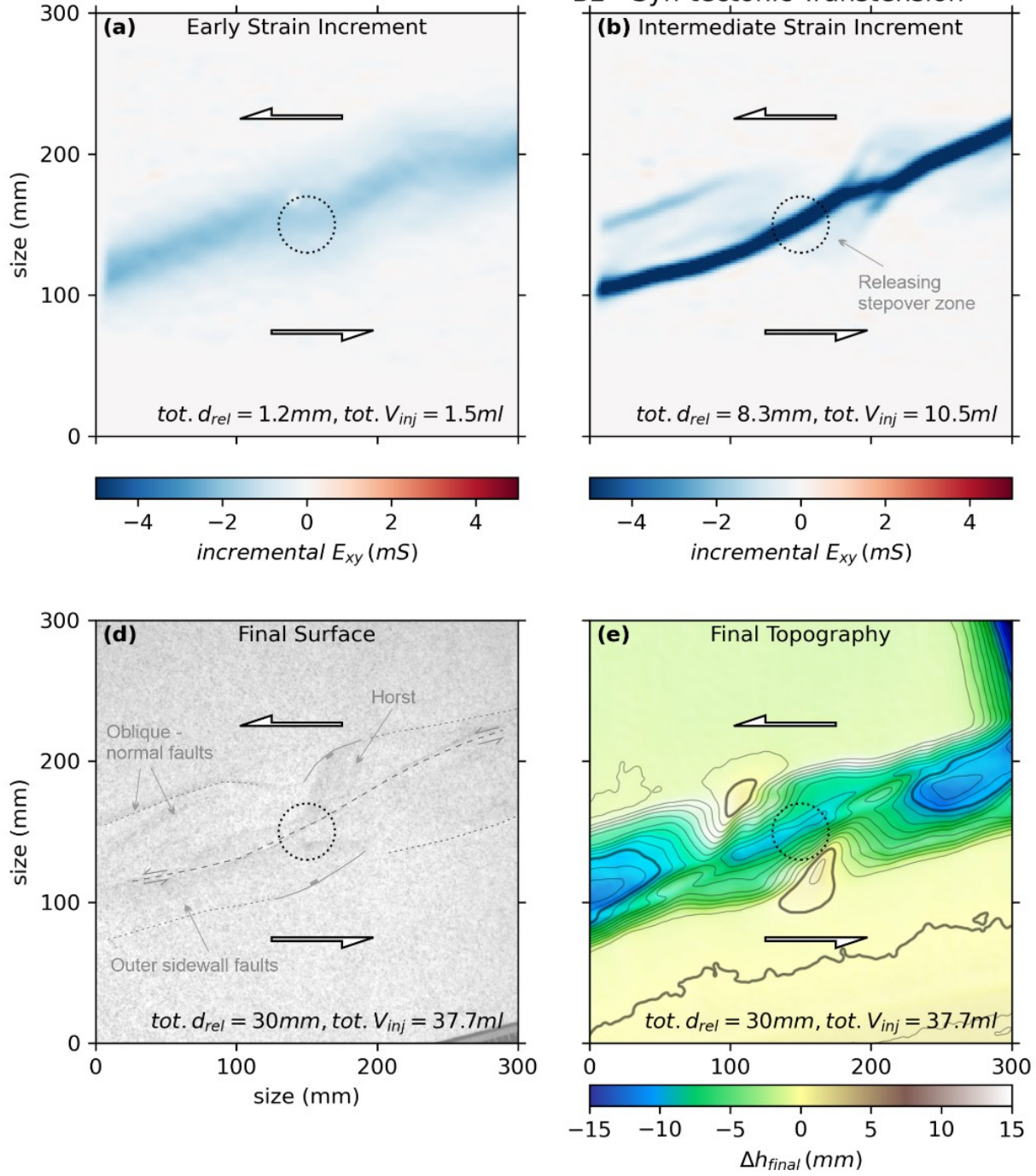
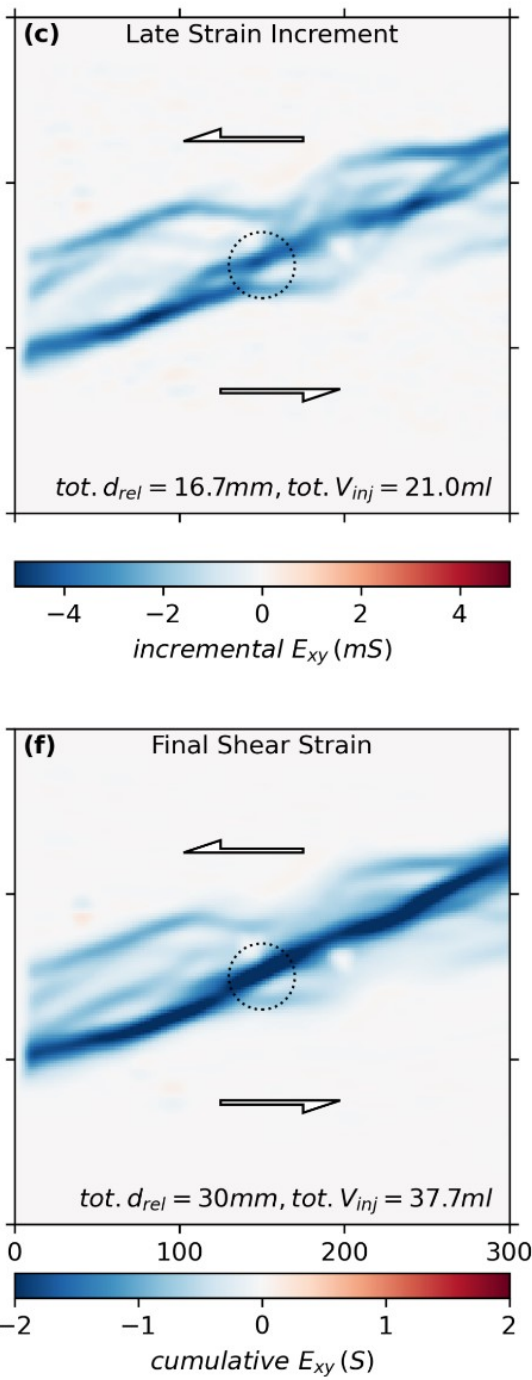

Fig. 9 Surface deformation of the syn-tectonic intrusion model in transtension (Model B2). Shown are snapshots representative of the evolution: Incremental strain during an (a) early $\left(V_{\mathrm{inj}}=1.5 \mathrm{ml}\right.$ and $\left.\mathrm{d}_{\text {rel }}=1.2 \mathrm{~mm}\right)$, (b) intermediate $\left(V_{\mathrm{inj}}=10.5 \mathrm{ml}\right.$ and $\left.d_{r e l}=8.3 \mathrm{~mm}\right)$ and $(c)$ late stage $\left(V_{\mathrm{inj}}=21.0 \mathrm{ml}\right.$ and $\left.d_{r e l}=16.7 \mathrm{~mm}\right)$. Panels in the second row show the final (cumulative deformation) stage $\left(d_{r e l}=30 \mathrm{~mm}, V_{\text {in }}=37.7 \mathrm{ml}\right)$ : (d) surface image; (e) cumulative vertical displacement (tot. $\left.d_{r e l}=30 \mathrm{~mm}\right)$ and $(f)$ cumulative shear strain $\left(E_{x y}\right)$. Dotted circles indicate the position of the basal injection. 


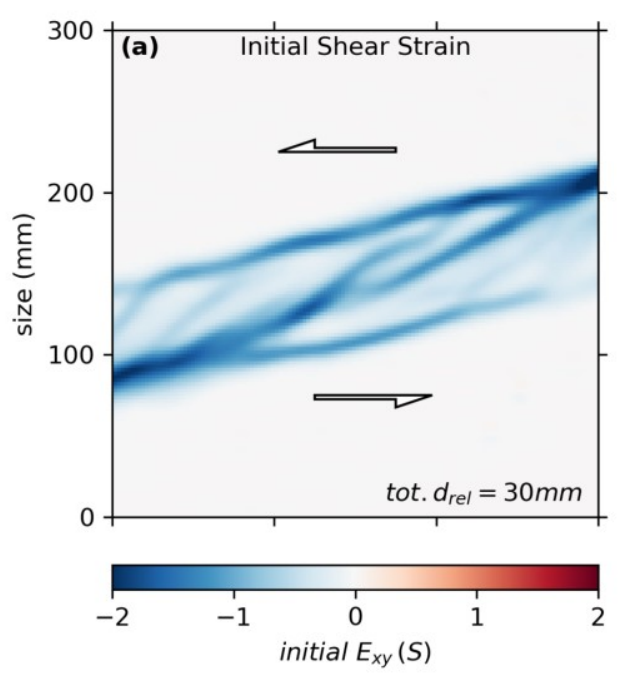

B3 - Post-tectonic Transtension
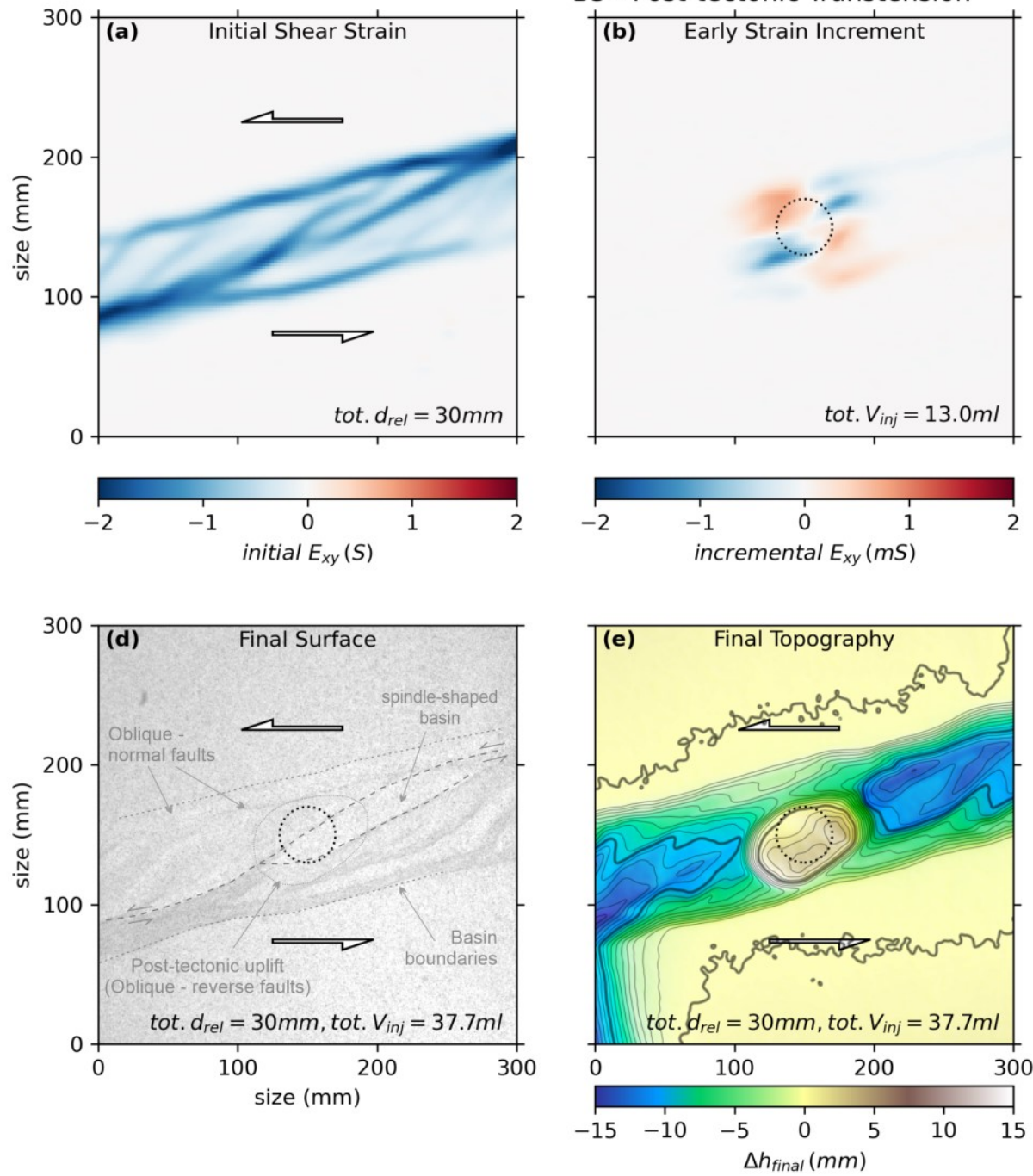
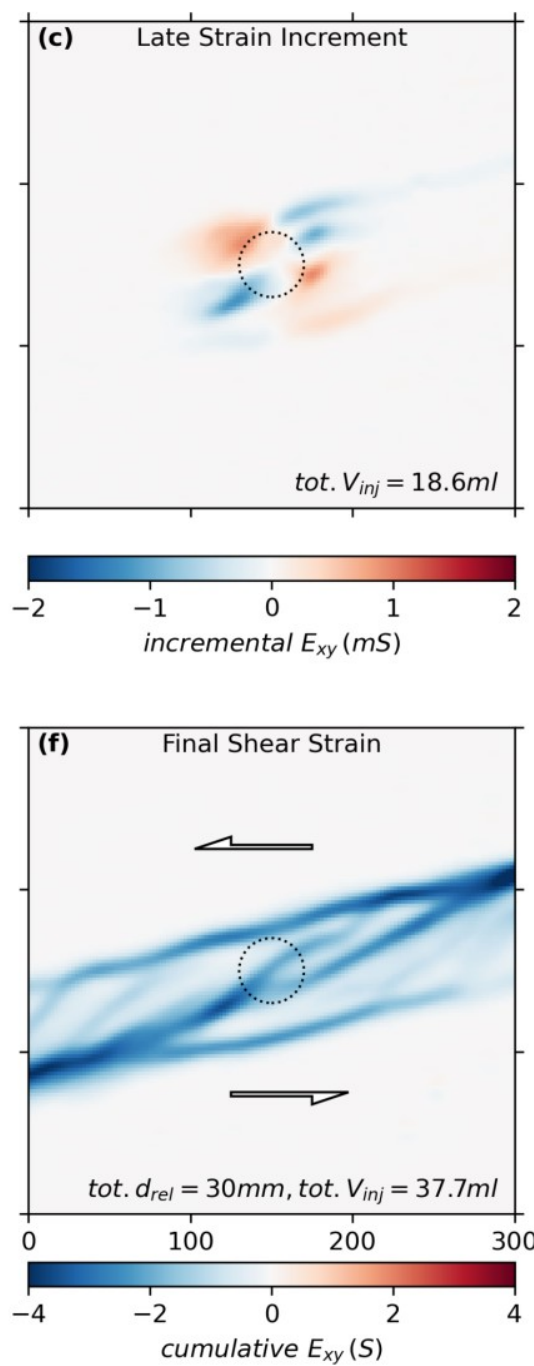

Fig. 10 Surface deformation of the post-tectonic intrusion model in transtension (Model B3). Shown are snapshots representative of the evolution: (a) Accumulated strain at the beginning of intrusion $\left(d_{\text {rel }}=30 \mathrm{~mm}\right),(b)$ incremental strain during an early $\left(\mathrm{V}_{\mathrm{inj}}=13 \mathrm{ml}\right)$ and $(c)$ late stage $\left(\mathrm{V}_{\mathrm{inj}}=18.6 \mathrm{ml}\right)$ of intrusion. Panels in the second row show the final (cumulative deformation) stage $\left(d_{\text {rel }}=30 \mathrm{~mm}, V_{\mathrm{inj}}=37.7 \mathrm{ml}\right)$ : (d) surface image; (e) cumulative vertical displacement (tot. $d_{r e l}=30 \mathrm{~mm}$ ) and $(f)$ cumulative shear strain $\left(E_{x y}\right)$. Dotted circles indicate the position of the basal injection. 

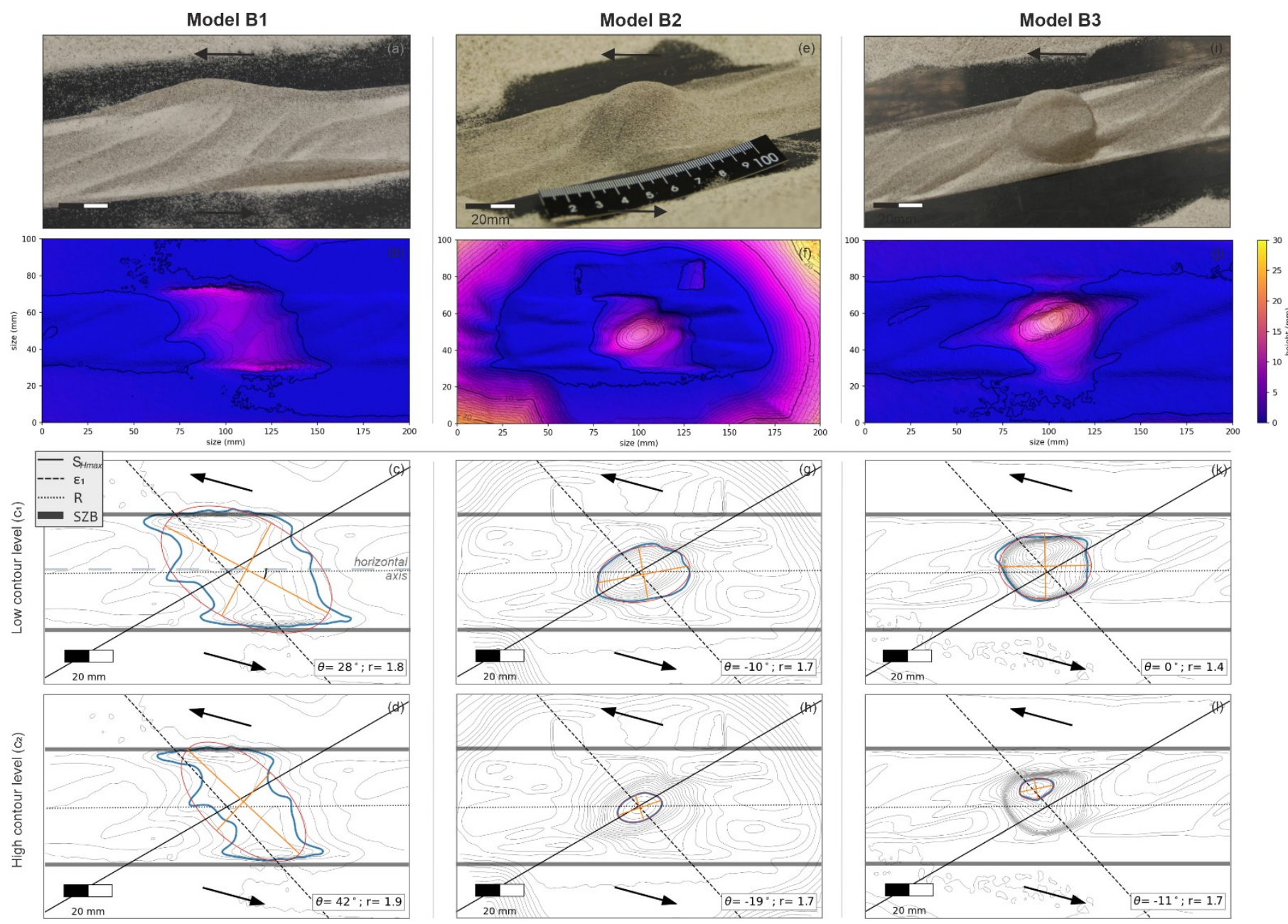

Fig. 11 Models of the intrusions in the transtensional regime (Group B): Model B1 (a-c); Model B2 (d-f) and Model B3 (g-i). (a, d, g) Oblique views of the excavated intrusions; (b, e, h) Digital Intrusion Models (DIM) coloured and with contour lines; (c, f, i) Orientation and geometry of the intrusion (in map view), where $\theta=$ the angle between the long axis (orange) of the fitted ellipse (red) and the strike of the basal shear zone. $r$ is the intrusion's aspect ratio (length-to-width ratio, L/W). Light and dark grey quadrants indicate contraction and extensional quadrants, respectively. 

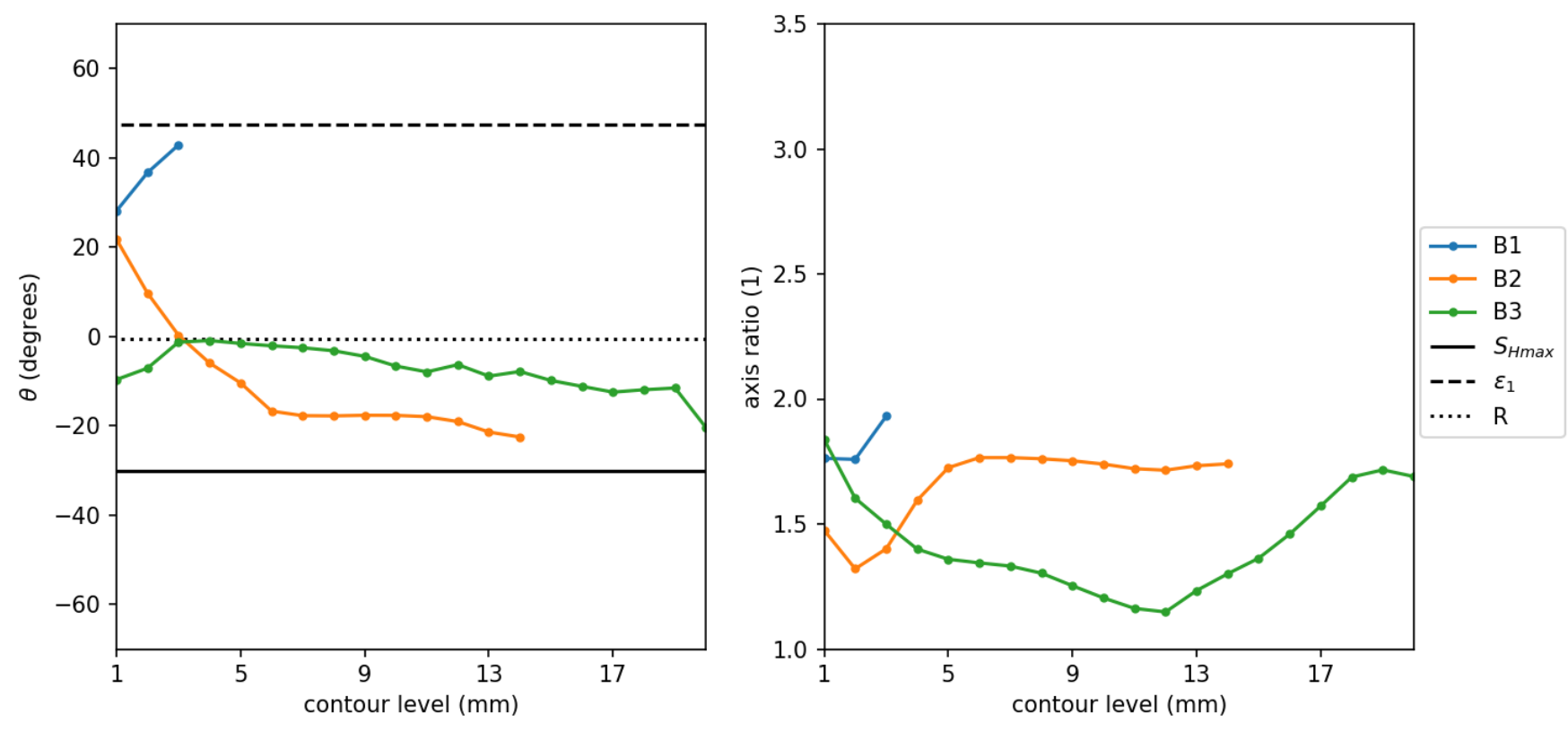

1018 Fig.12 Series B experimental results expressed in graph of angles and ratios ellipses vs. intrusion contour level. 
Natural Examples in Simple Shear
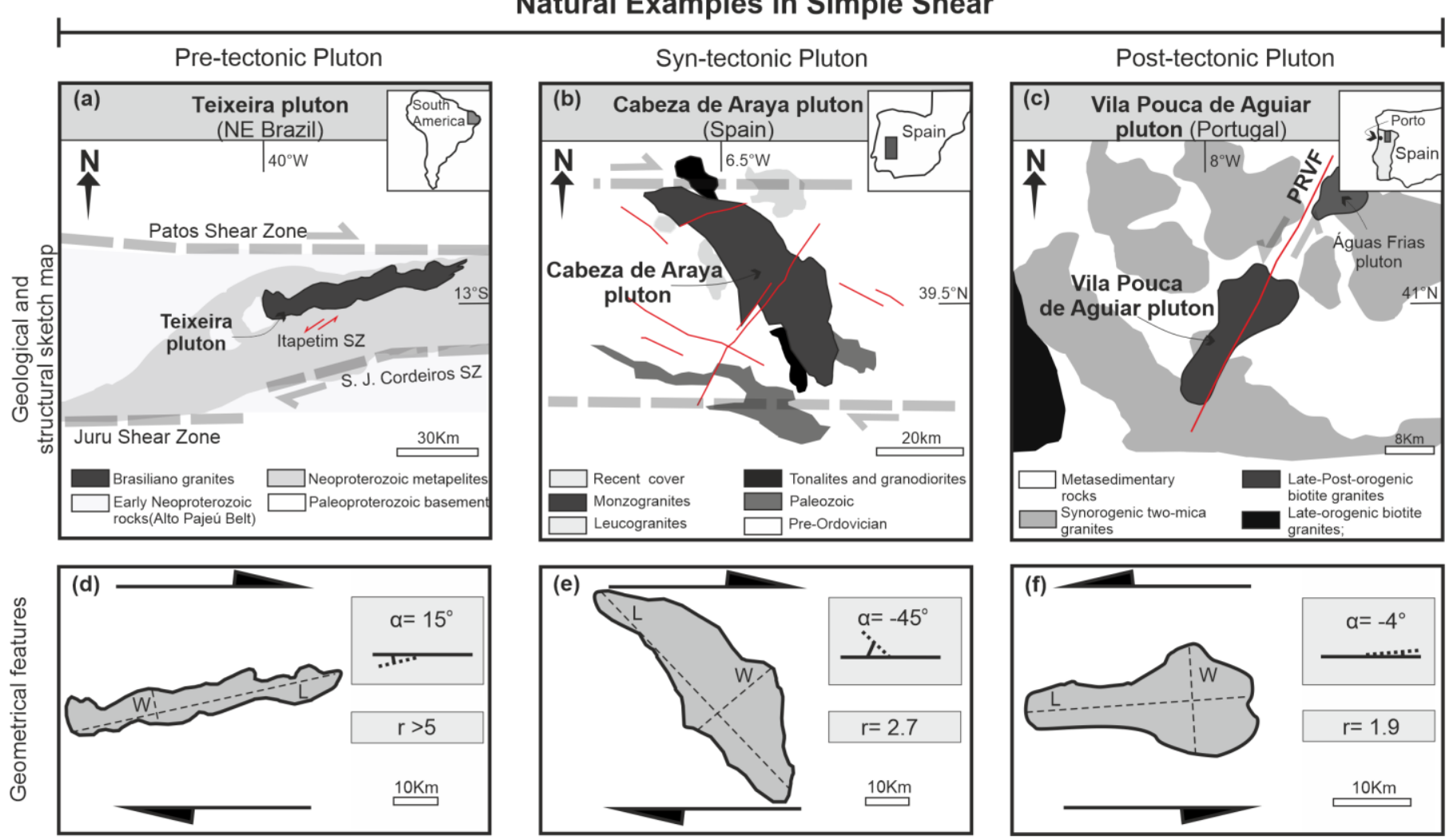

Natural Examples in Transtension
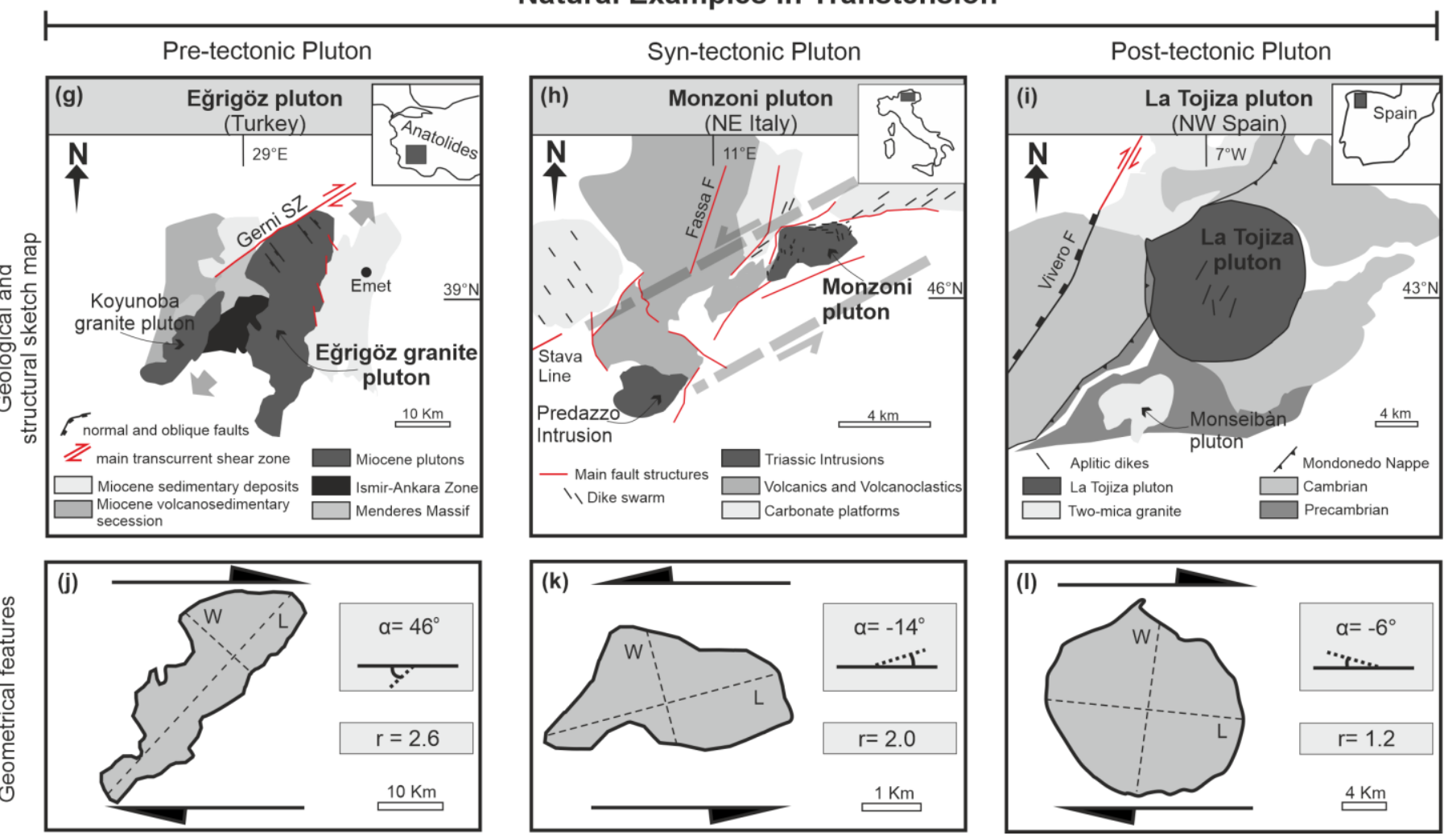

Fig. 13 Simplified geological maps and shapes of natural plutons emplaced in simple shear and transtensional 
1024 intrusion affected by rotation due to the transtensional deformation occurring after the emplacement (Erkül et

1025 al., 2017); (h, k) The Monzoni Pluton developed within a transtensional tectonic environment (Sloman, 1989;

1026 Bonadiman et al., 1994); (i, l) La Tojiza Pluton is a clear example of post-tectonic intrusion only slightly reac-

1027 tivating the previous transtensional tectonic structures (Aranguren et al., 2003). 
9 Appendix - Supplementary data
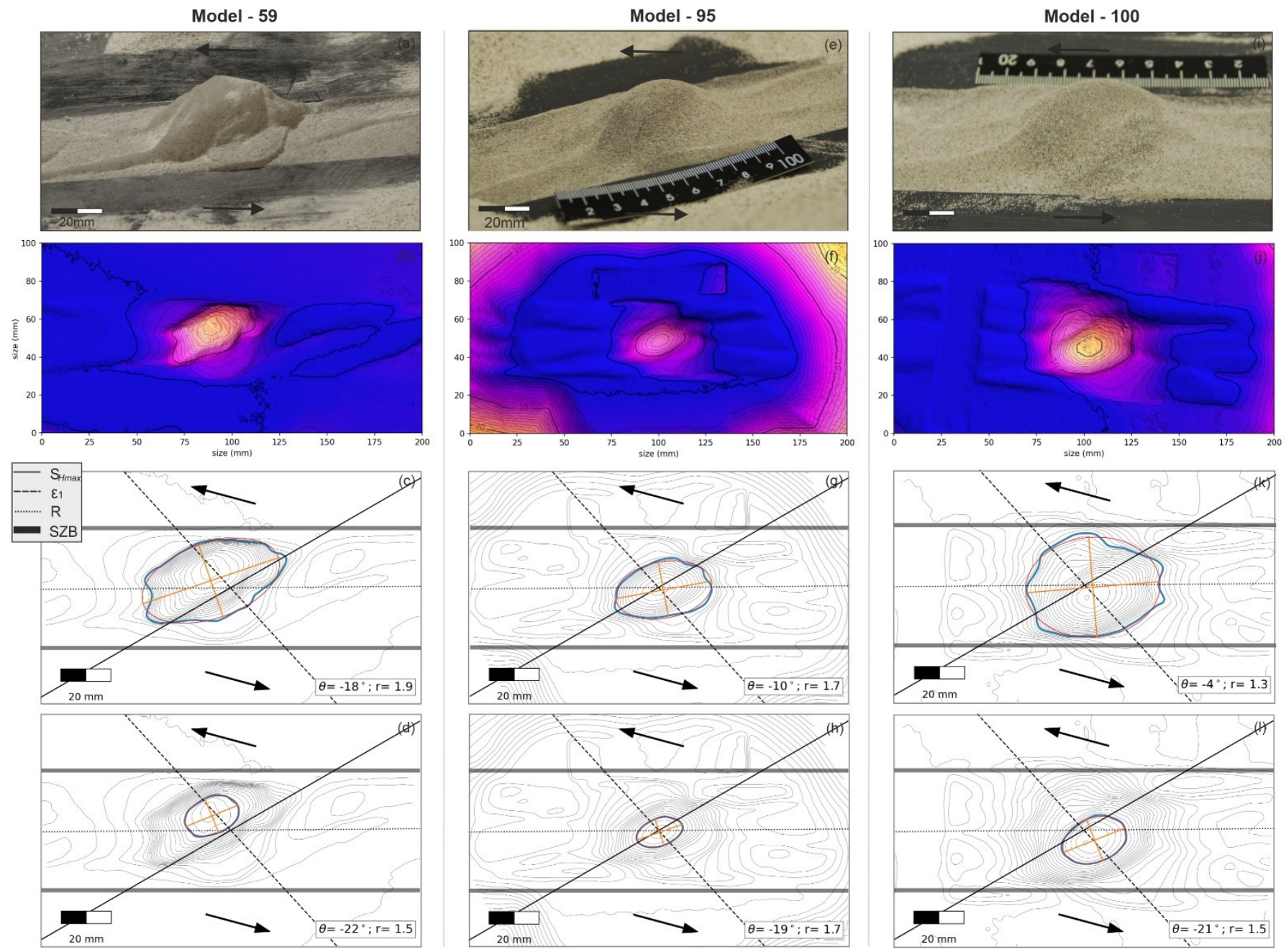

A.1 Intrinsic variability of intrusion models verified by repeating experiments (Model B2) in syn-tectonic intrusion in transtension. 


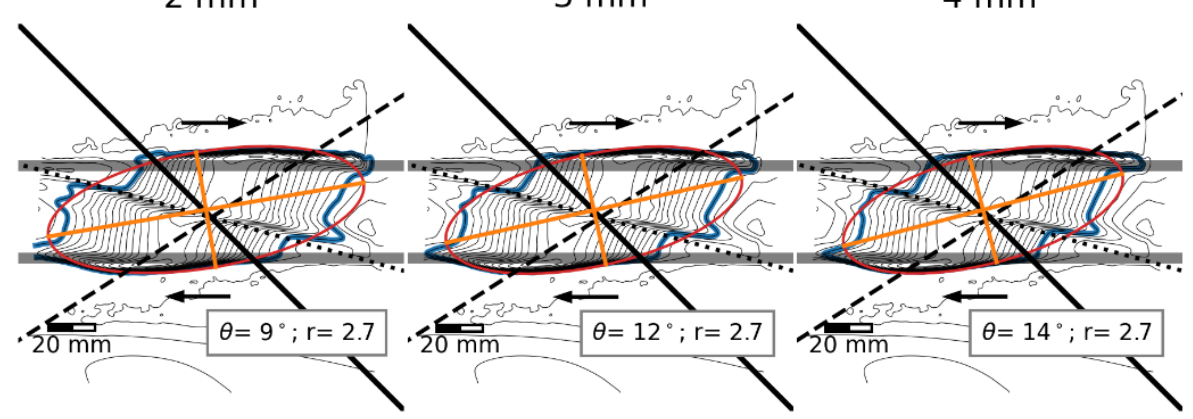

$5 \mathrm{~mm}$
$6 \mathrm{~mm}$

$7 \mathrm{~mm}$

$8 \mathrm{~mm}$

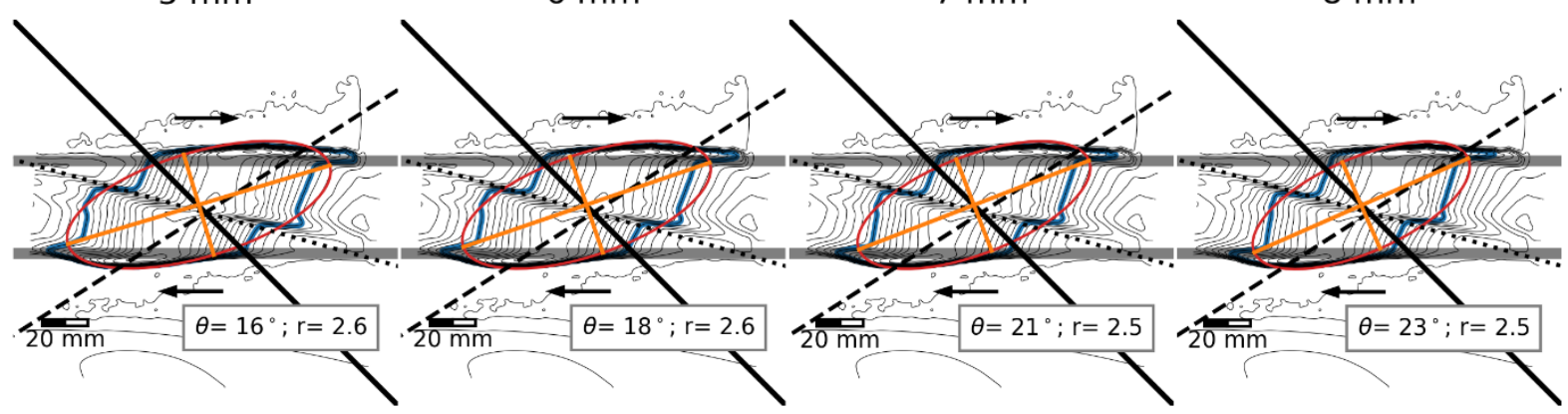

$9 \mathrm{~mm}$

$10 \mathrm{~mm}$

$11 \mathrm{~mm}$

$12 \mathrm{~mm}$

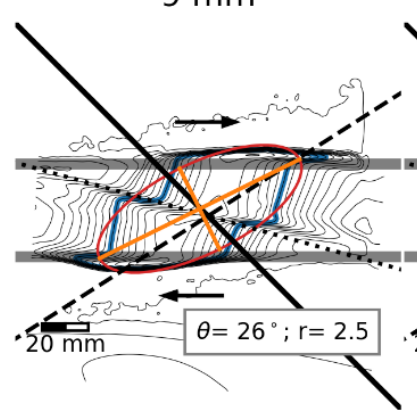

$13 \mathrm{~mm}$

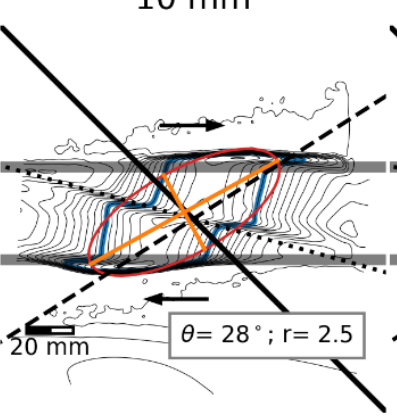

$14 \mathrm{~mm}$

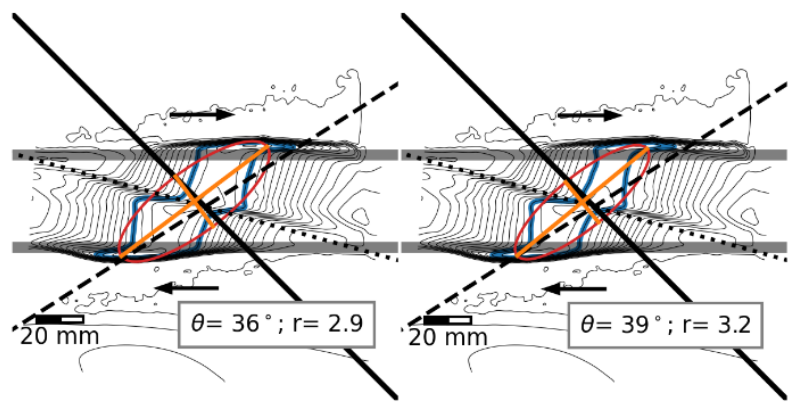




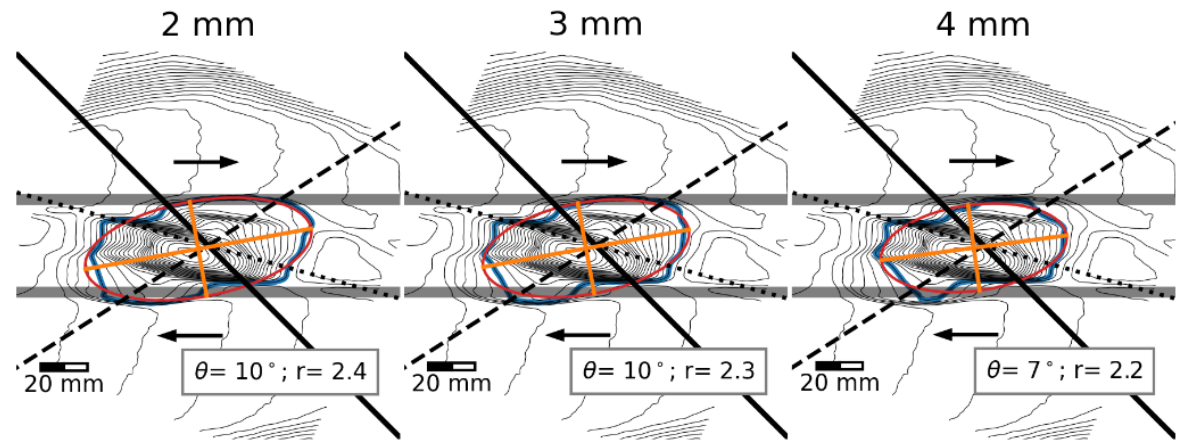

$5 \mathrm{~mm}$

$6 \mathrm{~mm}$

$7 \mathrm{~mm}$

$8 \mathrm{~mm}$

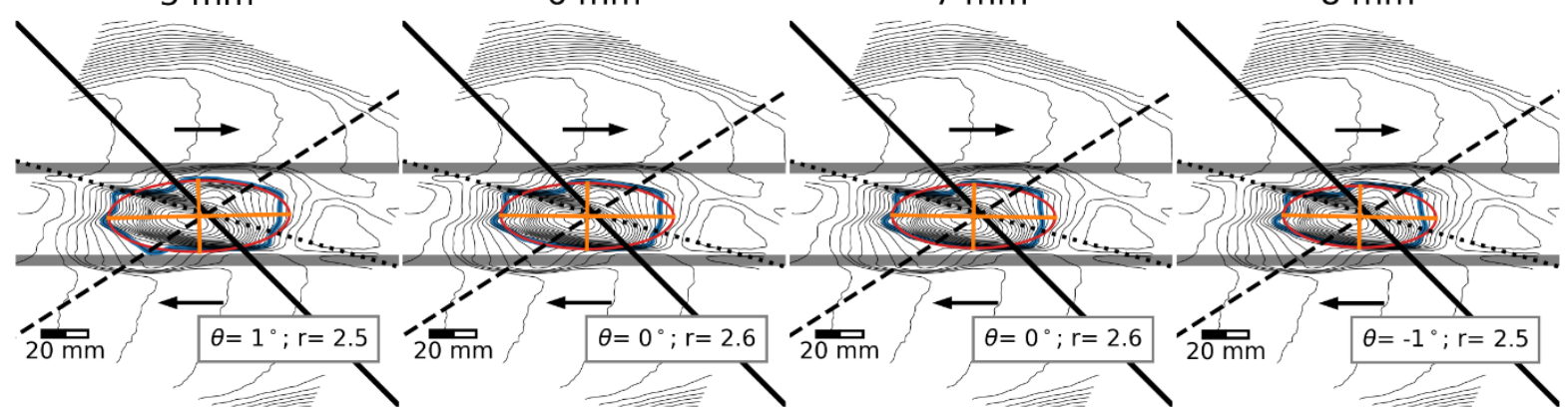

$9 \mathrm{~mm}$

$10 \mathrm{~mm}$

$11 \mathrm{~mm}$

$12 \mathrm{~mm}$

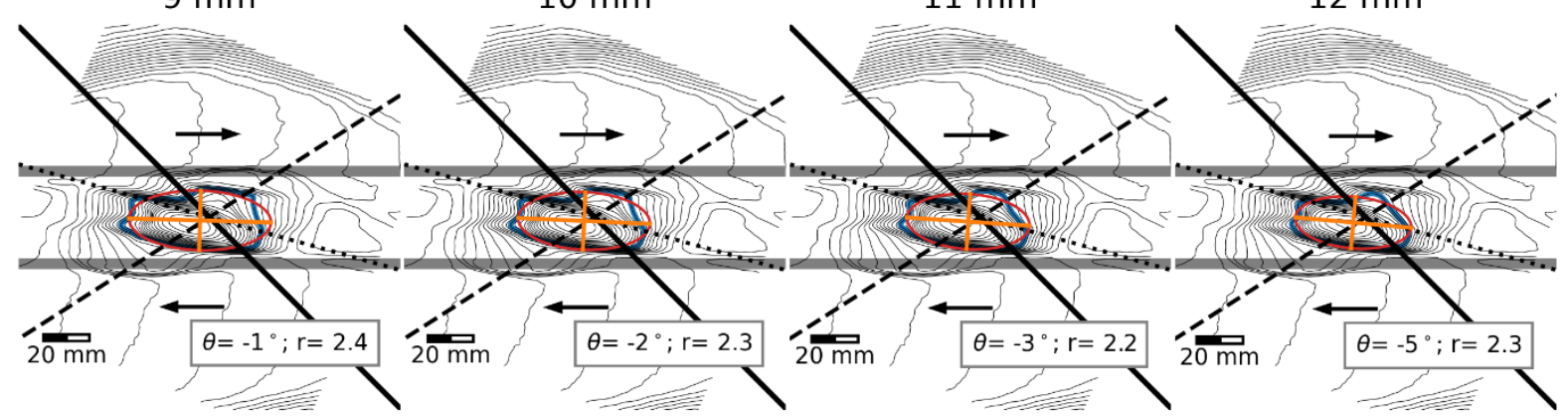

$13 \mathrm{~mm}$

$14 \mathrm{~mm}$

$15 \mathrm{~mm}$

$16 \mathrm{~mm}$

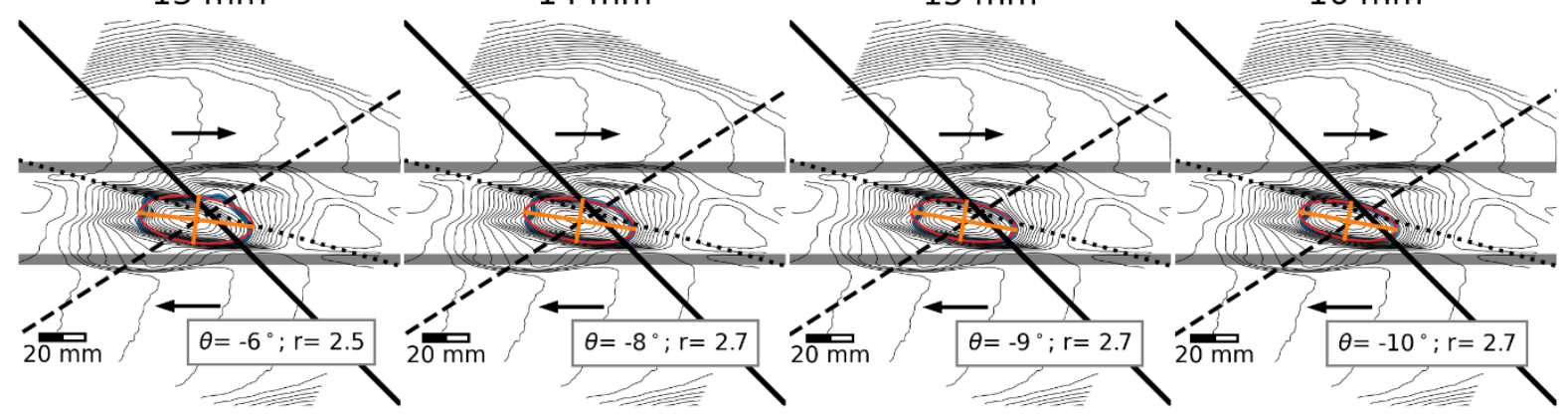

$17 \mathrm{~mm}$

$18 \mathrm{~mm}$

$19 \mathrm{~mm}$

$20 \mathrm{~mm}$

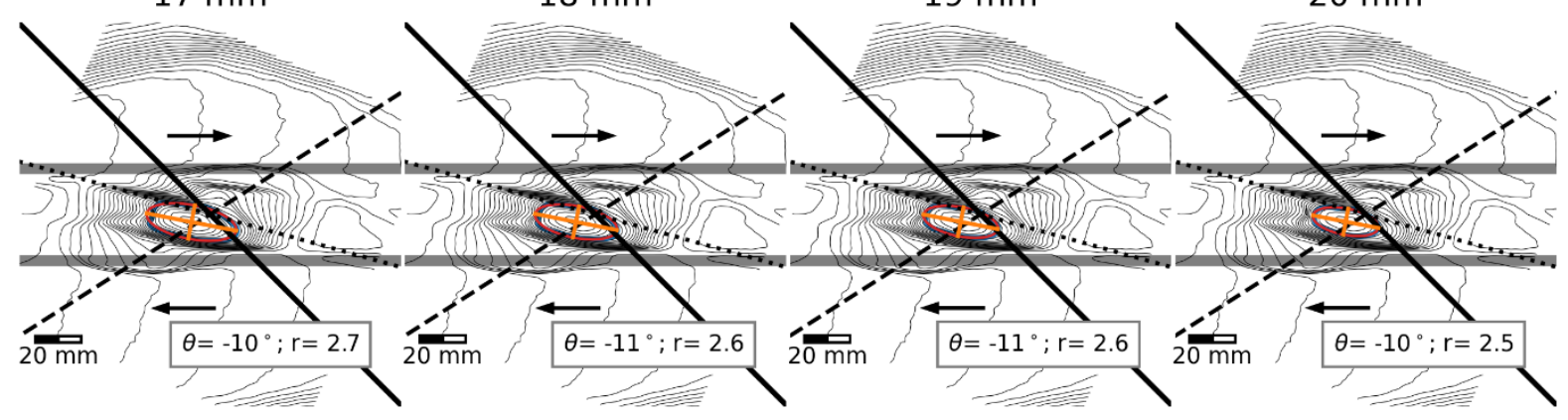



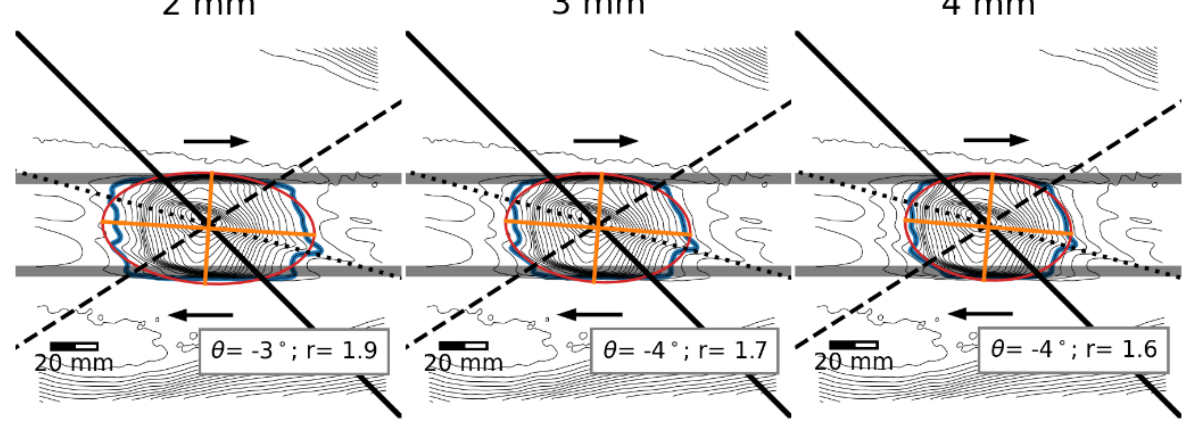

$5 \mathrm{~mm}$

$6 \mathrm{~mm}$

$7 \mathrm{~mm}$

$8 \mathrm{~mm}$
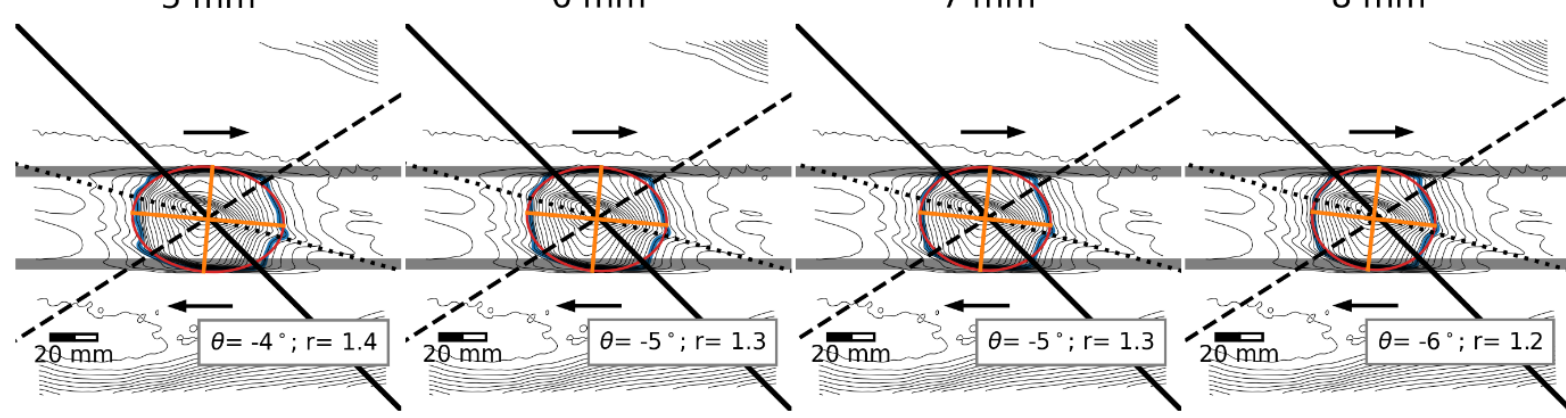

$9 \mathrm{~mm}$

$10 \mathrm{~mm}$

$11 \mathrm{~mm}$

$12 \mathrm{~mm}$

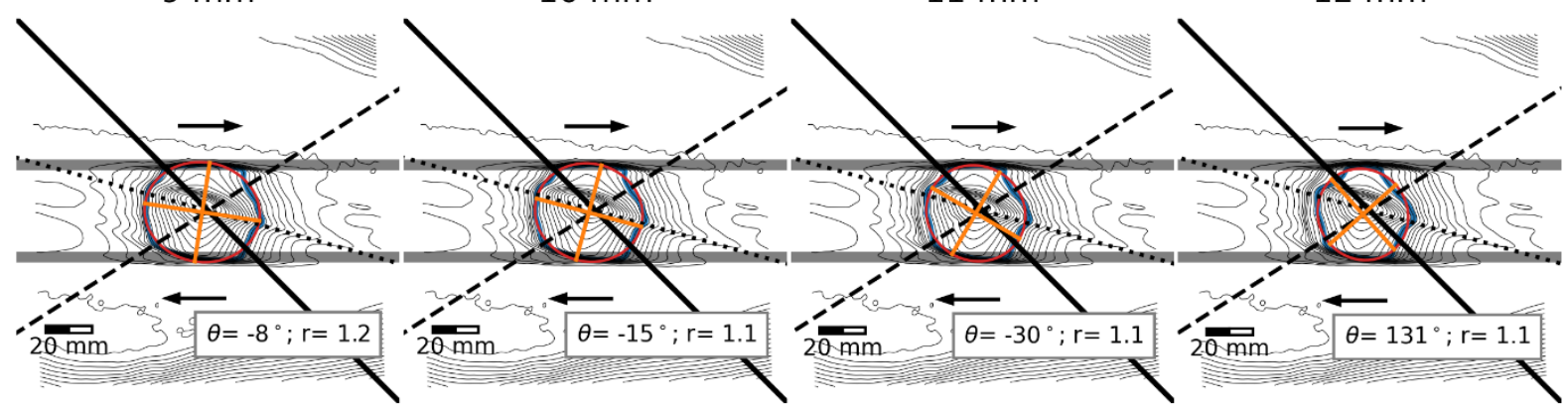

$13 \mathrm{~mm}$

$14 \mathrm{~mm}$

$15 \mathrm{~mm}$

$16 \mathrm{~mm}$

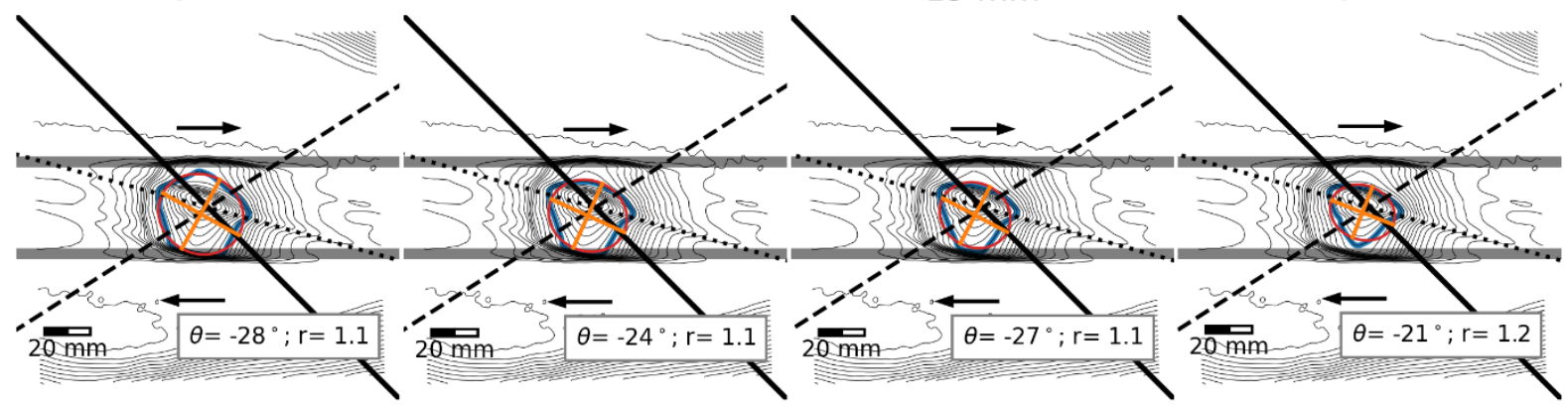

$17 \mathrm{~mm}$

$18 \mathrm{~mm}$

$19 \mathrm{~mm}$

$20 \mathrm{~mm}$

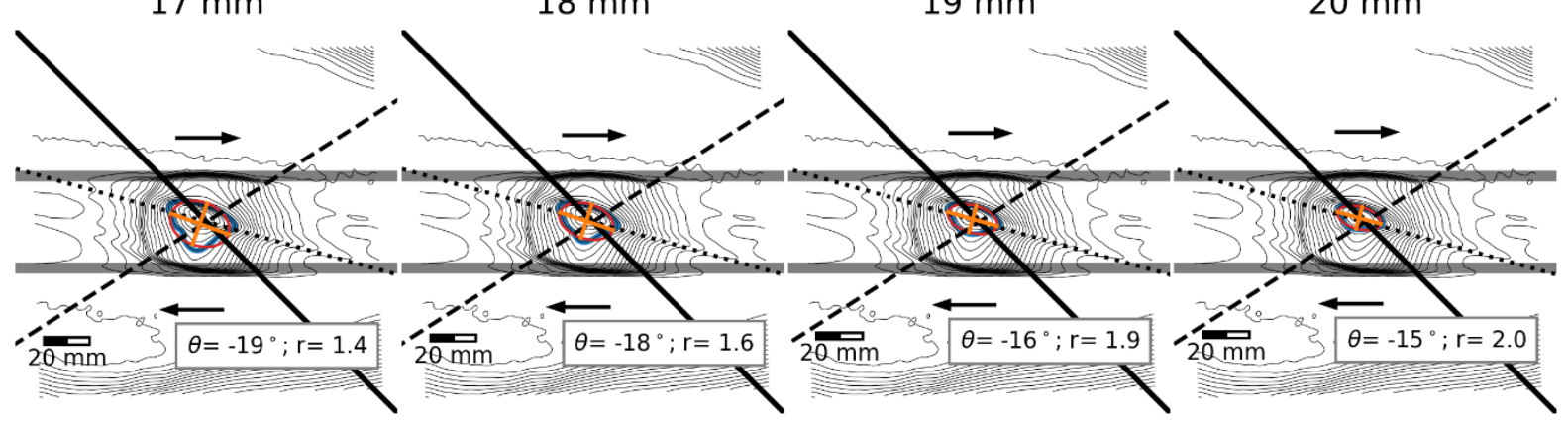




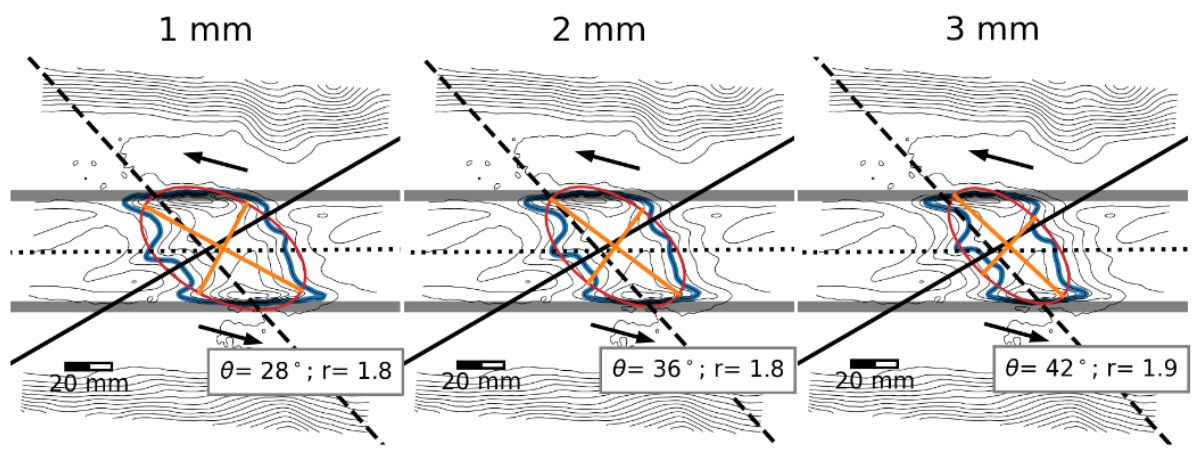

1040 A.5 Complete contour ellipses analysis of the Model B1 shape as a function of height 

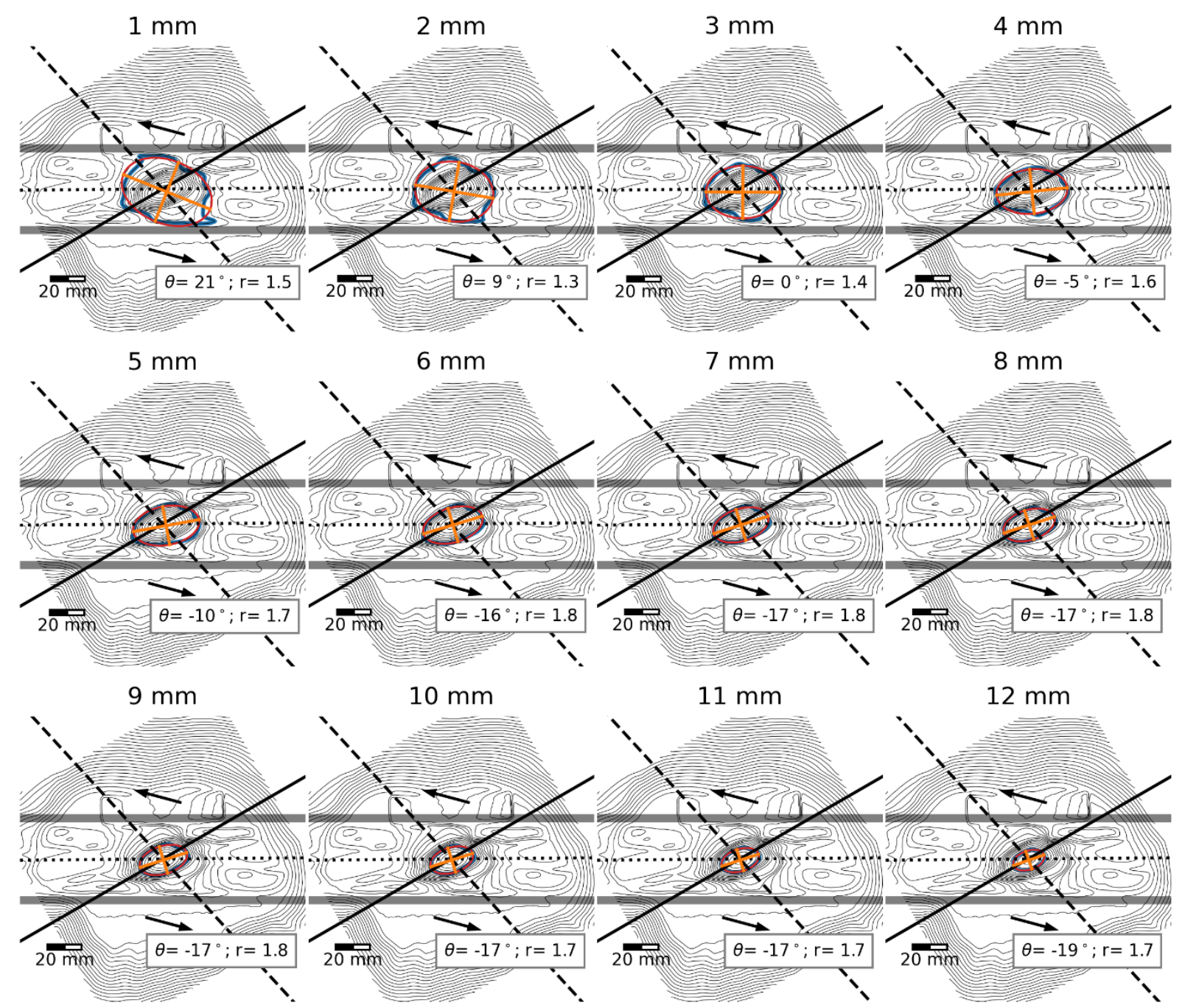

$11 \mathrm{~mm}$

$12 \mathrm{~mm}$
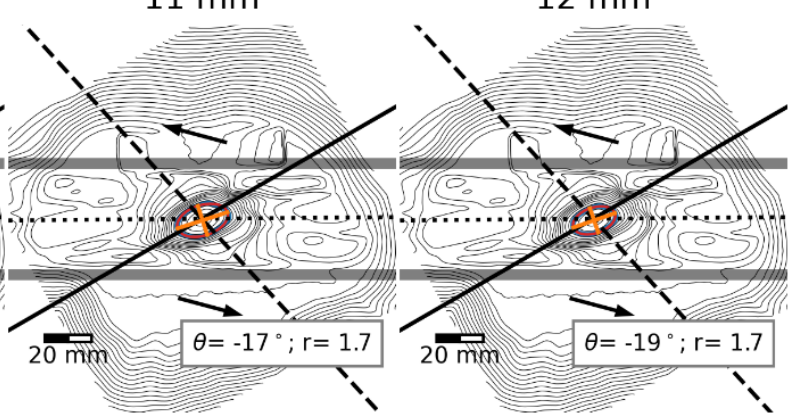

$13 \mathrm{~mm}$

$14 \mathrm{~mm}$

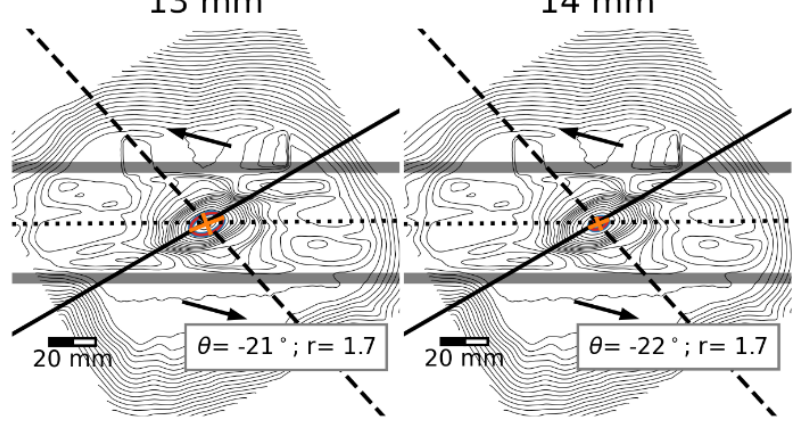

A.6 Complete contour ellipses analysis of the Model B2 shape as a function of height 
$1 \mathrm{~mm}$
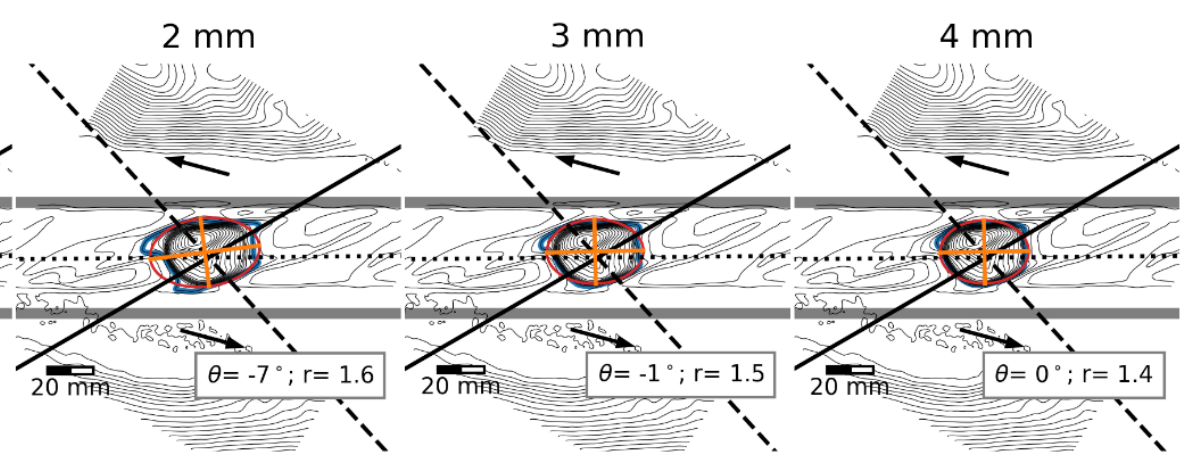

$5 \mathrm{~mm}$

$6 \mathrm{~mm}$

$7 \mathrm{~mm}$

$8 \mathrm{~mm}$
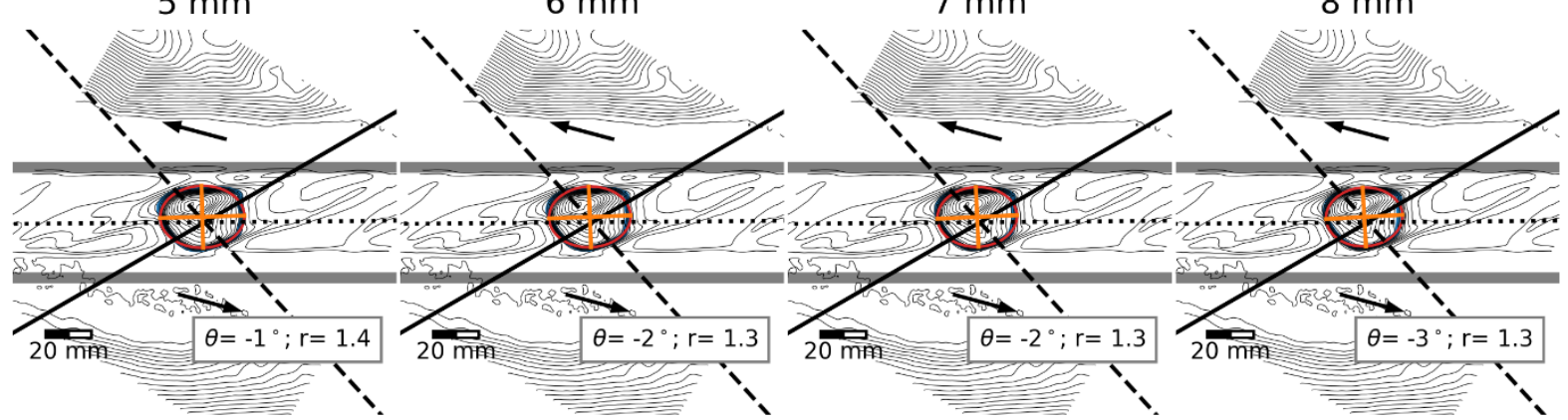

$9 \mathrm{~mm}$

$10 \mathrm{~mm}$

$11 \mathrm{~mm}$

$12 \mathrm{~mm}$
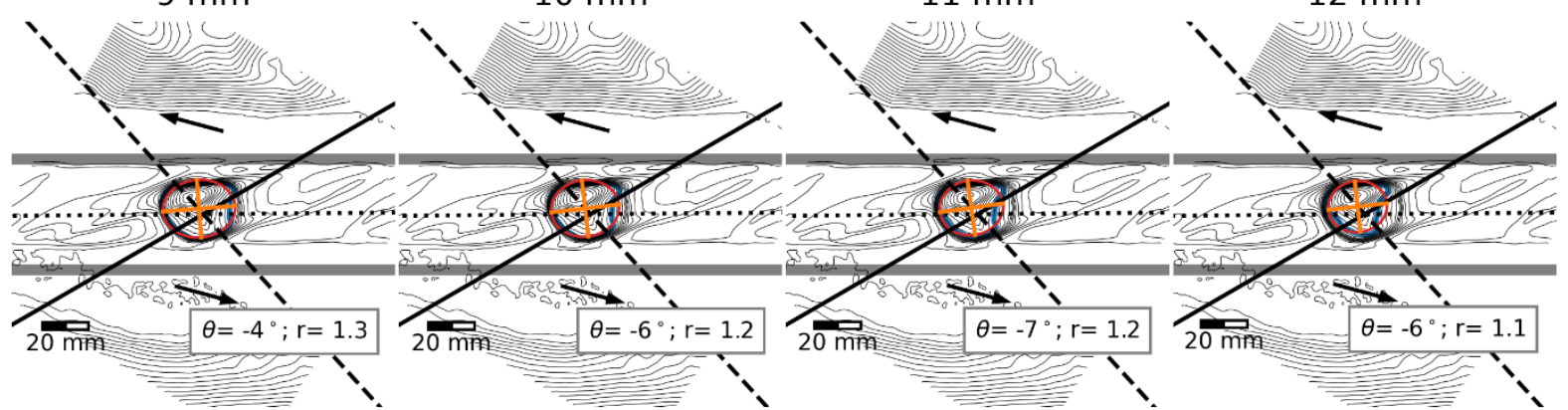

$13 \mathrm{~mm}$

$14 \mathrm{~mm}$

$15 \mathrm{~mm}$

$16 \mathrm{~mm}$
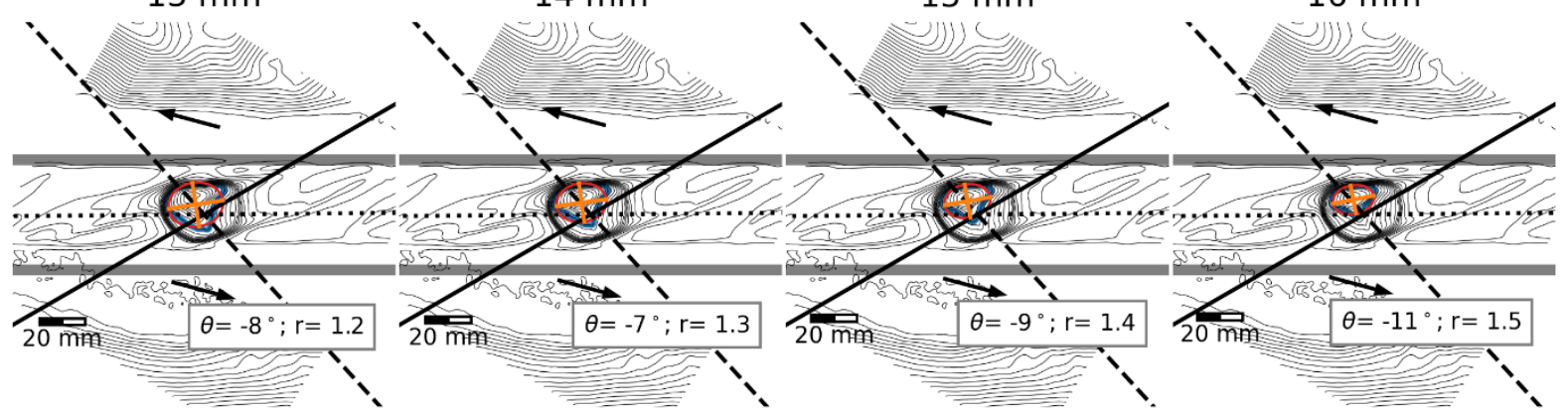

$17 \mathrm{~mm}$

$18 \mathrm{~mm}$

$19 \mathrm{~mm}$

$20 \mathrm{~mm}$
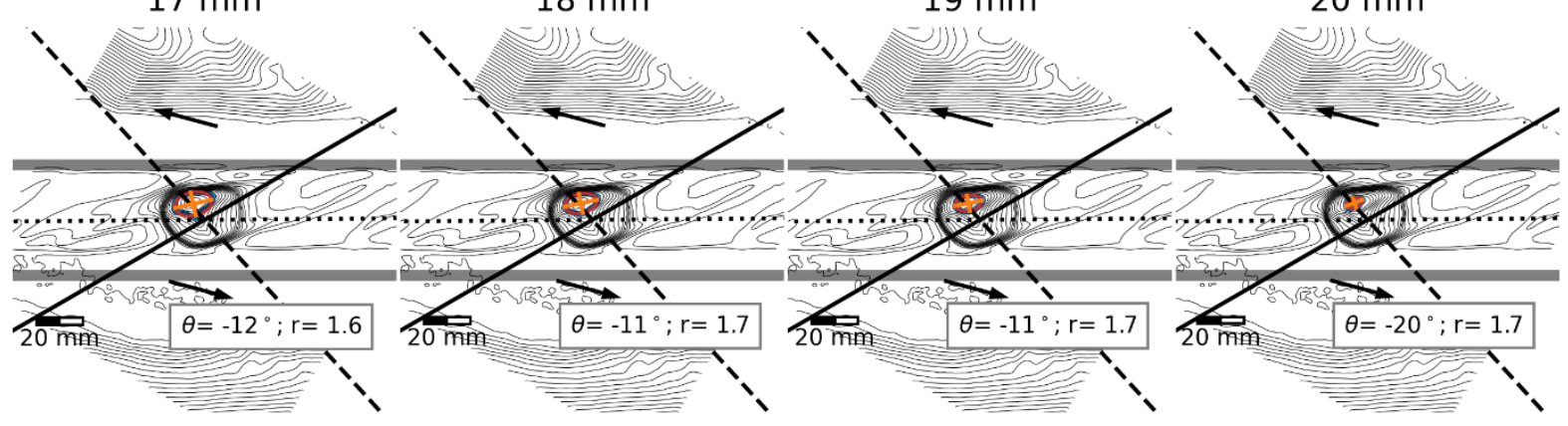